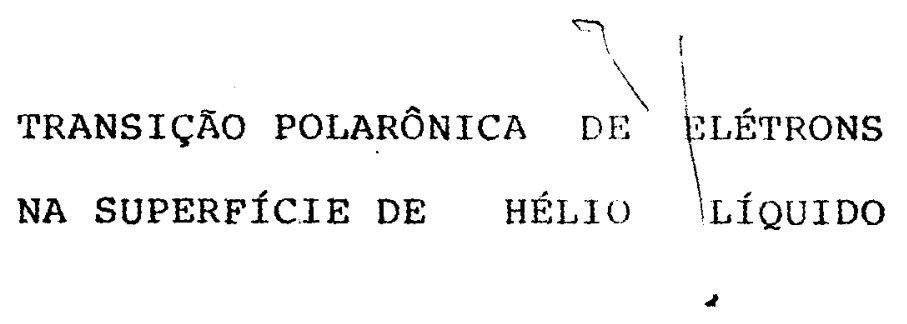

Marcos Henrique Degani

\begin{abstract}
Dissertação apresentada ao Instituto de Física e Química de são Carlos, da Universidade de são Paulo, para obtenção do título de mestre em Física Básica.
\end{abstract}

Orientador:

Prof. Dr. Oscar Hipólito

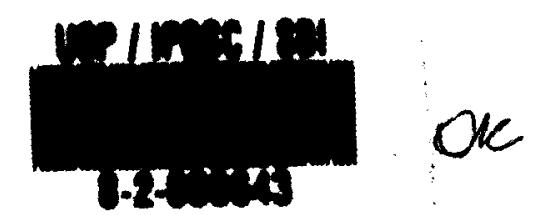

Departamento de Física e Ciência dos Materiais São Carlos

1983

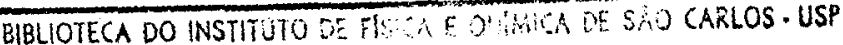
Flo: 
MEMBROS DA COMISSAO JULGADORA DA DISSEPTACAO DE MESTRADO DE Marcos Henrique Degani

APRESENTADA AO INSTITUTO DE FISICA E NUIMICA DE SAO CARLOS, DA UNIVERSIDADE DE SAO PAULO, EM $13 D E$ DE 1983.

COMISSAO JULGADORA:
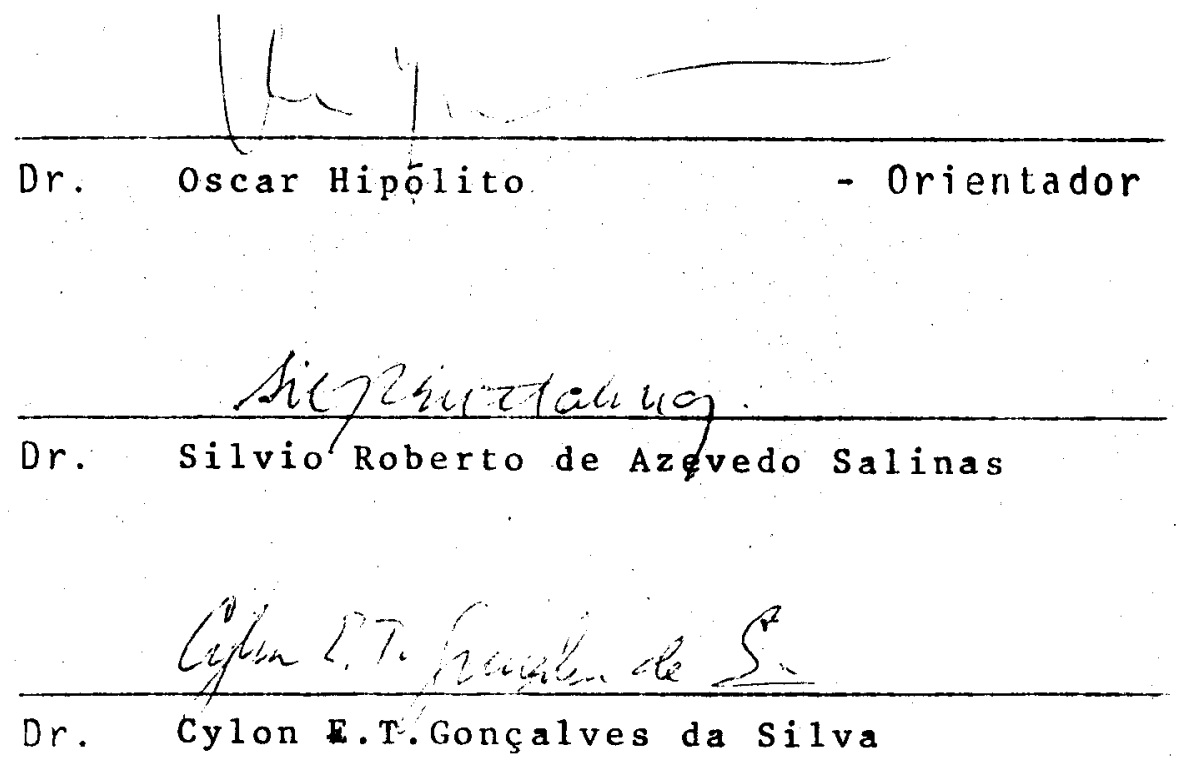
IISTA DAS FIGURAS................. i

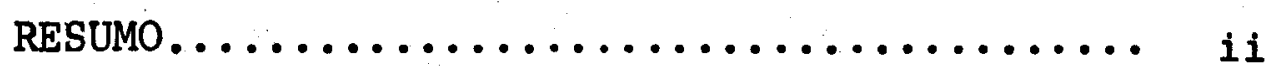

ABSTRACT ......................... ii

AGRADECIMENTOS................... iv

I

INTRODUÇฐ̃o......................... 1

II PROPRIEDADES GERAIS DOS ELETRONS NA SUPERFI CIE DE HELIO LIQUIDO................ 5

III MECANISMOS DE ESPALHAMENTO NO MOVIMENTO PARALELO A SUPERFICIE.................. 19

IV $\quad$ O METODO VARIACIONAL............... 30

v APLICAÇÃO DO METODO VARIACIONAL......... 37

VI DEPRESSÕES COM MUITOS ELETRONS NA SUPERFICIE DE HELIO LIQUIDO..................... 69

VII $\quad$ CONCLUSÕES........................ 117

APENDICE QUANTIZAÇÃO DAS ONDAS DE CAPILARIDADE-GRAVIDADE............................ 121 
esquema para filmes de hélio adsorvidos em um subs tato.

mobilidade dos elétrons na superfície de hélio....

7 (a) barreira de potencial para ions positivos........

(b) barreira de potencial para íons negativos........ 40 superfície deformada devido aos ions............ energia do estado fundamental de um elétron ligado à interface da mistura ${ }^{3} \mathrm{He}-{ }^{4} \mathrm{He}$. massa efetiva de um elêtron ligado à interface da mistura ${ }^{3} \mathrm{He}^{4}{ }^{4} \mathrm{He} . \ldots \ldots \ldots \ldots \ldots \ldots \ldots \ldots \ldots \ldots \ldots \ldots \ldots . \ldots \ldots$

energia do estado fundamental de um elétron ligado à superfície de filmes de hélio adsorvidos em

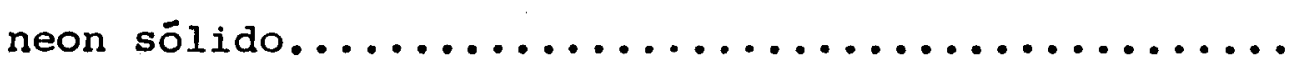

14 massa efetiva de um elētron ligado à superfície de filmes de hêlio adsorvidos em neon sōlido.........

15 energia do estado fundamental de um elétron ligado à superfície de filmes de hêlio adsorvidos em safi-

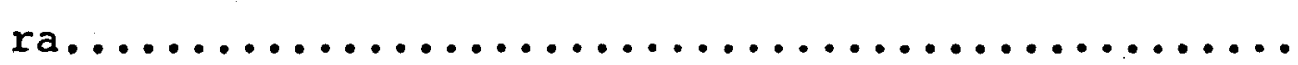
massa efetiva de um elétron ligado à superfície de filmes de hélio adsorvidos em safira............ resultados experimentais para filmes de hélio adsor

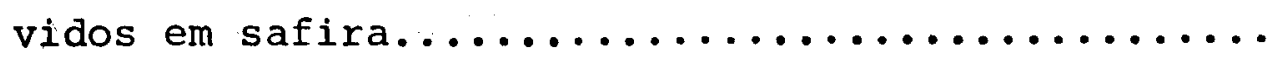


esquema de uma depressão na superficie de ${ }^{4} \mathrm{He}$ líquido energia de formação de uma depressão com muitos elētrons na interface da mistura ${ }^{3} \mathrm{He}-{ }^{4} \mathrm{He}$.

20 raio médio da depressão na interface da mistú ra ${ }^{3} \mathrm{He}-{ }^{4} \mathrm{He}$

21 massa efetiva da depressão na interface da mistura ${ }^{3} \mathrm{He}-{ }^{4} \mathrm{He} . \ldots \ldots \ldots \ldots \ldots \ldots \ldots \ldots \ldots$

22 (a) fotografia de uma depressão na interface da

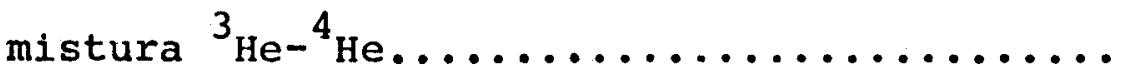

(b) fotografia de vãrias depressões na interface da mistura ${ }^{3} \mathrm{He}^{4}{ }^{4} \mathrm{He} . \ldots \ldots \ldots \ldots \ldots \ldots \ldots \ldots$

$23(a, b, b)$ fotografias de depressões na superfície de ${ }^{4}$ He líquido......................

24 perfil de uma depressão na superfície de ${ }^{4} \mathrm{He}$

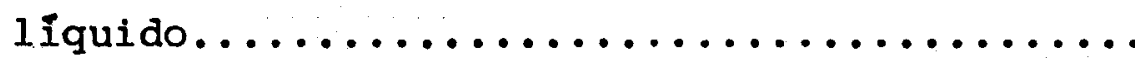
densidade média de carga para uma depressão na superfĩcie de filmes de hélio adsorvidos em :

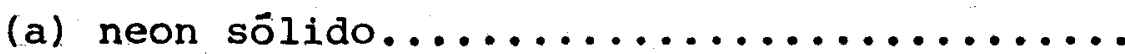

(b) safira energia de formação de uma depressão na super fície de filmes de hēlio adsorvidos em:

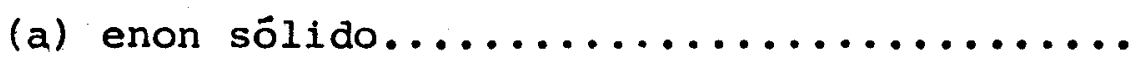

(b) safira. raio médio de uma depressão na superfície de filmes de hélio adsorvidos em:

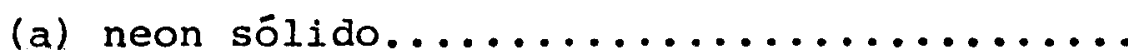

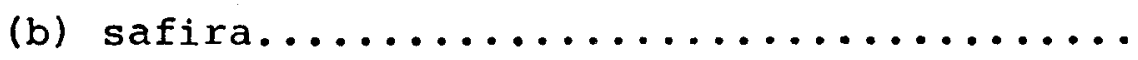


28 massa efetiva de uma depressão na superfície de filmes de hēlio adsorvidos em:

(a) neon sólido.................... 106

(b) safira $\ldots \ldots \ldots \ldots \ldots \ldots \ldots \ldots \ldots \ldots \ldots$

29 densidade de carga de uma depressão na super fície de ${ }^{4}$ He líquido $(d \rightarrow \infty) \ldots \ldots \ldots \ldots \ldots \ldots \ldots . . \ldots$

30 energía de formação de uma depressão na superfície de ${ }^{4}$ He líquido $(d \rightarrow \infty) \ldots \ldots \ldots \ldots \ldots$.

31 fotografias da formação do cristal de depres sões na superficie de ${ }^{4}$ He liquido..........

32. espessura crítica em função do número de elêtrons em depressões na superfície de fil mes de hélio...................... 
RESUMO 
Com o objetivo de investigar as propriedades do estado fundamental de elëtrons ligados à superfície de hẻlio líquido e interagindo com os modos superficiais de oscilação (riplons), utiliza mos um formalismo simples baseado em transformações canônicas, o qual è vālido para todos os valores da constante de acoplamento e Jétron-riplon. Calculamos a energía do estado fundamental e a massa efetiva de um elétron sobre a superfície de filmes de hēlio adsorvi dos em neon sōlido, em safira e também na interface de misturas ${ }^{3} \mathrm{He}-$ ${ }^{4}$ He. Um comportamento tipo transição de fase de primeira ordem, on de o: elëtron passa de um estado quase livre para um estado localizado quando o campo elétrico externo excede um certo valor crítico é observado. Este resultado foi recentemente confirmado experimentalmente através de medidaa da mobilidade de elétrons na superfície de filmes de hélio adsorvidos em safira. Em seguida, calculamos a ener gia de formação, a massa efetiva, o raio médio e a densidade mēdia de cargas em uma depressão ("dimple") contendo muitos elētrons localizada na superficie de ${ }^{4} \mathrm{He}$ líquido, na interface da mistura ${ }^{3} \mathrm{He}-{ }^{4} \mathrm{He}$ e finalmente em filmes de ${ }^{4}$ He líquido adsorvidos em neon sōlido e em safira. No caso de ${ }^{4} \mathrm{He}$ líquido e misturas de ${ }^{3} \mathrm{He}-{ }^{4} \mathrm{He}$ obtemos o campo elétrico crítico a partir do qual ocorrerá a localização da depres são. Para filmes de hēlio adsorvidos em neon sólido e em safira, obtemos as espessuras críticas do filme entre as quais a depressão com muitos elêtrons pode existir. Os resultados obtidos são comparados com dados experimentais e teöricos recentes e estão em excelente con cordância. 
ii i

ABSTRACT 
A simply unitary-transformations formalism is used in order $t c$ investigate the ground-state properties of an electron bounded on a liquid-helium surface and interacting with the surface modes of oscillation(ripplons). We have calculated the ground-state energy and the effective mass of an electron on films of helium adsorved on solid and saphyre and electron at the interface of phase separated ${ }^{3} \mathrm{He}-{ }^{4} \mathrm{He}$ mixtures. A first-order phase-transition-like behavior from the quasi free to the self trapping electron state as the clamping external electrical field exceeds a certain critical value is observed. After, we ha ve evaluated the ground-state energy, effective mass, the radius and the density of charge in an individual many electron dimple on the surface of helium liquid, films of helium adsorved on solid neon and saphyre and at the interface of phase-separated ${ }^{3}$ He- ${ }^{4}$ He mixtures.

For the dimple on the surface of helium and at the in terface of phase separated ${ }^{3} \mathrm{He}-{ }^{4} \mathrm{He}$ mixtures we have evaluated the critical external electrical field where the localization occurs. For the films of helium adsorved on solid neon and sa phyre we have evaluated the range of criticals thickness where the dimple exist.

The results are compared to those recently obtained and are in excelent concordance. 
AGRADECIMENTOS 
Ao Prof.Dr.Oscar Hipōlito pela orientação segura, constan te apoio e paciência na realização deste trabalho.

Aos colegas Pedro. Giomal, Nelson e Umbelino pelas pro veitosas discussões.

Ao Prof.Dr.Sylvio Goulart Rosa Jr. pela acolhida no Instị tuto de Fỉsica e Química de são Carlos.

Aos colegas e funcionários do Departamento de Física e Ciência dos Materiais do Instituto de Física e Quỉmica de são Car 10, USP, em especial do seu centro de computação, que direta ou indiretamente contribuiram para o desenvolvimento deste trabalho.

A Loreni pelo excelente trabalho de datilografia.

Ao CNPq e à FAPESP pelo suporte financeiro. 
CAPITULO I

INTRODUÇÃO 
Nos ültimos anos as propriedades eletrônicas de siste mas bidimensionais tèm sido intensamente estudadas tanto teórica quanto experimentalmente. Dentre os sistemas mais investigados está aquele formado de elétrons depositados na superfície de hẻlio líqui do e que, também será alvo de nossos estudos.

Elētrons localizados na superfície de hẻlio lỉquido exibem vảrios fenômenos interessantes dentre os quais podemos citar es pectro de estados ligados, mobilidade, localização, cristalização de Wigner, ondas de plasma bidimensional e redes macroscópicas. Nes tes sistemas os elétrons permanecem ligados à superfície sob a ação de uma foṛça eletrostātica imagem e de um campo elétrico externo perpendicular à superfície. Assim sendo, os elētrons estarão liga dos, perpendicularmente à superfície em estados quânticos discretos e movendo-se mais ou menos livremente na direção paralela. Para tem peraturas abaixo de $0,8 \mathrm{~K}$, os elētrons interagem sobre tudo com exci tações tērmicas superficiais (riplons) do hélio líquido sendo entre tanto desprezível suas interações com os àtomos do vapor de hélio. $\mathrm{Na}$ presença de um campo elētrico externo intenso, o elétron interage fortemente com os riplons favorecendo assim sua localização na superfíci do líquido. A pressão devido ao campo elétrico, faz com que a superfície se deforme formando uma pequena depressão na qual o elétron fica localizado.

Neste sistema, o intervalo de densidades eletrônicas a cessível experimentalmente, tem sido entre $10^{4}-10^{9}$ elétrons $/ \mathrm{cm}^{2}$. Pa ra este intervalo de densidades o gás de elétrons bidimensional é um gās puramente clássico, mesmo para temperaturas de alguns mili kelvins.

Neste trabalho estaremos interessados em obter a energia do estado fundamental e a massa efetiva para os elētrons localiza dos em filmes de hélio adsorvidos em neon sólido, em safira e tam - 
bém para elétrons na interface da mistura ${ }^{3} \mathrm{He}-{ }^{4} \mathrm{He}$. Os cálculos são desenvolvidos por meio de um formalismo variacional, baseado em transformações canônicas o qual jả foi utilizado com sucesso para diferentes tipos de polarons e è válido para qualquer valor da constante de acoplamento elētron-excitação. Nossos resultados mostram que a energia do estado fundamental apresenta uma discontinui dade na sua derivada com relação ao campo elētrico externo, o que caracteriza um comportamento do tipo transição de fase onde o pola ron passa de um regime quase-livre para um estado localizado. Esta previsão teōrica foi recentemente confirmada experimentalmente, atravēs de medidas da mobilidade dos elétrons em filmes de hêlio ad sorvidos em safira.

No capítulo II descrevemos algumas propriedades dos elé trons nos estados superficiais em hélio líquido. Discutimos o es pectro destes estados ligados nos vários modelos propostos para o potencial que localiza o elétron sobre a superfície, bem como a mu dança deste espectro devido à presença de campos elétricos exter nos. O sistema formado por filmes de hêlio líquido adsorvidos em substratos também è discutido. Finalmente os resultados experimentais mais significativos são apresentados.

No capitulo III discutimos detalhadamente os mecanismos de espalhamento dos elētrons por átomos de hēlio e pelas excitações tērmicas da superfície do hēlio. Obtemos o potencial de interação e lētron-excitação superficial e a Hamiltoniana que descreve o sistema. Esta Hamiltoniana è formalmente igual à Hamiltoniana de Frobhlich para o polaron. A energia do estado fundamental e a massa efetiva deste polaron são calculadas atravēs de um formalismo variacional , descrito no capītulo IV. Este método é válido para qualquer constan te de acoplamento elétron-excitação e tem sido aplicado com sucesso em diferentes tipos de polarons.

o capitulo $\mathrm{V}$ è dedicado ao estudo de superfícies de fluí dos carregadas bem como a análise relativa à estabilidade de tal 
sistema. Aqui aplicamos o formalismo variacional desenvolvido, no capitulo anterior para o caso de um único elétron localizado na in terface da mistura ${ }^{3} \mathrm{He}^{4}{ }^{4} \mathrm{He}$ e para filmes de hélio adsorvidos em neon sōlido e em safira. Para estes sistemas obtemos a energia do estado fundamental e a massa efetiva. Nossos resultados estão em excelente acordo com os resultados obtidos por Farias ${ }^{34}$ e Hipólito et.al ${ }^{35}$ que empregaram o método das integrais de trajetória apenas no limite de campo externo intenso.

No capitulo VI estendemos a teoria para o caso em que se tem muitos elētrons localizados em uma depressão da superfície, como foi observado experimentalmente por Wanner e Leiderer ${ }^{13}$ e Gian netta e Ikezi ${ }^{14}$, na superfície de hêlio líquido, em filmes de hélio adsorvidos em neon sólido e em safira e na interface da mistura ${ }^{3} \mathrm{He}-$ ${ }^{4}$ He. Calculamos a energia de formação, a massa efetiva, o raio mé dio e a densidade eletrônica na depressão.

Finalmente no capítulo VII, sumarizamos nossas conclusões e sugerimos alguns problemas, que deverão ser abordados futuramen te. 
CAPITULO II

PROPRIEDADES GERAIS DOS ELÉTRONS NA SUPERFICIE DE HELIO 
Neste capítulo resumiremos os conceitos bäsicos envolvidos no sistema de elētrons em estados superficiais sobre hêlio liquido e os principais resultados experimentais.

A origem dos estados superficiais dos elétrons sobre hêlio IIquido pode ser explicada usando a forma de energia potencial de interação de um elétron com um átomo de hélio. o resultado dos cālculos efetuados por Kestner et al. ${ }^{1}$ utilizando um pseudo-potencial para a interação de um elétron com um àtomo de hẻlio é mostra da na figura 1.

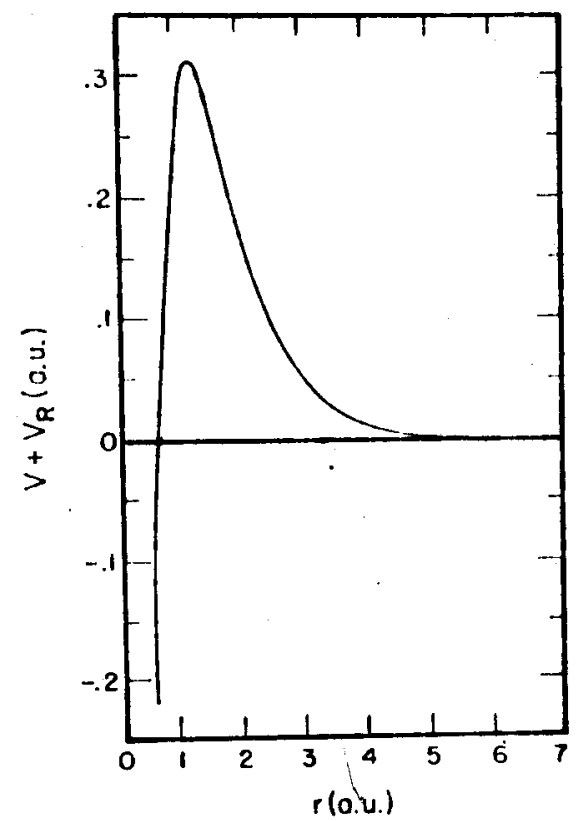

Figura 1

Para pequenas distâncias, existirā uma forte repulsão dẹ vido ao princípio de exclusão de Pauli exigir que a função de onda do elétron extra seja ortogonal aos estados atômicos ligados. Por outro lado, para distâncias maiores a interação dominante passa a ser atrativa, mas com uma intensidade muito fraca. E esta intera ção a responsável pelos estados que discutiremos aqui. o potencial atrativo origina-se da força entre o elétron e o momento de dipolo elétrico instantâneo do átomo.

Se os átomos de hélio preenchem a região $z<0$, tal que a 
superfície em $\mathrm{z}=0$ seja plana, a repulsão devido ao princípio de exclusão de Pauli origina uma barreira de potencial de aproximada mente um elētron-volt, enquanto que a atração devido â polariza ção dã origem ao potencial imagem. A barreira de potencial para $z<0$ juntamente com $\circ$ potencial imagem para $z>0$, formam um poço $u-$ nidimensional no qual aparecem estados ligados. Vărios modelos fo ram propostos para encontrar-se a forma do potencial que prende os elētrons na direção perpendicular à superfície e, portanto, determinar o espectro de auto-estados de energia.

Podemos supor que os movimentos dos elétrons sobre hélio líquido nas direções perpendicular e paralela à superfície são desacoplados e por hora ignoraremos o movimento paralelo ao líquido e nos concentramos no movimento perpendicular onde os elétrons estão confinados a um poço de potencial $V(z)$. Desta forma, podemos escrever a função de onda eletrônica (admitindo que a superfície do hélio seja plana) como o produto:

$$
\psi_{\vec{k}, \mathrm{n}}(\vec{R})=\frac{1}{\sqrt{\mathrm{A}}} \mathrm{e}^{\mathrm{i} \cdot \overrightarrow{\mathrm{K}} \cdot \overrightarrow{\mathrm{r}}} \phi_{\mathrm{n}}(z)
$$

onde $\vec{r}$ é um vetor no plano $x-y$ da superfície do líquido, e A é a área. Com isso estamos admitindo que os elétrons estão livres para - movimento paralelo e a função de onda $\phi_{n}(z)$ satisfaz a equação de Schrodinger:

$$
\frac{n^{2}}{2 m} \cdot \frac{d^{2} \phi_{n}(z)}{d z^{2}}+\left(E_{n}-V(z)\right)_{\phi_{n}}(z)=0
$$

A energia potencial $V(z)$ de um elétron fora do líquido de hélio, è, como já enfatizamos, constituỉa por dois termos:

(a) o potencial imagem clássico atrativo de longo alcance, devido à polarização eletrostática da superfície. 


$$
V(z)=-\frac{\varepsilon-1}{4(\varepsilon+1)} \frac{e^{2}}{z}=-\frac{\Omega_{0}}{z} \quad ; \quad z>0
$$

onde $\varepsilon$ è a constante dielētrica do hēlio líquido, $\varepsilon=1.057$;

(b) uma barreira repulsiva de curto alcance, devido ao princípio de exclusão de Pauli, obrigando a função de onda de um elétron extra ser ortogonal às dos dois elētrons presentes em cada ātomo de hểio.

Esta descrição é muito apropriada quando $|z|$ é maior que algumas distâncias atômicas. Entretanto próximo à z=0, o potencial não é conhecido com detalhe e informações sobre sua forma nesta re gião seriam de considerāvel interesse.

A primeira tentativa para descrever os estados ligados e obter as energias de ligação dos átomos foi feita independentemente por Sommer ${ }^{2}$, Cole e Cohen $^{3}$ e Shikin ${ }^{4}$.

O modelo mais simples para o potencial visto pelo elétron è o de uma barreira infinita na superfície mais o potencial imagem clássico. Nesta aproximação, a equação de Schrödinger é idêntica à equação radial para $x(r)=r R_{n, 0}(r)$, onde $R_{n, o}$ é a n-ésima solu ção com $\ell=0$, ou seja, ondas "s" do átomo de hidrogênio. o espectro de energias será hidrogênico, ou seja:

$$
E_{n}=-\frac{\Omega_{0}^{2}}{e^{4} n^{2}} \quad \text { Ryd } \simeq-\frac{0,65}{n^{2}} \mathrm{meV}
$$

Neste caso, o comprimento característico ou raio de Bohr efetivo será:

$$
a=\frac{a_{0} e^{2}}{\Omega_{0}}=76 \AA
$$

o elétron será localizado longe da superfície nestes estados fraca mente ligados. Os valores de <z> para os três mais baixos auto es- 
tados são respectivamente 114,456 e $1026 \AA$. Isto justifica usar a aproximação em que a superfície é plana. Como $E_{0} \sim 0,7 \mathrm{meV}$ a aproxi mação de barreira infinita também é justificável.

Os resultados obtidos para a transição entre estes estados são aproximadamente $5 \%$ maiores que os valores preditos pelo mo delo hidrogênico:

$\begin{array}{ccc}\text { Transição } & \text { Teōrico } & \text { Experimental } \\ 1+2 & 119,7 \mathrm{GHz} & 125,9 \pm 0,2 \mathrm{GHz} \\ 1 \rightarrow 3 & 141,8 \mathrm{GHz} & 148,6 \pm 0,3 \mathrm{GHz}\end{array}$

Esta pequena discrepância $\vec{e}$ atribuída aos efeitos interfaciais tais como: valor finito da barreira de potencial e o com portamento real da interação de polarização para pequenas distân cias.

Outro modelo consiste em introduzir a barreira de potencial finita $v_{0}$, da ordem de um elétron-volt e o potencial imagem clássico:

$$
v(z)=\left\{\begin{array}{cc}
v_{0} & z<0 \\
-\frac{\Omega_{0}}{z} & z>0
\end{array}\right.
$$

Neste caso, a exigência da continuidade da função de onda e de sua derivada em $z=0$, introduz sérias dificuldades matemáticas devido à singularidade do potencial.

M.Cole ${ }^{5}$ propôs então um modelo no qual evitava-se a singularidade do potencial imagem. O potencial proposto é dado por:

$$
v(z)=\left\{\begin{array}{cc}
-\frac{\Omega_{0}}{z} & z>z_{0} \\
-\frac{\Omega_{0}}{z_{0}} & 0<z<z_{0} \\
v_{0} & z<0
\end{array}\right.
$$


onde a constante $z_{0}$ foi tomada como a distância interatômica do hélio, 3,6 $\AA$. Para este modelo devemos resolver as seguintes equações:

$$
\begin{cases}\frac{d^{2} \phi}{d z^{2}}-\gamma^{2} \phi=0 & z<0 \\ \frac{d^{2} \phi}{d z^{2}}+\mu^{2} \phi=0 & 0<z<z_{0} \\ \frac{d^{2} \phi}{d z^{2}}+\frac{2 m}{\hbar^{2}}\left(E-\frac{\Omega_{0}}{z}\right) \phi=0 & z>z_{0}\end{cases}
$$

onde $\gamma^{2}=\frac{2 m}{\hbar^{2}}\left(V_{0}-E\right)$ e $\mu^{2}=\frac{2 m}{\hbar^{2}}\left(E+\frac{\Omega}{z}\right)$ com as relações de continuidade usuais e a condição de contorno ${ }^{\circ}$ no infinito. A solução da última equação é a função de whittaker $w_{\ell, 1 / 2}\left(2 \Omega_{0} z / l e^{2} a_{o}\right)$ onde " $\ell$ " è um nủmero quântico relacionado à energia através da equação:

$$
E_{\ell}=-\frac{\Omega_{0}^{2}}{e^{4} \ell^{2}} \text { Ryd }
$$

Embora a divergência do potencial imagem fôsse evitada neste modelo a altura da barreira de potencial $v_{0}$ é estimada em $1.3 e V$ para que os resultados coincidam com os experimentais, com parâmetro $z_{0}=3,6 \AA$. Para que a altura da barreira fôsse lev, como medida experimentalmente o parâmetro $z_{0}$ cresce rapidamente e os re sultados diferem significativamente dos resultados experimentais. Um outro potencial aproximado para o elétron na superfície de hẻlio que tem sido usado na determinação do espectro de e nergia é:

$$
V(z)= \begin{cases}-\frac{\Omega_{0}}{z+\beta} & z>0 \\ v_{0} & z<0\end{cases}
$$


Fisicamente, trata-se o potencial fora da superficie como se o po tencial imagem tivesse sua origem a uma pequena distância $\beta$ den tro do liquido. Recentemente, Hipólito et. al ${ }^{6}$ resolveram exatamen te este wudelo e calcularam os níveis de energia dos elétrons a justando o parâmetro $\beta$ com os resultados experimentais, 0 melhor a juste foi encontrado quando $\beta=1.01 \stackrel{\circ}{\AA}$. A primeira evidência experimental da existência dos estados superficiais induzidos pelo poten cial imagem para elétrons fora de superfície de hélio foi apontada por Sommer ${ }^{7}$. Em uma elegante experiência ele mediu a barreira de potencial, da ordem de leV, para a penetração de elētrons no hélio líquido. A observação experimental destes estados foi feita por Sommer e Tanner ${ }^{8}$ e Williams et al. ${ }^{9}$, atravēs de medidas de mobilidades dos elétrons sobre hélio. Entretanto estes resultados mostra ram estar em desacordo com os de Ostermeier e Schwarz ${ }^{10}$ obtidos por meio de outra técnica experimental. A prova definitiva da exís tência destes estados superficiais foi apresentada por Grimes e Brown $^{11}$ que utilizando técnicas espectroscōpicas mediram a separação de energia entre o estado fundamental e os dois primeiros estạ dos excitados, observando a absorção de radiação de microondas pelos elētrons sobre hélio líquido, sujeitos a um campo elétrico externo perpendicular à superfície.

A figura 2 mostra o traço experimental tomado a $160 \mathrm{GH}_{z}$. onde aparecem os sinais da derivada de absorção mais pronunciados devido às transições do estado fundamental para os dois primeiros estados excitados em função do campo elétrico externo aplicado entre dois eletrodos planos localizados acima da superfície e dentro do hēlio líquido. 


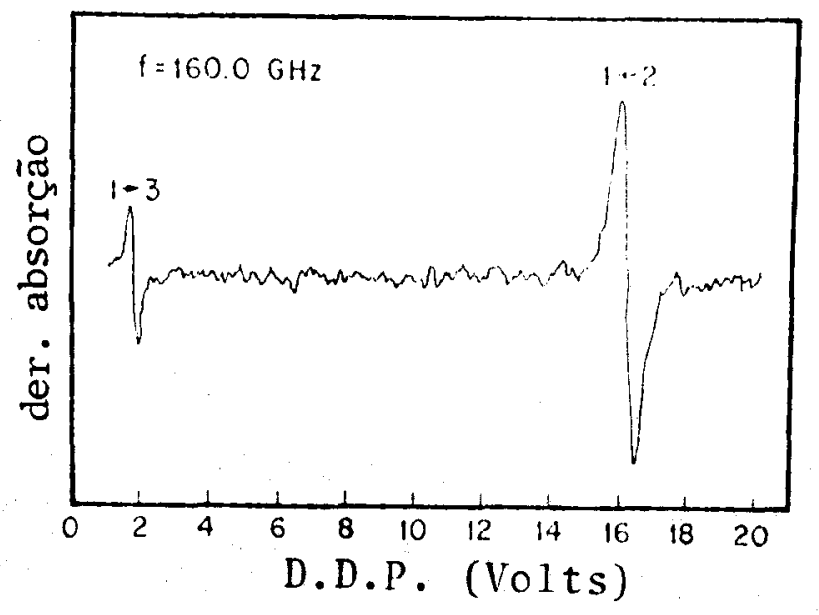

Figura 2

Na figura 3 estão os resultados para transições dos prí meiros estados excitados para o estado fundamental. A linha tracejada é a previsão do modelo de Grimes et al. ${ }^{31}$ e os símbolos (t) são os resultados experimentais por eles obtidos. A linha cheia são os resultados de Hipólito et al. ${ }^{6}$ baseado na solução exata do mode lo de potencial dado pela equação (2.10) no qual utilizou-se $\beta=$ $=1.01 \AA$.

Em vista da concordância com os resultados experimentais, podemos concluir que o melhor modelo fenomenológico para o poten cial è aquele dado pela equação (2.10).

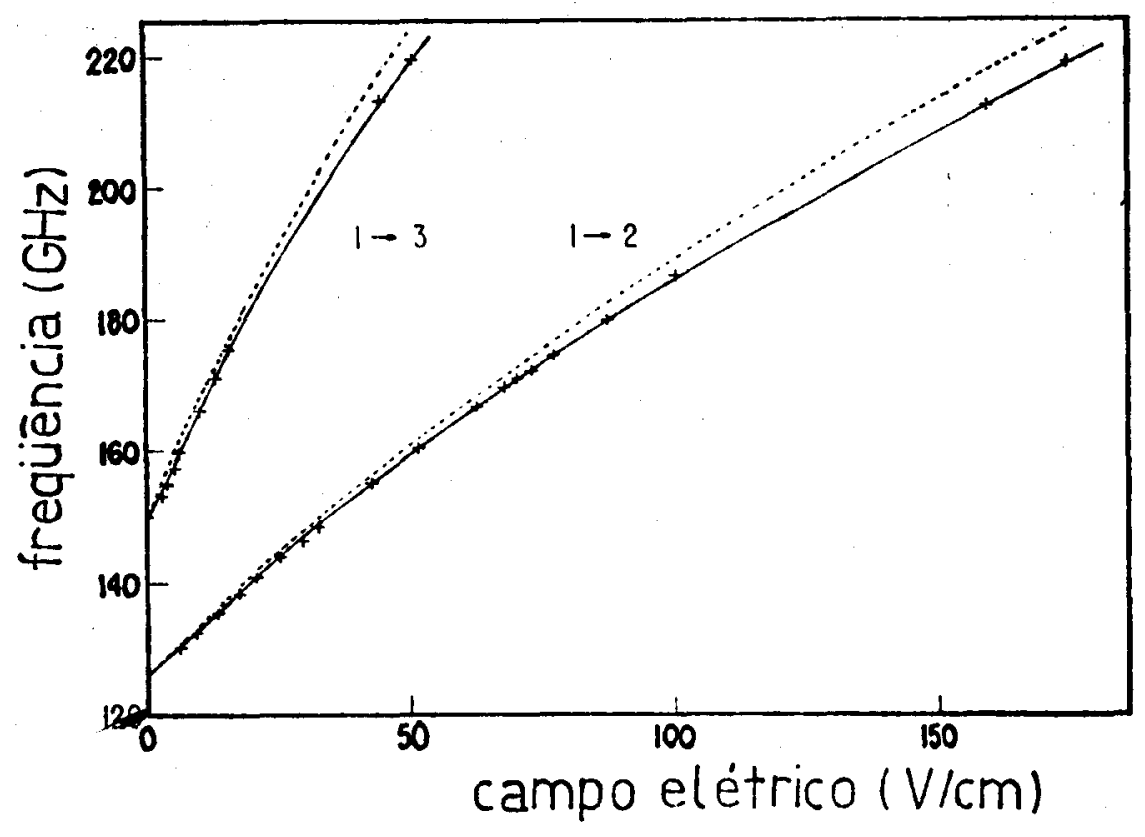

Figura 3 
Até agora temos discutido a origem e detecção dos esta dos superficiais em hélio líquido, mas nada dissemos do porquê da utilização deste dielētríco e não um outro qualquer. A vantagem de se usar hêlio lî́quido é sobretudo devido à pequena diferença entre sua constante dielétrica e o vācuo $(\varepsilon-1=0.0057)$. Como resultado, a função de onda do elētron superficial tem uma extensão de decaimen to, no vácuo, macroscópica ( $100 \AA)$. Assim os estados não são sensỉveis à estrutura microscōpica da superfície o que permite-nos des crevê-los melhor teoricamente.

o método prático para obter-se elétrons superficiais em hêlio líquido é muito simples e não requer tecnologia especial. Uma placa metālica de um capacitor plano carregada positivamente localizada abaixo da superfície do líquido e uma fonte de elétrons situada na fase gasosa é suficiente. Na figura 4 esquematizamos o a parato experimental ${ }^{12}$.

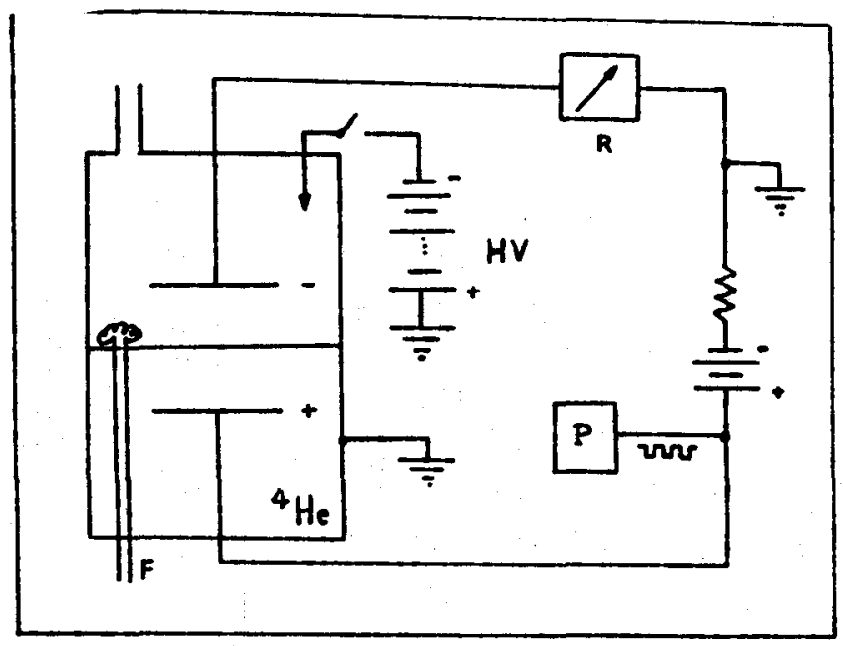

$$
\begin{aligned}
\mathrm{F} & \text { : filamento } \\
\mathrm{P} & \text { : gerador de pulsos } \\
\mathrm{R}: & \text { eletrômetro } \\
\mathrm{HV}: & \text { voltagem para discarga } \\
& \text { corona }
\end{aligned}
$$

\section{Figura 4}

Neste caso, a concentração de equilíbrio dos elétrons sobre a su perfície è determinada pela condição que o campo elētrico externo . na fase gasosa, seja completamente blindado pelo campo dos elétrons superficials, ou seja, o campo elētrico total $E_{T}$ na fase gasosa é nulo. Se $E_{\perp}$ for o campo elétrico externo e $n_{s}$ a concentração superficial, a condição de equilíbrio será: 


$$
E_{T}=E_{\perp}-4 \pi n_{S} e=0
$$

ou

$$
E_{\perp}=4 \pi n_{S} e
$$

Então, pela variação do campo elétrico externo é facilmente possível obter a densidade de elétrons $n_{s}$ em um grande intervalo: $10^{5}$ $10^{9}$ elëtrons $/ \mathrm{cm}^{2}$. Para densidades variando neste intervalo, elé trons na superfície de hêlio líquido formam um gás clássico bidi mensional, mesmo para temperaturas acima de poucos milikelvins . Uma vez que energia de Fermi em duas dimensões é dada por:

$$
\varepsilon_{F}=\frac{\pi \hbar^{2} n_{S}}{m}
$$

para $\mathrm{n}_{\mathrm{S}}=2 \times 10^{9} \mathrm{~cm}^{-2} \quad \varepsilon_{\mathrm{F}}<10^{-2} \mathrm{~K}$.

Alēm do mais, como pode-se variar a densidade por vărias ordens de grandeza, a condensação dos elétrons em um sólido de wigner pode ser detectada experimentalmente.

Precisamos, agora, verificar o efeito do campo elétrico externo $E_{\perp}$ que estã sempre presente nos experimentos com elétrons superficiais. A presença do campo externo distorce a forma do po tencial tal que:

$$
V(z)=-\frac{\Omega_{0}}{z}+e E_{\perp} z \quad z>0
$$

Neste caso è necessārio calcularmos o efeito Stark para os estados eletrônicos superficiais. Infelizmente uma solução analítica exata para este problema ainda não foi obtida. Uma aproximação seria trá tar o problema de um campo elētrico aplicado perpendicularmente à superficie através de teoria de perturbação de primeira ordem para o modelo hidrogênico, onde a barreira de potencial é infinita na o rigem $z=0$. Outro procedimento seria empregar o método variacional 
para resolvermos a equação de Schrbdinger:

$$
-\frac{\ddot{n}^{2}}{2 m} \frac{\mathrm{d}^{2} \phi}{d z^{2}}-\frac{\Omega_{0}}{z} \phi+e E_{\perp} z_{\phi}=E_{\phi}
$$

Para a função de onda variacional do estado fundamental escolhemos:

$$
\phi(z)=\left(\frac{4}{b^{3}}\right)^{1 / 2} z e^{-z / b}
$$

onde o parâmetro variacional b è dado por:

$$
b=\frac{4 a}{3 \lambda} \operatorname{senh}\left[\frac{1}{3} \operatorname{senh}^{-1} \frac{9 \lambda}{4}\right]
$$

com "a" sendo o raio de Bohr efetivo e $\lambda=\sqrt{2 \mathrm{ma}^{3} \mathrm{eE}+/ \hbar^{2}}$.

Na presença de um campo elétrico bastante forte $(E>3000$ $\mathrm{V} / \mathrm{cm})$ o potencial imagem pode ser desprezado e a equação de onda reduz-se à equação de Airy onde os resultados para as autofunções e autovalores de energia são conhecidos e dados por:

$$
\phi_{n}(z)=\text { const } \times A\left[\left(z-\frac{E_{n}}{e E_{L}}\right)\left(\frac{2 E_{\nu}}{e a_{o}}\right)^{1 / 3}\right]
$$

e

$$
E_{n}=\xi_{n} e E_{\perp}\left(\frac{e a_{0}}{2 E_{\perp}}\right)^{1 / 3} \quad n=1,2,3 \ldots
$$

onde $A(z)$ è a função de Airy e $\xi_{n}$ denota o seu n-ésimo zero (por e xemplo $\left.\xi_{1} \approx 2,34\right)$. Neste caso, o elētron no estado fundamental está localizado a uma distância $\left\langle z>\simeq 1,3\left(e_{0} / E_{\perp}\right)^{1 / 3}\right.$ da superfície.

Um outro sistema de relevante interesse, tem sido a loca lização de elétrons sobre filmes de hêlio adsorvidos em um substra to sólido de constante dielétrica $\varepsilon_{S}$. O espectro dos estados ligados se modifica significantemente pois o substrato induz altera - 
ఢ̧ões na força imagem. 0 arranjo experimental utilizado estă esque matizado na figura 5

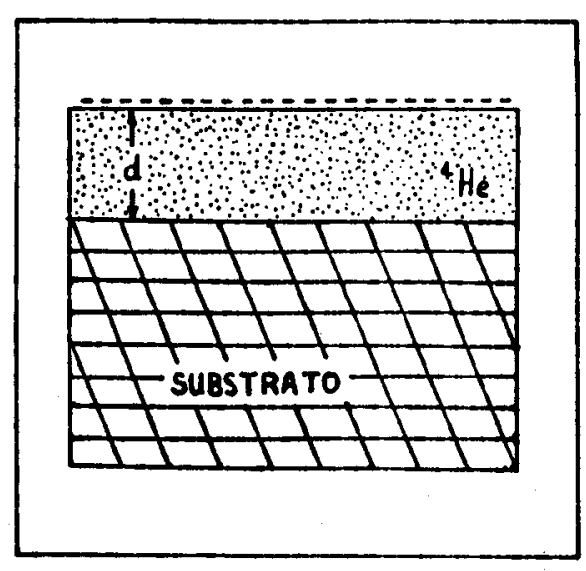

Figura 5

O potencial imagem neste caso è dado por (15) :

$$
V(z)=-\frac{\Omega_{0}}{z}-\Omega_{1} \sum_{\ell=1}^{\infty} \frac{(-a)^{\ell-1}}{z+\ell d}
$$

onde: $\Omega_{0}=\frac{(\varepsilon-1) e^{2}}{4(\varepsilon+1)} ; \Omega_{1}=\frac{e^{2} \varepsilon\left(\varepsilon_{S}-\varepsilon\right)}{(\varepsilon+1)^{2}\left(\varepsilon_{S}+\varepsilon\right)} \quad$ e $\quad a=\frac{(\varepsilon-1)\left(\varepsilon_{S}-\varepsilon\right)}{(\varepsilon+1)\left(\varepsilon_{S}+\varepsilon\right)}$

Esta sērie, em geral, apresenta uma rápida convergência e pode ser aproximada pelo primeiro termo. Gabovich et al. ${ }^{16}$ obtiveram o es pectro dos estados eletrônicos, para filmes de hêlio adsorvidos em metal $\left(\varepsilon_{\mathbf{S}} \rightarrow \infty\right)$. No limite de filmes finos o potencial será:

$$
v(z)=-\frac{\Omega_{0}}{z}-\frac{\Omega_{1}}{z+d}
$$

Neste li.. te a condição $d>>\langle z\rangle_{n}$ é sempre satisfeita, então podemos expandir o potencial na seguinte forma:

$$
V(z) \simeq-\frac{\Omega_{0}}{z}-\frac{\Omega_{1}}{d}+\frac{\Omega_{1} z}{d^{2}}
$$

o substrato atuará como um campo externo de intensidade $E_{\perp}=\frac{\Omega_{1}}{\mathrm{ed}^{2}}$ e a presença do termo negativo $\frac{\Omega_{1}}{d}$ contribuirá para o aumento da e nergia potencial dos elētrons. 
Platzman e Ikezi ${ }^{17}$ mostraram que no caso de filmes de hẹ 1io, a densidade máxima de carga na superfície serä aumentada dras ticamente devido ao campo elétrico efetivo e ao aparecimento das forças de van der Waals as quais tendem a estabilizar o sistema elētron-filme.

A correção no espectro de energia obtido na aproximação hidrogênica em função da espessura do filme será:

$$
\Delta E_{n}(d)=-\frac{\Omega_{1}}{d}\left[1-\frac{3}{2} \frac{\hbar^{2}}{m_{\Omega_{0}}} \frac{n^{2}}{d}\right] \text {, }
$$

correspondendo a primeira ordem do efeito Stark do campo elétrico $E_{d}=\frac{\Omega_{1}}{e^{2}}$.

Como vimos, os elétrons na superfície de hëlio podem ser considerados como um sistema de elētrons bidimensional dentro de um poço de potencial $\mathrm{V}(z)$. Agora estudaremos as propriedades do mo vimento eletrônico na direção paralela à superfície. Para baixas densidades, o găs de elétrons pode ser tomado como um gás de elé trons livres ideal e neste regime, o movimento eletrônico é impedi do por dois mecanismos de espalhamento:

(a) espalhamento por átomos de hélio no vapor

(b) espalhamento por riplons termicamente excitados so bre a superficie do líquido .

Estes riplons são quasi-partículas relacionadas com as os cilações da interface líquido-vapor. São ondas superficiais de capi laridade-gravidade dos líquidos em geral e que quando quantizadas recebem o nome de riplons. Estas quasi-partículas são bosons com concentração de equilíbrio:

$$
\mathrm{N}_{K}=\left(e^{\frac{\hbar \omega}{\mathrm{K}_{\mathrm{B}} \mathrm{T}}}-1\right)^{-1}
$$

e relação de dispersão: 


$$
w_{K}^{2}=g K+\frac{o}{\rho} k^{3}
$$

onde $g$ è a constante da gravidade, $\sigma_{0}$ é a tensão superficial e $\rho$ a densidade do líquido.

Uma anălise quantitativa destes mecanismos de espalhamen to será apresentada no próximo capítulo, mas podemos adiantar que em baixas temperaturas $\left(T<0,7^{\circ} \mathrm{K}\right) \circ$ espalhamento predominante $\ddot{\mathrm{e}} \mathrm{de}-$ vido ã interação elétron-riplon, e que para campos externos da ordem de $400 \mathrm{~V} / \mathrm{cm}$ este espalhamento é elástico. Para campos intensos $(E \sim 3000 \mathrm{~V} / \mathrm{cm})$ a superfície de hélio deforma-se devido à pressão exercida pelo elétron. A depressão da superfície em torno de cada $\underline{\text { }}$ létron forma um "dimple" no qual o elétron se localiza. Experimentos recentes de wanner e Leiderer ${ }^{13}$ e Giannetta e Ikezi ${ }^{14}$ tèm verí ficado com sucesso a localização de elétrons seja na interface de misturas de ${ }^{3} \mathrm{He}-{ }^{4} \mathrm{He}$ ou de ${ }^{4} \mathrm{He}$ líquido.

Entre as características bāsicas dos elētrons superfi clais em hēlío, enfatizamos mais uma vez, a pureza do sistema, sua simplicidade de preparação e a possibilidade de variarmos alguns parâmetros do sistema num longo intervalo. Neste sentido, elétrons superficiais em hêlio são objetos ideais para a investigação de princípios fundamentais da teoria de um gás de elétrons de baixa densidade e a física dos sistemas de baixa dimensão. Não é surpreendente que as descobertas básicas experimentais nesta linha tais como: plasmons bidimensionais, cristalização de wigner e outros fo ram obtidos com o uso de elétrons superficiais em hēlio ?

No prôximo capítulo faremos uma análise detalhada dos me canismos de espalhamento e deduziremos a Hamiltoniana que descreve a interação do elétron com a superfície de hẻlio líquido para baixas temperaturas, ou seja, na região onde somente a interação elētron-riplon è importante. 
CAPITULO III

MECANISMOS DE ESPALHAMENTO NO MOVIMENTO PARALELO A SUPERFICIE 
Neste capítulo, estudaremos as propriedades do movimento eletrônico na direção paralela à superfície. Como citamos anterior mente, para batxas densidades, o gás de elëtrons pode ser considerado como um găs de elétrons livres ideal e, neste regime, o movimento eletrônico é impedido por dois mecanismos de espalhamento: o espalhamento pelos átomos de hélio no vapor e o espalhamento devido âs excitações térmicas da superfície do líquido.

M.Cole ${ }^{18}$, Crandall ${ }^{19}$ e Saitoh $^{20}$ estudaram o espalhamento de elétrons na superfície por átomos no vapor e encontraram que a va riação de momentum devido ao espalhamento (inverso do tempo de colisão) depende sómente da densidade dos átomos de vapor e é inde pendente da energia do elétron. Como a densidade de vapor aumenta quase exponencialmente com $\circ$ aumento da temperatura, o espalhamento pelos átomos no vapor é desprezível em baixas temperaturas e é predominante em altas temperaturas, como pode ser visto nos resultados experimentais para a mobilidade, mostrados na figura 6 .

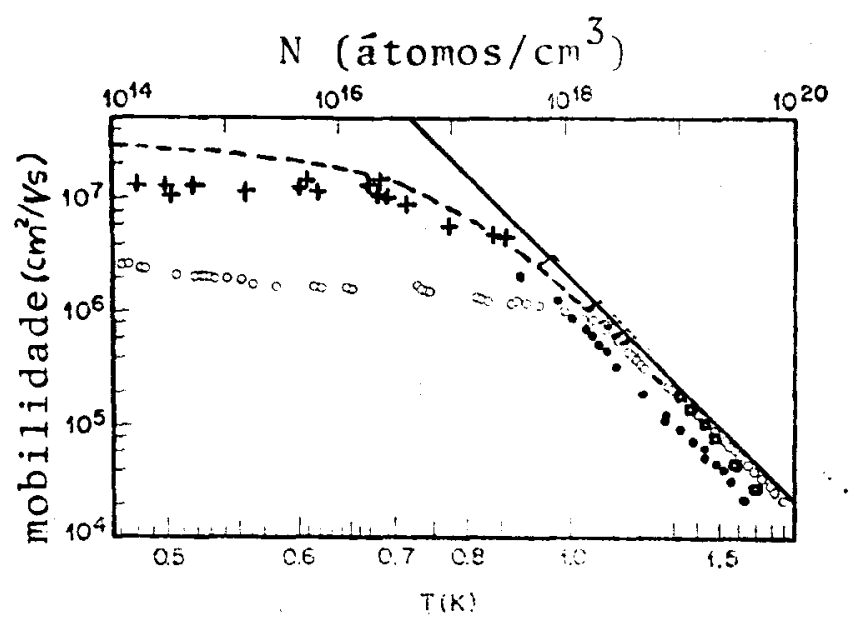

Figura 6 
Na figura anterior temos a mobilidade eletrônica paralela â superfície do hēlio em função da temperatura e da densidade do vapor de hêlio. A linha cheia é obtida considerando-se apenas o espalhamento com os átomos no vapor ${ }^{23}$. A linha tracejada é o resul tado dos cálculos efetuados por saitoh ${ }^{20}$ onde considera-se o espa1hamento com os riplons e os átomos no vapor. Os pontos experimentais $(t)$ foram obtidos por Grimes e Adams ${ }^{21},(\cdot)$ por Sommer e Tanner $^{8}$ e (o) por Rybalko et al. ${ }^{22}$.

Nos cãlculos de Saitoh $^{20}$, o tempo de colisão é obtido através da solução da equação de transporte de Boltzmann para a fun ção distribuição de elētrons $f(\vec{k})$, quando um campo elētrico $E_{\text {/ }}$ aplicado paralelamente à superfície, por simplicidade na direção $\mathbf{x}$

$$
-\frac{e E_{\|}}{\hbar} \frac{\partial}{\partial K} f(\vec{K})=\mathscr{L}_{x}(\vec{K})
$$

onde $\mathfrak{L}$ é o operador colisão.

Admitiremos que a função distribuição dos elētrons $f(\vec{K})$ tenha a forma:

$$
f(\vec{K})=h\left(\varepsilon_{k}\right)+K_{x} G\left(\varepsilon_{k}^{\prime}\right)
$$

com um termo isotrópico e outro anisotrópico.

Para a colisão do elétron com o gãs de hélio, considera mos um pseudo-potencial de contato do tipo:

$$
H_{e-G}=U_{G} \sum_{i, \alpha} \delta\left(\vec{r}_{i}-\vec{R}_{\alpha}\right),
$$

onde $\vec{r}_{i}$ e $\vec{R}_{\alpha}$ são vetores posição do i-ésimo elétron e do $\alpha$-ésimo ā tomo de hélio.

o operador colisão atuando em $h\left(\varepsilon_{k}\right)$, após alguma álgebra, pode ser escrito na forma 


$$
\mathscr{L}_{G} h(\varepsilon)=\frac{d}{d \varepsilon}\left[W_{G}(\varepsilon)\left(h(\varepsilon)+K_{B} T \frac{d h}{d \varepsilon}(\varepsilon)\right)\right]
$$

onde:

$$
W_{G}(\varepsilon)=\frac{\pi \hbar A n_{G}}{4 M b}\left(\frac{\hbar^{2}}{m b^{2}}+3 \varepsilon\right)
$$

M é a massa do átomo de ${ }^{4} \mathrm{He}$ e $\mathrm{K}_{\mathrm{B}}$ ē a constante de Boltzmann. Com o parâmetro b dado por:

$$
\mathrm{b}=\frac{4 a}{3 \lambda} \operatorname{senh}\left[\frac{1}{3} \operatorname{senh}^{-1} \frac{9 \lambda}{4}\right]
$$

onde: $\lambda=\sqrt{2 \mathrm{ma}^{3} \mathrm{eE}_{\perp} / \hbar^{2}}$ e $\mathrm{A}$ é a seção de choque de um átomo de hélio relacionado $\operatorname{com} \mathrm{U}_{\mathrm{G}}$, através da relação:

$$
\mathrm{A}=\mathrm{m}^{2} \mathrm{U}_{\mathrm{G}}^{2} / \pi^{4}
$$

e $n_{G} \bar{e}$ a densidade do vapor saturado dado por:

$$
n_{G}=\left(\frac{M T K_{B}}{2 \pi \hbar^{2}}\right)^{3 / 2} e^{-Q / K_{B} T}
$$

onde $Q$ é a energia de vaporização.

o operador colisão aplicado ao termo anisotrópico pode ser escrito na forma:

$$
\mathscr{J}_{G}\left(K_{X} G(\varepsilon)\right)=-\frac{K_{X} G(\varepsilon)}{{ }_{\tau_{G}}(\varepsilon)}
$$

onde $\tau_{G}$ é o tempo de colisão devido ao espalhamento do găs de hẻ lio e dado pela expressão:

$$
\frac{1}{{ }^{T} G}=\frac{3 \pi \hbar A n_{G}}{8 \mathrm{mb}}
$$


que ê independente da energia do elétron.

Por outro lado, o espalhamento pelas excitações superficiais tambẻm apresenta muitos aspectos interessantes, pois depende detalhadamente da interação entre elétrons e as vibrações da intẹ face líquido-vapor. Vários autores calcularam o tempo de colisão para o espalhamento elētron-riplon e contrariamente ao caso ante rior, existe aqui bastante controvērsia tanto com os resultados teó ricos quanto com os resultados experimentais, como podemos ver na figura 6 . Sabemos dos resultados experimentais que o espalhamento por âtomos do gás predomina acima de cerca de $0,8 \mathrm{~K}$ e o espalhamento por riplons é dominante abaixo de $0,6 \mathrm{~K}$. Contudo, existe uma apreciável discrepância entre os valores medidos da mobilidade limitada aos riplons por diferentes autores, tal que medidas mais cui dadosas são necessārias para temperaturas mais baixas.

Em relação aos cālculos teōricos, o problema fundamental consiste na descrição correta da interação elētron-riplon. Shikin e Monarka ${ }^{15}$ usaram uma aproximação adiabática, no sentido que a função de onda eletrônica na aproximação de ordem zero, depende da coordenada do riplon. A mobilidade calculada por saitoh ${ }^{20}$, no regi me de ri on, é essencialmente a mesma que a encontrada por Shikin e Monarka ${ }^{15}$.

Platzman e Beni ${ }^{24}$ tambëm mostraram que quando esta interação elétron-riplon è aplicada ao problema de largura de linha do plasmon os resultados obtidos concordam com os valores observados experimentalmente por Grimes e Adams ${ }^{21}$.

Gaspari e Bridges ${ }^{25}$ reexaminaram o espalhamento elētronriplon e concluiram que os resultados de Shikin e Monarka ${ }^{15}$ são corretos somente se a barreira de potencial na superfície é infini ta. Monarka ${ }^{26}$ reanalisou o espalhamento elétron-riplon usando o mesmo princípio adiabático e mostrou uma inconsistência no traba Iho de Gaspari e Bridges ${ }^{25}$, reconfirmando os resultados anteriores 
de Shikin e Monarkha ${ }^{15}$

A seguir calcularemos o potencial de interação elētron riplon e identificaremos a Hamiltoniana resultante com a Hamilto niana de Froblich, típica para o problema do polaron.

Para obtermos o potencial de interação elētron-riplon se guiremos os procedimentos de Shikin e Monarkha ${ }^{15}$.

A equação de Schrödinger para um elétron sobre a super fícle de hẻlio líquido deformada devido à presença do campo elétrí co $E_{\perp} \bar{e}$

$$
\frac{\hbar^{2}}{2 m} \nabla^{2} \psi(\vec{r}, z)+\left[E-V(\vec{r}, z)-e E_{\perp} z\right] \psi(\vec{r}, z)=0
$$

As condições de contorno impostas à função de onda $\psi(\vec{r}, z)$ são:

$$
\left.\psi(\vec{r}, z)\right|_{z=u(\vec{r})}=0 \quad \text { e }\left.\psi(\vec{r}, z)\right|_{z \rightarrow \infty}=0
$$

onde $u(\vec{r})$ representa a deformação da superfície com relação ao plano $z=0$ devido à pressão exercida pelo elétron. $u(\vec{r})$ satisfaz a condição:

$$
\int d^{2} r u(\vec{r})=0
$$

o potencial $V(\vec{r}, z)$ representa a interação de polarização do elētron com os átomos de hélio e é dado por:

$$
V(\vec{r}, z)=-\frac{\Omega_{0}}{\pi} \int d^{2} r^{\prime} \int_{-\infty}^{u\left(\vec{r}^{\prime}\right)} \frac{d z^{\prime}}{\left[\left(\vec{r}^{\prime}-\vec{r}\right)^{2}+\left(z^{\prime}-z\right)^{2}\right]^{2}}
$$

onde: $\Omega_{0}=\frac{\varepsilon-1}{4(\varepsilon+1)} ; \varepsilon$ é a constante dielētrica do hélio $(\varepsilon=$ $=1.057)$. Evidentemente, para $u \rightarrow 0$, reencontramos o potencial ima gem clässico: 


$$
V(z)=-\frac{\Omega_{0}}{z}
$$

Uma discussão detalhada de $V(\vec{r}, z)$ é realizada por M.W.Cole ${ }^{18}$. Fazendo uma mudança de variáveis, tais que

$$
\xi=z-u(\vec{r}) \quad \text { e } \quad \vec{r}=\vec{r} \text {, }
$$

a equação de Schrơdinger pode ser escrita na forma:

$$
\mathrm{H}=\mathrm{H}_{0}+\mathrm{H}_{1}
$$

onde:

$$
\begin{aligned}
& \mathrm{H}_{0}=\frac{1}{2 \mathrm{~m}}\left[\mathrm{P}_{\xi}^{2}+\mathrm{P}_{\mathrm{r}}^{2}\right]-\frac{\Omega_{0}}{\xi}+\mathrm{eE}_{\perp} \xi ; \xi>0 \\
& \mathrm{H}_{1}=-\frac{1}{2 \mathrm{~m}}\left[\left(\frac{\partial \mathrm{u}}{\partial \vec{r}} \mathrm{P}_{r}\right) \mathrm{P}_{\xi}+\left(\mathrm{P}_{\mathrm{r}} \frac{\partial \mathrm{u}}{\partial \vec{r}}\right) \mathrm{P}_{\xi}\right]+\Delta \mathrm{V}+\mathrm{eE} u(\vec{r})
\end{aligned}
$$

com: $\overrightarrow{\mathrm{P}}=-i \hbar \nabla$

$$
\Delta V=-\frac{\Omega_{0}}{\pi} \int d^{2} r^{\prime} \int_{0}^{u\left(\vec{r}^{\prime}\right)-u(\vec{r})} \frac{d \xi^{\prime}}{\left[\left(\vec{r}^{\prime}-\vec{r}\right)^{2}+\left(\xi^{\prime}-\xi\right)^{2}\right]^{2}}
$$

o operador $\mathrm{H}_{\mathrm{O}}$ é o Hamiltoniano dos elétrons acima da superfície do líquido. O primeiro termo de $H_{l}$, aparece devido a transformação do Laplaciano e apresenta a seguinte propriedade: os ele mentos de matriz entre dois estados que diferem apenas pelo vetor de onda paralelo à interface, ou seja, estados com mesmo número quântico, são todos zeros. A parte residual, equação (3.19), tem um intervalo de integração muito pequeno, o que permite-nos reescrever $\Delta \mathrm{V}$ na forma: 


$$
\Delta v=\frac{\Omega_{0}}{\xi^{2}} u(\vec{r})-\frac{\Omega_{0}}{\pi} \int \frac{u\left(\vec{r}^{\prime}\right)}{\left[\left(\vec{r}^{\prime}-\vec{r}\right)^{2}+\xi^{2}\right]^{2}} d^{2} r^{\prime}
$$

Utilizando o conceito de riplons, podemos expandir um pe (*)

queno deslocamento arbitrário $u(\vec{r})$ da superfície de hélio em ter mos dos operadores de criação e destruição de riplons, $a_{\vec{k}}^{+}$e $a_{\vec{k}}$ res pectivamente. Então:

$$
u(\vec{r})=\sum_{\vec{k}}\left(a_{\vec{k}}^{+}+a_{-\vec{k}}\right) Q_{\vec{k}} e^{i \vec{k} \cdot \vec{r}}
$$

com:

$$
Q_{\vec{k}}=\left(\frac{\hbar k}{2 A \rho W_{\vec{k}}}\right)^{1 / 2} ; A \text { é a ārea da superficie. }
$$

Substituindo a equação (3.21) na equação (3.20) teremos:

$$
\Delta V=\frac{\Omega_{0}}{\xi} u(\vec{r})-\Omega_{0} \sum_{\vec{k}}\left(a_{\vec{k}}^{+}+a_{-\vec{k}}\right) Q_{\vec{k}} \frac{k}{\xi} K_{l}(k \xi) e^{i \vec{k} \cdot \vec{r}}
$$

onde: $K_{1}(x)$ é a função de Bessel modificada de segunda espécie. Agora reescrevemos $\mathrm{H}_{1}$ com a nova expressão de $\Delta \mathrm{V}$ :

$$
H_{1}=\sum_{\vec{k}}\left(a_{\vec{k}}^{t}+a_{-\vec{k}}\right) Q_{\vec{k}} e^{i \vec{k} \cdot \vec{r}}\left[\frac{\Omega_{0}}{\xi^{2}}-\frac{\Omega_{0} k}{\xi} K_{l}(k \xi)+e E\right]
$$

No caso de filmes de hẻlio líquido adsorvidos em um subs trato de constante dielétrica $\varepsilon$, haverá a interação do elëtron com o substrato, e o potencial imagem que antes era $V(z)=-\frac{\Omega_{0}}{z}$ será alterado para ${ }^{15}$,

$$
V(z, d)=-\frac{\Omega_{0}}{z}-\Omega_{1} \sum_{\ell=1}^{\infty} \frac{(-a)^{\ell-1}}{z+\ell d}
$$

com 


$$
\Omega_{1}=\frac{e^{2} \varepsilon(\varepsilon s-\varepsilon)}{(\varepsilon+1)^{2}(\varepsilon+\varepsilon)} \quad ; \quad a=\frac{(\varepsilon-1)(\varepsilon s-\varepsilon)}{(\varepsilon+1)(\varepsilon s+\varepsilon)}
$$

onde d ê a espessura do filme, $\varepsilon$ e $\varepsilon_{\mathbf{s}}$ as constantes dielétricas do hélio e do substrato respectivamente.

Uma vez que a série da equação (3.24) apresenta uma rápida convergência, aproximaremos o potencial imagem da seguinte forma ,

$$
V(z, d)=-\frac{\Omega_{0}}{z}-\frac{\Omega_{1}}{z+d}
$$

Fazendo a mesma mudança de variāveis, equação (3.16), em (3.25) e expandindo até primeira ordem em $u(\vec{r})$, teremos que a contribuição do substrato na interação elétron-riplon será dada por

$$
\mathrm{V}_{\mathrm{S}}(\vec{r}, \xi)=\frac{\Omega_{1}}{(\xi+d)^{2}} \mathrm{u}(\vec{r})
$$

Para este caso, $\mathrm{H}_{1}$ eq. (3.18), terā a seguinte forma:

$$
\mathrm{H}_{1}=\sum_{\vec{k}}\left(a_{\vec{k}}^{+}+a-\vec{k}\right) e^{i \vec{k} \cdot \vec{r}_{Q_{\vec{k}}}}\left[\frac{\Omega_{0}}{\xi^{2}}-\frac{\Omega_{0} k}{\xi} K_{1}(k \xi)+\frac{\Omega_{1}}{(\xi+d)^{2}}+\right.
$$

$$
\left.+\mathrm{eE}_{\perp}\right]
$$

com $\quad Q_{\vec{k}}=\left(\frac{\hbar k \tanh (k d)}{2 \mathrm{~A} \rho \mathrm{W}_{\vec{k}}^{+}}\right)^{1 / 2}$

onde $W_{\vec{k}}$ é a nova relação de dispersão dos riplons devido à presença do substrato,

$$
\mathrm{w}_{\overrightarrow{\mathrm{k}}}^{\prime 2}=\left[g^{\prime}+\underset{\rho}{\left(\frac{\sigma}{\rho}\right) k^{2}}\right] \mathrm{k} \tanh (k d)
$$




$$
g^{\prime}=g+\frac{3 n}{\rho d^{4}}
$$

Aquin é a constante de van der Waals, responsável pelas forças atrativas que atuam nos átomos de hélio no lado do substrato.

0 potencial de interação elétron-riplon para filmes de hélio de espessura d ê então dado por,

$$
V_{\vec{k}}=\underset{k}{Q_{k}^{\prime}}\left[\frac{\Omega_{0}}{\xi}-\frac{\Omega_{0} k}{\xi} K_{1}\left(k_{\xi}\right)+\frac{\Omega_{1}}{(\xi+d)^{2}}+e_{1}\right]
$$

Em geral, utilizamos filmes onde $d\rangle\rangle\langle\xi\rangle$. No limite de grandes comprimentos de onda, onde os experimentos têm sido feito, podemos aproximar $K_{1}\left(k_{\xi}\right) \simeq \frac{1}{k_{\xi}}$, tal que o termo de polarização desaparece e obtemos,

$$
V_{\vec{k}}=\underset{\vec{k}}{Q}\left[\frac{\Omega}{d^{2}}+e E_{\perp}\right]
$$

E evidente que neste caso limite, a interação elētron riplon pode existir somente se os fatores externos, ou seja, o campo elétrico perpendicular à superfície eicu o potencial do subs trato estiverem presentes.

Finalmente a Hamiltoniana para um elétron interagindo com os riplons será, então

$$
H=\frac{p^{2}}{2 m}+\sum_{\vec{k}} \hbar \omega \vec{k} a_{\vec{k}}^{+} a_{\vec{k}}+\sum_{\vec{k}} V_{\vec{k}}\left(a_{\vec{k}}^{+}+a_{-\vec{k}}\right) e^{i \vec{k} \cdot \vec{r}}
$$

onde o primeiro termo é a energia cinética do elétron, o segundo a energia dos riplons e o terceiro termo nos dá a interação elētron-riplon.

Farias ${ }^{34}$ e Hipólito et al. ${ }^{35}$ resolveram esta Hamiltonia na utilizando-se o formalismo de integral de trajetória, entretan to os cālculos foram concluidos somente no regime de campo elétrí 
co externo intenso correspondendo ao regime de acoplamento forte . Jackson e Platzman ${ }^{37}$ utilizaram este mesmo formalismo para um sistema par cicular, onde a espessura do filme de hélio líquido é de $100 \AA$ e não há restrições no valor do campo elêtrico externo. No próximo capítulo, entretanto, discutiremos o método variacional que utilizaremos na resolução da Hamiltoniana (3.31), o qual ê baseado em transformações canônicas e tem sido empregado com sucesso no problema do polaron. 
CAPITULO IV

O MÉTODO VARIACIONAL 
Neste capítulo apresentaremos o formalismo do método variacional que será utilizado. Este método é vâlido para todos os valores da constante de acoplamento e tem sido empregado com suces so no estudo de diferentes tipos de polarons.

o movimento de uma partícula carregada com uma carga $Q$ e massa $M$ paralelamente à superfície e interagindo com as excitações superficiais, é descrito pela Hamiltoniana de Frolich

$$
H=\frac{p^{2}}{2 M}+\sum_{\vec{k}} \hbar \omega_{\vec{k}} a_{\vec{k}}^{+} a_{\vec{k}}+\sum_{\vec{k}} V_{\vec{k}}\left(a_{-\vec{k}}^{+}+a_{\vec{k}}\right) e^{i \vec{k} \cdot \vec{r}}
$$

onde $\vec{p}$ e $\vec{r}$ são o momentum e a coordenada da partícula, $a_{\vec{k}}^{+}$e $a_{\vec{k}}$ são os operadores de criação e destruição respectivamente das excita ções superficiais com um vetor de onda $\vec{k}$ paralelo à superfície, $\vec{V}_{\vec{k}}$ é o coeficiente de Fourier do potencial de interação e $\omega_{\vec{k}} \bar{e}$ a rela ção de dispersão das excitações.

\section{A Hamiltoniana (4.1) è translacionalmente invariante,}

portanto o momentum total do sistema, isto é, a soma do momentum da partícula com o momento das excitações superficiais deve ser con servado : Ou seja:

$$
\left[H, \vec{P}_{t}\right]=0
$$

onde: $\overrightarrow{\mathrm{P}}_{t}=\overrightarrow{\mathrm{p}}+\sum_{\overrightarrow{\mathrm{k}}} \hbar \overrightarrow{\mathrm{k}} \mathrm{a}_{\overrightarrow{\mathrm{k}}} \mathrm{a}_{\overrightarrow{\mathrm{k}}}$.

Para o estado fundamental partícula carregada-excitação, a função de onda variacional $|\psi\rangle$ será postulada ser o produto da função de onda da partícula com um estado coerente de excitação. Consequentemente este estado superficial não será um auto-estado do operador momentum total $\overrightarrow{\mathrm{P}}_{t}$ e não preservará a invariança da Hamil- 
toniana (4.1). Por esta razão a minimização da energia será realizada vinculando-se o operador momentum total $\overrightarrow{\mathrm{P}}_{t}$ atravēs do mētodo dos multiplicadores de Lagrange. Introduz-se o multiplicador de La grange $\vec{\mu}$, para manter-se o valor esperado do momentum total uma constante. Faremos então a variação da seguinte forma

$$
\delta\left\langle\psi\left|H-\vec{\mu}_{t} \cdot \vec{E}_{t}\right| \psi\right\rangle=0
$$

onde $\vec{\mu}$ serä identificado com a velocidade do "polaron superficial" ou seja do sistema partịcula-excitação superficial.

A técnịca introduzida por Huybrechts ${ }^{27}$, consiste em em pregar as transformações de Lee-Low-Pines ${ }^{28}$ modificadas à Hamiltoniana 16 , onde

$$
H=H-\vec{\mu} \cdot \vec{P}_{t}
$$

A primeira transformação unitāria é definida por

$$
s_{1}=\exp \left(-i \quad a \sum_{\vec{k}} \vec{k} \cdot \vec{r} a_{\vec{k}}^{+} a_{\vec{k}}\right)
$$

onde a é um parâmetro variacional a ser determinado pela minimiza ção do estado fundamental do sistema. E interessante notar que esta expressão reproduz os resultados de Lee-Low-Pines para acoplamentos fracos no caso em que $a=1$. Por outro lado, no limite $a \rightarrow 0$ obtemos $a$ aproximação para acoplamentos fortes, o qual tem sido discutido recentemente por Hipólito et.al. 29

$$
\begin{aligned}
& \text { 'Definimos, então, } f^{\prime} \text { tal que } \\
& H^{\prime}=s_{1}^{-1} H s_{1} \\
& \text { Ou, explicitamente }
\end{aligned}
$$




$$
\begin{aligned}
H^{\prime} & =\frac{1}{2 M}\left(\vec{p}-a \sum_{\vec{k}}+\vec{k} a_{\vec{k}}^{+} a_{\vec{k}}\right)^{2}+\sum_{\vec{k}}+w_{\vec{k}} a_{\vec{k}}^{+} a_{\vec{k}}+\sum_{\vec{k}} v_{\vec{k}}\left(a_{-+\vec{k}^{+}+a_{\vec{k}}}\right) \exp [i(1- \\
& -a) \vec{k} \cdot \vec{r}]
\end{aligned}
$$

A função de onda yariacional do estado fundamental $|\psi\rangle$, é escolhida como sendo

$$
|\psi\rangle=s_{2}|0>| e>,
$$

onde |è è a função de onda da partícula carregada, $\mid 0>$ é a função de onda do estado fundamental dos riplons obtida por $a_{\vec{k}} \mid 0>=0$ e $<0|0\rangle=1 ; S_{2} \bar{e}$ um operador unitário, também chamado de segunda trans formação de Lee-Low-Pines definido por

$$
s_{2}=\exp \left[\sum_{\vec{k}}\left(a_{\vec{k}}^{+} f_{\vec{k}}-a_{\vec{k}} f_{\vec{k}}^{*}\right)\right]
$$

onde $f_{\vec{k}}$ e $f_{\vec{k}}^{*}$ são funções variacionais a serem determinadas requeren do-se que a energia do sistema seja minimizada.

A transformação unitária $s_{2}$ atua como um operador deslocamento sobre os operadores $a_{\vec{k}}^{+}$e $a_{\vec{k}}$, ou seja

$$
\begin{aligned}
& s_{2}^{-1} a_{\vec{k}}^{+} s_{2}=a_{\vec{k}}^{+}+f_{\vec{k}}^{*} \\
& s_{2}^{-1} a_{\vec{k}} s_{2}=a_{\vec{k}}+f_{\vec{k}}
\end{aligned}
$$

Este cálculo variacional é baseado no uso do vetor de estado $s_{2} \mid 0>$ e estā intimamente relacionado à aproximação introduzida por Tomonaga ${ }^{30}$ no tratamento do acoplamento entre mésons e núcleons, - qual mais tarde foi chamado de aproximação de acoplamento interme dỉario. A aproximação de Tomonaga consiste numa técnica variacional 
baseada na hipótese que os mésons (riplons) no campo em torno do núcleon (partícula-carregada) são emitidos independentemente, en tão não hã correlação, isto é interação, entre mẻsons (riplons) dí ferentes.

Para a função de onda do estado fundamental da partícula escolhemos

$$
|e\rangle=\left(\frac{M \lambda}{\pi \hbar}\right)^{1 / 2} \exp \left(-\frac{M \lambda}{2 \hbar} r^{2}\right) \exp \left(-i \frac{M \lambda}{2 \hbar} \vec{p}_{\circ} \cdot \vec{r}\right)
$$

onde $\overrightarrow{\mathrm{F}}_{\mathrm{o}}$ e $\lambda$ são dois parâmetros variacionais, os quais serão obtidos minimizando a energia do sistema.

$$
\begin{aligned}
& \text { Definindo a função } F\left(a, \lambda, f_{\vec{k}}, \vec{p}_{\circ}, \vec{\mu}\right) \text { por } \\
& F\left(a, \lambda, f_{\vec{k}}, \vec{p}_{o}, \vec{\mu}\right)=\left\langle e K\left(0\left|s_{2}^{-1} f b^{\prime} s_{2}^{\prime}\right| 0\right\rangle \mid e\right\rangle,
\end{aligned}
$$

e utilizando as equações $(4.7),(4.9)$ e (4.11), temos

$$
\begin{aligned}
F\left(a, \lambda, f_{\vec{k}}, \vec{p}_{0} \vec{\mu}\right) & =\frac{\hbar \lambda}{2}+\frac{\hbar \lambda}{4} p_{o}^{2}+\sqrt{\frac{m h \lambda}{2}} \vec{\mu} \cdot \vec{p}_{0}+\sum_{\vec{k}}\left(\hbar \omega_{\vec{k}}+\right. \\
& \left.+a^{2} \frac{\hbar^{2} k^{2}}{2 M}-\hbar \vec{\mu} \cdot \vec{k}\right)|f \vec{k}|^{2}+\sum_{\vec{k}}\left(v_{\vec{k}}^{*} f_{\vec{k}}+\right. \\
& \left.+v_{\vec{k}} f_{\vec{k}}\right) \exp \left[-\frac{(1-a)^{2} \hbar}{4 m \lambda} k^{2}\right]
\end{aligned}
$$

A função variacional $f_{\vec{k}}$ e o parâmetro $\overrightarrow{\mathrm{P}}_{\circ}$ são determinados minimizando a equação (4.13) com respeito a $f_{\vec{k}}$ e $\overrightarrow{\vec{P}}$ orespectivamente, ou seja

$$
\frac{\delta F}{\delta f_{\vec{k}}}=0 \quad \text { e } \quad \frac{\delta F}{\delta P_{o j}}=0 \quad \text { para } j=x, y
$$

Os valores ótimos de $\mathrm{f}_{\vec{k}}$ e $\overrightarrow{\mathrm{P}}_{\mathrm{o}}$ obtidos são 


$$
f_{\vec{k}}=-\frac{v_{\vec{k}} \exp \left[-\frac{(1-a)^{2} \hbar}{4 M \lambda} k^{2}\right]}{\hbar \omega \vec{k}+a^{2} \frac{\hbar^{2} k^{2}}{2 M}-\hbar \vec{\mu} \cdot \vec{k}}
$$

e

$$
\overrightarrow{\mathrm{E}}_{\mathrm{O}}=\left(\frac{2 \mathrm{M}}{\mathrm{h \lambda}}\right)^{1 / 2} \overrightarrow{\mathrm{\mu}}
$$

Substituindo as equações $(4.15),(4.16)$ em $(4.13)$ e ex pándindo a função $F$ até termos da ordem de $\mu^{2}$, obtēm-se

$$
\begin{aligned}
F(a, \lambda, \vec{\mu}) & =\frac{\hbar \lambda}{2}-\sum_{\vec{k}} \frac{\left|v_{\vec{k}}\right|^{2} \exp \left[-\frac{(1-a)^{2} \hbar}{2 M \lambda} k^{2}\right]}{\hbar \omega \vec{k}+a^{2} \frac{\hbar^{2} k^{2}}{2 M}}- \\
& -\frac{M}{2} \mu^{2}\left[1+\frac{\hbar^{2}}{M} \sum_{\vec{k}} \frac{k^{2}\left|v_{\vec{k}}\right|^{2} \exp \left[-\frac{(1-a)^{2} \hbar k^{2}}{2 M \lambda}\right]}{\left(\hbar \omega \vec{k}+a^{2} \frac{\hbar^{2} k^{2}}{2 M}\right)^{3}}\right]
\end{aligned}
$$

onde os dois primeiros termos do lado direito representam a energia do estado fundamental $\mathrm{E}_{\mathrm{O}}$

$$
E_{0}=\frac{\hbar \lambda}{2}-\sum_{\vec{k}} \frac{\left|v_{\vec{k}}\right|^{2} \exp \left[-\frac{(1-a)^{2} h}{2 M \lambda} k^{2}\right]}{\hbar \omega_{\vec{k}}+a^{2} \frac{\hbar^{2}{ }^{2}}{2 M}}
$$

e o coeficiente do termo $\mu^{2}$ è a massa efetiva da particula,

$$
\frac{m^{*}}{M}=1+\frac{\hbar^{2}}{M} \sum_{\vec{k}} \frac{\left|V_{\vec{k}}\right|^{2} k^{2} \exp \left[-\frac{(1-a)^{2} \hbar}{2 M \lambda} k^{2}\right] .}{\left(\hbar \omega \vec{k}+a^{2} \frac{\hbar^{2} k^{2}}{2 M}\right)^{3}} .
$$

A equação (4.18) deverá agora, ser minimizada oom rela ção aos parâmetros variacionais a e $\lambda$ e estes mesmos valores serão utilizados no cálculo da massa efetiva. Como a equação da energia do estado fundamental não é linear nos parâmetros a e $\lambda$ em geral é 
necessārio utilizarmos aproximações numéricas para resolver o sistema de equações

$$
\frac{\partial E_{0}}{\partial \lambda}=0 \quad \text { e } \quad \frac{\partial E_{O}}{\partial a}=0
$$

No capítulo seguinte, aplicaremos este método, para ob termos a energia do estado fundamental e a massa efetiva para os seguintes dois sistemas; elētrons na superfície de filmes de hëlio adsorvidos em neon sólido e em safira e finalmente, para elétrons na interface de misturas separadas de ${ }^{3} \mathrm{He}-{ }^{4} \mathrm{He}$. 
CAPITULO V

APLICAÇÃO DO METTODO VARIACIONAL 
Neste capitulo aplicamos o formalismo desenvolvido anteriormente para obtermos a energia do estado fundamental e a massa e fetiva de elëtrons localizados na superficie de filmes de hêlio líquido adsorvidos em neon sólido e safira e também para elétrons localizados na interface de mistura separada de ${ }^{3} \mathrm{He}^{-4} \mathrm{He}$. A escolha dos substratos neon sólido e safira foi devida às experiências que têm sido realizadas recentemente por Kajita ${ }^{32}$ e Andrei ${ }^{33}$, respecti vamente.

Recentemente Farias ${ }^{34}$, depois Hipólito et.al ${ }^{35}$ utiliza ram o formalismo de integrais de trajetória introduzido por Feyn $\operatorname{man}^{36}$ para o problema do polaron, nos cálculos da energia do estado fundamental e da massa efetiva do complexo formado pelo elétron e os riplons o qual chamaremos aqui de polaron. Os cálculos citados acima, foram desenvolvidos estritamente na região de acoplamentos fortes (campos elētricos fortes). Um cálculo similar foi realizado por Jackson e Platzman 37 para um filme de espessura $100 \AA$. Eles encontraram um comportamento tipo transição de fase para o polaron. Utilizando este mesmo método saitoh ${ }^{38}$ tem investigado as proprieda des deste polaron na presença de um campo magnético forte.

Antes porém de aplicarmos. o método variacional propriamente dito aos sistemas, serä ütil discutirmos com algum detalhe a estabilidade de uma interface quando carregada com elétrons. A superfície de um líquido está normalmente sujeita a duas forças, devido à gravidade e à tensão superficial. Ambas são responsáveis pe la estabilidade da superfície do líquido.

Quando um campo elétrico é aplicado perpendicularmente à superfície, uma força adicional aparecerá reduzindo os efeitos de estabilização devido à gravidade e à tensão superficial. Evidente- 
mente o espectro das excitações superficiais será marcadamente alterado e para campos suficientemente fortes uma instabilidade, cha mada instabilidade eletrohidrodinâmica, è esperada.

A condição para termos igualdade de pressão na interface de dois fluídos è governada pela equação 39

$$
\left(\rho_{-}+\rho_{+}\right): \frac{\partial \Phi}{\partial t}=\left(\rho_{-}-\rho_{+}\right) g \xi+\sigma \frac{\partial^{2} \xi}{\partial x^{2}}
$$

onde estamos considerando a interface situada no plano $x-y, p_{-}$e $p_{-}$ são as densidades da fase abaixo e acima da interface respectiva mente, $\Phi$ é o potencial velocidade, g è a aceleração da gravidade,o a tensão superficial e $\xi$ è a elongação da interface da posição de equilibrio.

Fazendo: $\quad \xi=\xi_{0} e^{i(k x-\omega t)}$, e utilizando: $v_{z}=\frac{\partial \Phi}{\partial z}=\frac{\partial \xi}{\partial t}$, ob teremos a relação de dispersão para ondas interfaciais, que é dada por:

$$
\left(\rho_{-}+\rho_{+}\right) \omega^{2}=\left(\rho_{-}-\rho_{+}\right) g K+\sigma K^{3} .
$$

Aqui utilizamos uma simplificação (que em geral è satisfeita experi mentalmente) : a distância da interface à base e ao teto do recipien te que contém os fluídos é grande o suficiente tal que a aproxima ção $\tanh \left(k d_{ \pm}\right) \simeq 1$ é verificada, onde $d_{+}\left(d_{-}\right)$é a espessura do fluído a cima (abaixo) da interface.

Pará valores pequenos de $K$ a equação (5.2) terá o comportamento das ondas de gravidade onde $\omega \mathrm{K}^{1 / 2}$ e para grandes valores de $K \circ$ comportamento das ondas de capilaridade onde $\omega \propto K^{3 / 2}$, será ob tido. A transição entre estes dois tipos de onda ocorre em torno do comprimento de capilaridade a:

$$
a=\left[\sigma /\left(\rho_{-}-\rho_{+}\right) g\right]^{1 / 2}
$$


Incidentalmente a velocidade de fase das ondas interfaciais tem um minimo em $\mathrm{K}=1 / \mathrm{a}$. No caso da interface estar carregada, as ondas com este particular vetor de onda serão importantes.

Leiderer et al. ${ }^{40}$ mostraram que a equação (5.2) descreve multo bem a interface de misturas de ${ }^{3} \mathrm{He}-{ }^{4} \mathrm{He}$ onde uma fase rica su perfluida de ${ }^{4}$ He coexiste com uma fase rica normal de ${ }^{3}$ He. E conhe cido $^{41}$ que para temperaturas abaixo do ponto tricritico, a interfa ce de mistura ${ }^{3} \mathrm{He}^{4} \mathrm{He}$ apresenta uma barreira de potencial através da qual ions podem formar estados ligados. A direção na qual esta barreira é efetiva depende do sinal das cargas dos ions, ou seja , ions positivos não penetram do ${ }^{4} \mathrm{He}$ para $\circ{ }^{3} \mathrm{He}$ e ions negativos não penetram do ${ }^{3}$ He para o ${ }^{4} \mathrm{He}$. Então com a aplicação de um campo elétrico apropriado pode-se localizar os íons próximos à interface . Para temperaturas da ordem $0,3 \mathrm{~K}$ a barreira de potencial tem sido es timada ser $\Delta W \sim 220 \mathrm{~K}$. Quando aproxima-se do ponto tricritico, onde a temperatura $T_{t} \bar{e}$ de $0,867 \mathrm{~K}$ e a concentração de ${ }^{3}$ He é de 0,675 , a barreira decresce rapidamente tal que $\Delta W$ fica comparāvel a $K_{B} T$ e os ions podem passar a barreira pela simples excitação tērmica.

Nas figuras $7 a$ e $7 \mathrm{~b}$ mostramos as barreiras de potencial pa ra Ions positivos e negativos respectivamente.

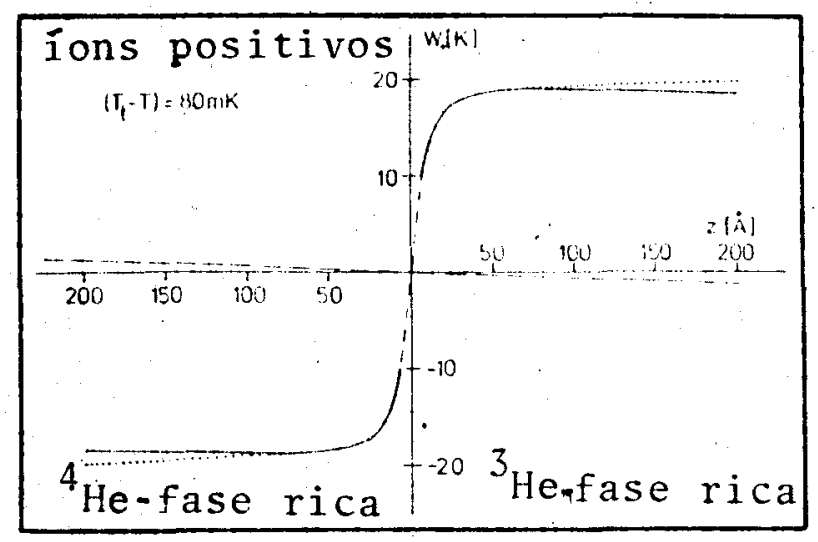

Figura $7 a$

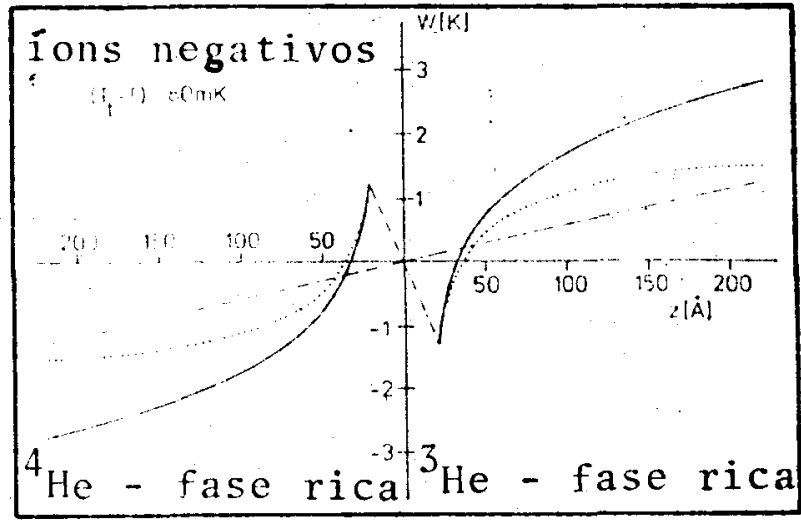

Figura $7 b$ 
Nestas figuras as linhas pontilhadas são os cālculos de Leiderer et.al. ${ }^{41}$, a linha tracejada representa um campo elétrico externo perpendicular à interface (neste caso $E=50 \mathrm{~V} / \mathrm{cm}$ ) e a linha sólida é a soma das duas contribuições iniciais.

Estaremos restritos à baixas temperaturas, onde o tempo em que os íons permanecem ligados è suficientemente longo $(\tau \propto \exp$ $\left.\left(\Delta W / K_{B} T\right)\right)$, de tal forma que eles se rearranjam formando uma camada de cargas bidimensional em equilíbrio. O sinal dos íons será irrelevante para os efeitos que aqui serão estudados.

Quando a interface está carregada, os ions, sob a influência de um campo elétrico externo homogêneo, exercem uma pressão na interface. Para uma distribuição de cargas completamente uni forme esta pressão será também uniforme. Qualquer deslocamento lo cal dà interface resultará num rearranjamento dos ions, os quais se acumularão, para uma perturbação senoidal por exemplo, nos "va les", deixando as "cristas" com uma densidade abaixo da média. Os Ions tendem, então, a aumentar qualquer deformação da interface (Veja esquematicamente este comportamento na. Figura 8 ).

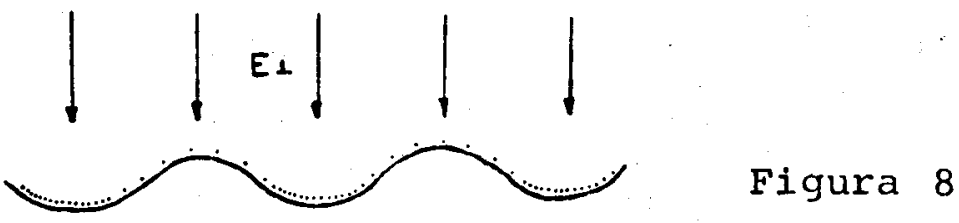

Consequentemente na equação de movimento da interface carregada um termo adicional aparecerá devido à pressão provocada pela descontinuidade na componente perpendicular do campo elétrico

$$
\left(\rho_{-}+\rho_{+}\right) \frac{\partial \Phi}{\partial t}=\left(\rho_{-}-\rho_{+}\right) g \xi+\sigma \frac{\partial^{2} \xi}{\partial x^{2}}-\frac{|E(x)+|^{2}-|E(x)-|^{2}}{8 \pi}
$$

onde os sinais (t) e (-) se referem a fase superior e inferior res pectivamente. 
Supondo que a interface esteja carregada com a densidade de saturação $n_{s^{\prime}}$ o campo médio na fase superior ou inferior(de pendendo do tipo de íon usado) será completamente blindado e no outro lado da interface será

$$
E_{O \perp}=4 \pi n_{S} e
$$

onde e è a carga elementar.

Para determinarmos a modulação da pressão eletrostática na interface devido à redistribuição dos íons na presença dos riplons, consideraremos o potencial eletrostático nas vizinhanças da interface como sendo 42

$$
\phi(z=\xi)=\phi_{0}+\phi_{1} e^{i(K x-\omega t)} e^{-K z}
$$

com $\phi_{0}=-4 \pi n_{s} e z$, ou seja, o potencial da interface não perturbada e $\phi_{1}$ uma pequena correção que satisfaz a equação de Laplace, $\Delta \phi_{1}=0$. A partir da equação de continuidade para as cargas movendo-se na interface sob a ação de um campo elétrico paralelo $E_{\|}$,

$$
\frac{\partial \mathrm{n}}{\partial t}=-\operatorname{div}\left(\mathrm{n} \vec{\mu} \mathrm{E}_{\|}\right)=-\operatorname{div}\left[\mathrm{n} \vec{\mu}\left(\left.\frac{\partial \phi}{\partial x}\right|_{z=\xi}\right)\right]
$$

e lembrando que

$$
\mathrm{n}=\left.\frac{1}{4 \pi \mathrm{e}} \frac{\partial \phi}{\partial z}\right|_{\mathrm{z}=\xi}
$$

obtemos

$$
\phi_{1}=\frac{\left(4 \pi n_{s}\right)^{2} e \mu k \xi_{0}}{4 \pi n_{s} \mu K-i \omega}
$$


Então, a pressão devido ao campo elétrico será dada por

$$
p(x)=\frac{|E(x)|^{2}}{8 \pi} \simeq \frac{1}{8 \pi}\left[\left(4 \pi n_{s} e\right)^{2}+8 \pi n_{s} e_{1} e^{i(K x-\omega t)}\right]
$$

Inserindo este termo na equação (5.4), obteremos a relação de dis persão para a interface completamente carregada

$$
\left(\rho_{-}+\rho_{+}\right) \omega^{2}=\left(\rho_{-}-\rho_{+}\right) g K+\sigma K^{3}-\frac{16 \pi^{2}\left(n_{s} e\right)^{3} \mu K}{4 \pi n_{s} e \mu K-i \omega} K^{2}
$$

Desta equação observamos, que em geral, os îons alēm de diminuir a frequência dos riplons eles também os amortecem. Podemos analisar dois casos limites que ocorrem na equação (5.11):

(a) $w<<4 \pi n_{s} e_{\mu k}$, ou equivalentemente $v_{f}=\frac{\omega}{K}<<E_{\perp} \mu$. Neste limite a equação (5.11) reduzirà à seguinte forma

$$
\left(\rho_{-}+\rho_{+}\right) \omega^{2}=\left(\rho_{-} \mp \rho_{+}\right) g K+\sigma K^{3}-4 \pi\left(n_{s} e\right)^{2} K^{2}
$$

- que concorda excelentemente com os resultados de Gor'kov e Chernikova ${ }^{43}$ e Mima et.al. 44

(b) $w>>4 \pi n_{s} e \mu k$

Neste limite o ủltimo termo da equação (5.11) será nulo, uma vez que a mobilidade dos ions será tão pequena que eles não po derão seguir as ondas interfaciais. Então o espectro de excitação será igual ao de uma interface não carregada.

A instabilidade da interface mencionada no início segue imediatamente da equação (5.11), uma vez que para uma densidade crí tica

$$
n_{s} e=\left[\left(\rho_{-}-\rho_{+}\right) g \sigma / 4 \pi^{2}\right]^{1 / 4}
$$


A frequência dos riplons anula-se, $\omega\left(K_{C}\right) \rightarrow 0$, correspondendo a um campo critico

$$
E_{c}=\left[64 \pi^{2}\left(\rho_{-}-\rho_{+}\right) g \sigma\right]^{1 / 4}
$$

o vetor de onda $K_{c}$ desta instabilidade è

$$
k_{c}=\left[\left(\rho_{-}-\rho_{+}\right) g / \sigma\right]^{1 / 2}
$$

que è igual ao inverso do comprimento de capilaridade definido em $(5.3)$.

Wanner e Leiderer ${ }^{13}$ obtiveram excelentes resultados expe rimentais para a relação de dispersão tanto para ions positivos quanto para íons negativos. Os resultados por eles obtidos estão mostrados nas figuras 9 e 10 .

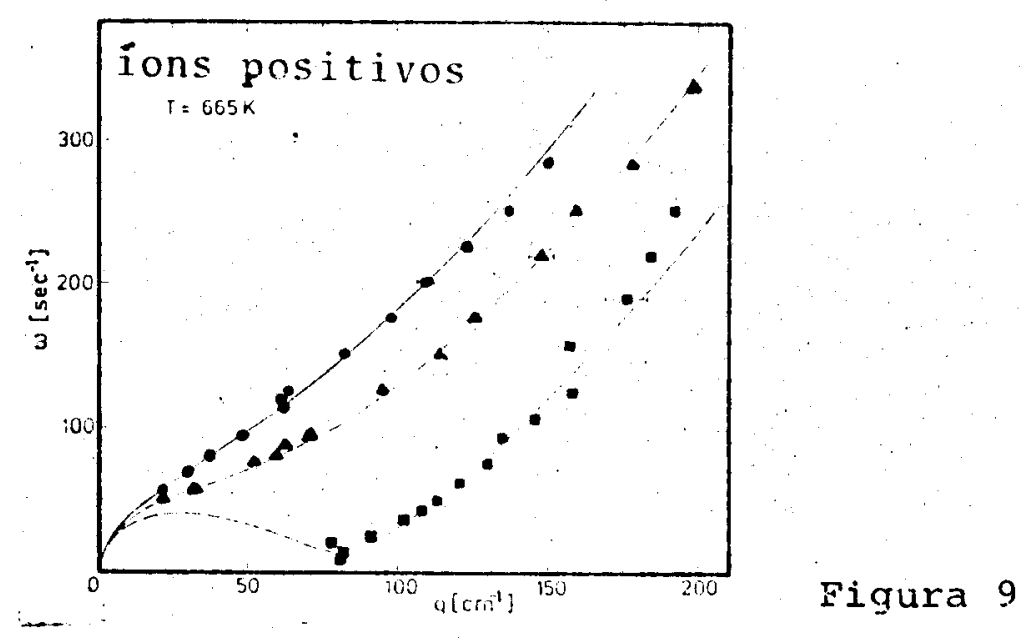

Na figura 9 estão os resultados da relação de dispersão na interface da mistura ${ }^{3} \mathrm{He}-{ }^{4} \mathrm{He}$, com a interface completamente car regada de ions positivos para uma temperatura de $0.665 \mathrm{~K}$. O campo critico ē $\mathrm{E}_{\mathrm{C}}=875 \mathrm{~V} / \mathrm{cm}$ e corresponde a uma densidade $\mathrm{n}_{\mathrm{s}}=4.8 \times 10^{8} \mathrm{~cm}^{-2}$. Os símbolos (A) são para um campo tal que $\mathrm{E} / \mathrm{E}_{\mathrm{C}}=0.71$, (A) para $\frac{\mathrm{E}}{\mathrm{E}}=$ 0.995. As linhas tracejadas são calculadas pela equação $(5.12)$. $^{\mathrm{C}} \mathrm{A}$ linha cheia è obtida para a interface não carregada. O vetor de on da crítico è $\mathrm{K}_{\mathrm{c}} \simeq 82 \mathrm{~cm}^{-1}$. 


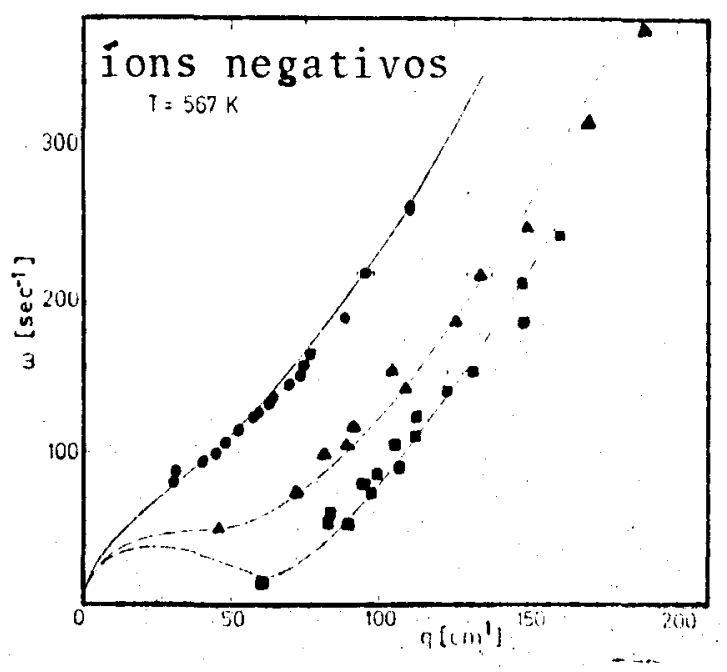

Figura 10

A figura 10 mostra os resultados da relação de dispersão na interface da mistura ${ }^{3} \mathrm{He}-{ }^{4} \mathrm{He}$, com a interface completamente car regada com ions negativos para uma temperatura de $0.567 \mathrm{~K}$. o campo crítico é $\mathrm{E}_{\mathrm{c}}=1130 \mathrm{~V} / \mathrm{cm}$ e o vetor de onda crítico é $\mathrm{k}_{\mathrm{c}} \simeq 63 \mathrm{~cm}^{-1}$. Os

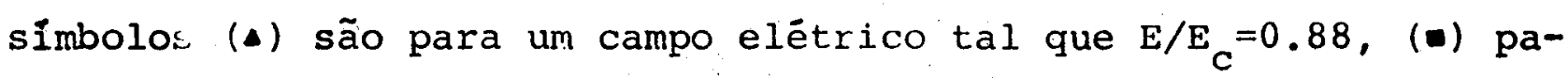
ra $E / E_{c}=0.99$. As linhas tracejadas são calculadas pela equação ( 5 . 12) e a linha cheia representa a dispersão para a interface não carregada nesta temperatura.

Pode-se observar quão sensível è o campo elētrico crítico com a temperatura, pois ele depende das propriedades da interfa ce, mais propriamente da tensão interfacial a qual varia fortemente com a temperatura.

Se a aproximação feita na equação (5.2), de que tanhKd $\approx$ 1 não é aplicável, deveremos levar em conta o efeito do substrato. Para um filme de hēlio superfluido, as equações linearizadas que governam o movimento do fluído são

$$
\rho \frac{\partial \vec{v}}{\partial t}=-\nabla p+\left[\left(\sigma \frac{\partial^{2} \xi}{\partial x^{2}}-\text { en } \frac{\partial \phi}{\partial z}\right) \delta(z-\xi)-\frac{3 \eta}{(z+d)^{4}}-\rho g\right] \hat{z}
$$

A condição de incompressibilidade è dada por 


$$
\nabla \cdot \vec{v}=0
$$

onde $\vec{v}$ è a velocidade do fluỉdo, p é a pressão, $\sigma$ è a tensão super ficial, d é a espessura do filme, $n$ è a constante de van der Waals caracterizando a força entre o substrato e o hëlio, $\xi$ è o desvio da superfície da posição de equilíbrio, $\phi$ é o potencial eletrostātica n é a densidade de carga, $\rho$ é a densidade do hélio e e é a carga e lementar. Novamente analisaremos o caso de perturbações da forma

$$
\xi=\xi_{0} e^{i(K x-\omega t)}
$$

Agora se faz necessário, a condição de contorno em $z=-\alpha$, de que a componente $z$ da velocidade seja nula, ou seja

$$
\left.\overrightarrow{\mathrm{v}} \cdot \hat{\mathbf{z}}\right|_{z=-d}=0
$$

Então, a relação de dispersão será

$$
\omega^{2}=\omega_{0}^{2} \tanh (k d)
$$

onde

$$
\omega_{o}^{2}=\left(\frac{3 \eta}{\rho d^{4}}+g\right) K+\frac{\sigma}{\rho} K^{3}-\frac{4 \pi e^{2} n^{2}}{\rho} K^{2} F(K)
$$

onde $F(K)$ é a função que considera o efeito das cargas imagens no substrato.

$$
F(K)=\frac{1+\varepsilon_{s}-\left(1-\varepsilon_{s}\right) e^{-2 K d}}{1+\varepsilon_{s}+\left(1-\varepsilon_{s}\right) e^{-2 K d}}
$$

onde $\varepsilon_{S}$ é a constante dielētrica do substrato. Evidentemente no limite $\mathrm{d} \rightarrow \infty$, a equação (5.12) é reobtida. 
No limite de filmes finos $(K d<<1)$ a equação $(5.22)$ será

$$
F(K)=\varepsilon_{s}
$$

A instabilidade eletrohidrọinâmica ocorre para uma den sidade critica

$$
n_{c}=\frac{(3 n \sigma)^{1 / 4}}{\left(2 \pi e^{2} \varepsilon_{s}\right)^{1 / 2} d}
$$

e o vetor de onda $k_{c}$ desta instabilidade $e ́$

$$
k_{c}=\frac{(3 n / \sigma)^{1 / 2}}{d^{2}}
$$

Apōs termos feito uma anālise detalhada das propriedades de uma interface carregada, faremos a aplicação do método variacio nal para obtermos a energia do estado fundamental e a massa efetiva para elétrons na interface de misturas separadas de ${ }^{3} \mathrm{He}-{ }^{4} \mathrm{He}$ e depois para filmes de hēlio adsorvidos em neon sólido e safira.

$$
\text { (A) - Misturas }{ }^{3} \mathrm{He}-{ }^{4} \mathrm{He}
$$

O potencial que descreve a interação elētron-riplon na interface da mistura ${ }^{3}$ He- ${ }^{4}$ He pode ser obtido a partir da equação (3.30), e é dado por

$$
V_{\vec{K}}=\left[\frac{\hbar K}{2 A\left(\rho_{d}+\rho_{3}\right) \omega_{\vec{K}}}\right]^{1 / 2} e_{\perp}
$$

com $\rho_{3}$ e $\rho_{4}$ sendo as densidades do ${ }^{3}$ He e do ${ }^{4}$ He respectivamente. A relação de dispersão é dada pela equação (5.2), ou seja 


$$
\left(\rho_{4}+\rho_{3}\right) \omega_{\vec{K}}^{2}=\left(\rho_{4}-\rho_{3}\right) g K+\sigma K^{3}
$$

Substituindo as equações $(5.26)$ e (5.27) na expressão da energia do estado fundamental, equação (4.18), e reescrevendo-a em termos de grandezas admensionais, obteremos a seguinte expressão

$$
E_{0}^{*}=\frac{\lambda}{2}-2 \alpha^{\prime} \int_{0}^{1} d x \frac{x^{2}}{\sqrt{x\left(1+x^{2}\right)}} \frac{\exp \left[-\frac{(1-a)^{2}}{\lambda^{1}} x^{2}\right]}{\sqrt{\rho_{4-3}} \sqrt{x\left(1+x^{2}\right)}+\frac{a^{2}}{\gamma} x^{2}}
$$

onde $\alpha^{\prime}$ é conhecido como constante de acoplamento e é definida por

$$
\alpha !=\frac{e^{2} E_{ \pm}^{2} \sqrt{\rho} 4-3}{8 \pi \sigma \frac{\hbar^{2} K_{c}^{2}}{2 m}}
$$

com $\rho_{4-3}=\frac{\rho_{4}-\rho_{3}}{\rho_{4}+\rho_{3}}$ e $\gamma=\frac{2 m \sqrt{g K} c}{\hbar k_{c}^{2}}$.

$K_{c}$ é a constante de capilaridade. Para elétrons na interface usare mos o valor experimental $\mathrm{K}_{\mathrm{C}} \simeq 63 \mathrm{~cm}^{-1}$ obtido por Wanner e Leiderer ${ }^{13}$. $E_{0}^{*}$ está dado em unidades de $\hbar^{2} K_{C}^{2} / 2 m$ e $\lambda^{\prime}$ em unidades de $\hbar K_{C}^{2} / 2 m$. A constante de acoplamento pode ser reescrita na forma

$$
\alpha^{\prime}=1.43 \mathrm{E}_{\perp}^{2}
$$

onde o campo elétrico está em unidades de $\mathrm{V} / \mathrm{cm}$.

A massa efetiva é obtida atravēs da equação (4.19) na qual subsitituímos as equações $(5.26)$ e (5.27) como tendo a seguinte forma

$$
\frac{m^{*}}{m}=1+\frac{4 a^{\prime}}{\gamma^{2}} \int_{0}^{1} d x \frac{x^{4}}{\sqrt{x\left(1+x^{2}\right)}} \frac{\exp \left[-\frac{(1-a)^{2}}{\lambda^{\prime}} x^{2}\right]}{\left[\sqrt{\rho 4-3} \sqrt{x\left(1+x^{2}\right)}+\frac{a^{2}}{\gamma} x^{2}\right]^{3}}
$$


A energia do estado fundamental será, finalmente, calcụ lada minimizando a equação $(5 . \hat{1} 8)$ com relação aos parâmetros varia cionais a e $\lambda^{\prime}$, para um dado campo elétrico externo. Então devemos resolver as seguintes equações

$$
\frac{\partial E_{O}^{*}}{\partial a}=0 \quad \text { e } \quad \frac{\partial E_{o}^{*}}{\partial \lambda^{\prime}}=0
$$

Estas equações foram resolvidas numericamente pelo método modificado de Newton ${ }^{45}$ para sistemas de equações não lineares.

Na figurall estão os resultados para a energia em função do campo elétrico. A energia apresenta dois ramos distintos: o primeiro correspondendo ao regime de acoplamento fraco e o segundo ao regime de acoplamento forte. A interseção dos dois ramos ocorre para o campo crítico de $0,65 \mathrm{~V} / \mathrm{cm}$. Nesta região a energia de ligação é extremamente baixa, da ordem de $10^{-10} \mathrm{meV}$, não sendo portanto aces sível fisicamente.

Farias $^{34}$ e Hipólito et.al. ${ }^{35}$ utilizaram o mētodo da inte gral de trajetória, introduzido por Feynman para calcular a energia de ligação. Seus cálculos são válidos somente no regime de acọ plamento forte, e estão em excelente concordāncia com os nossos.

A massa efetiva é obtida atravēs da equação (5.31), onde os parâmetros a e $\lambda$ ' são os mesmos que minimizaram a energia do estado fundamental. A transição do regime de acoplamento fraco para o de acoplamento forte é melhor visualizado no gráfico da massa efeti va mostrado pela figura 12

(B) Filmes de Hëlio

o potencial que descreve a interação elétron-riplon para filmes de hélio está dado pela equação (3.30) e reescreveremos aqui 
Figura 11 - Energia do estado fundamental de um elétron ligado à interface da mistura ${ }^{3} \mathrm{He}-{ }^{4} \mathrm{He}$ em fun ção do campo elétrico externo. o valor do campo elétrico externo crỉtico é de $E_{\perp_{C}}=$ $=0,65 \mathrm{~V} / \mathrm{cm}$ onde ocorre a transição. A energia de ligação correspondente é extremamente baixa não sendo acessível experimentalmente. 


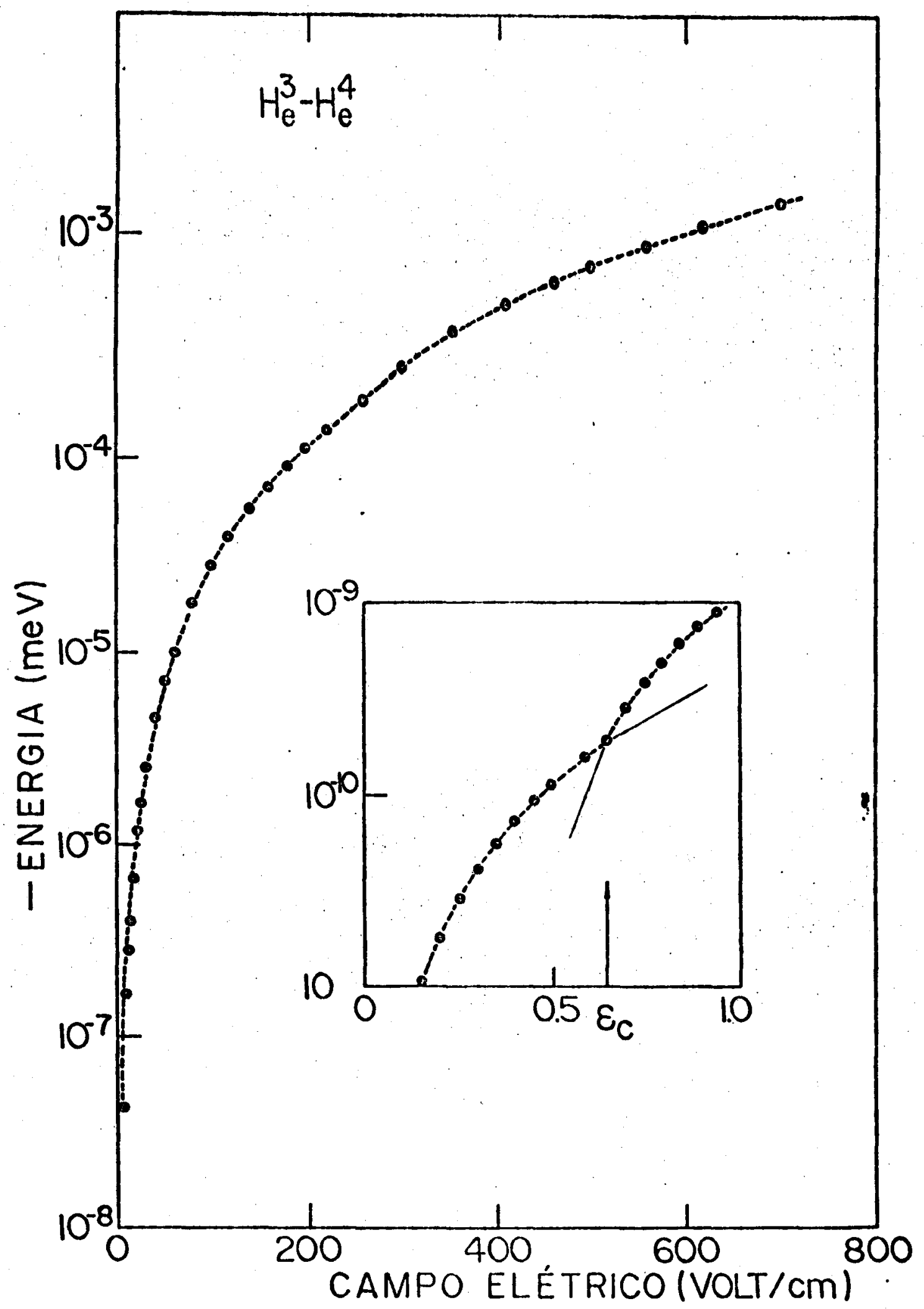


Figura 12- Massa efetiva de um elétron ligado à intertase da mistura ${ }^{3} \mathrm{He}-{ }^{4} \mathrm{He}$, em unidades da massa atômi ca do ${ }^{4} \mathrm{He}$, em função do campo elétrico externo. O campo crítico é $\mathrm{E}=0,65 \mathrm{~V} / \mathrm{cm}$. 
53

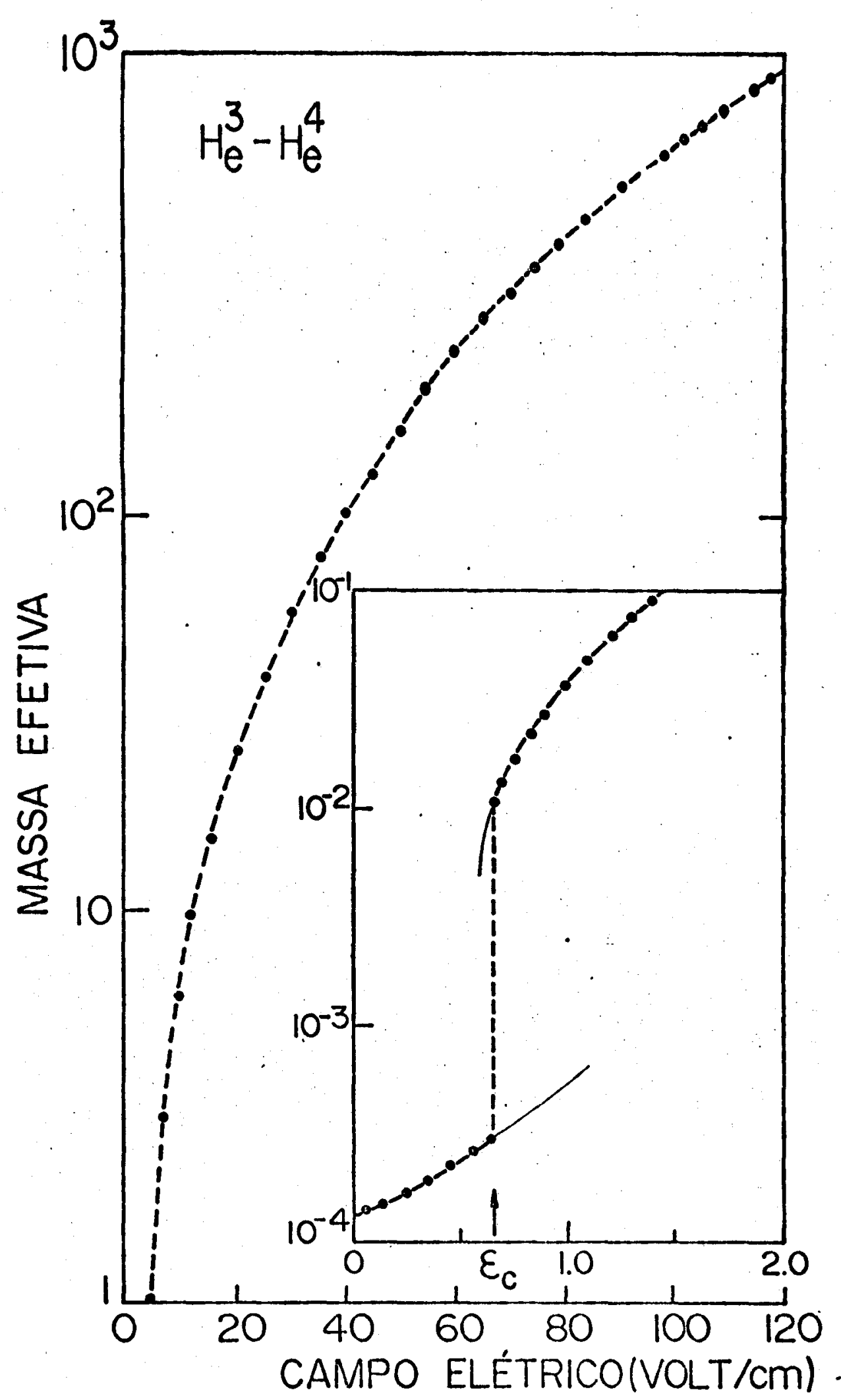




$$
\mathrm{V}_{\vec{K}}=\left(\frac{\hbar K \tanh (K d)}{2 A \rho \omega_{\vec{K}}}\right)^{1 / 2}\left(e E_{\perp}+\frac{\Omega_{1}}{d^{2}}\right)
$$

onde a relação de dispersão é

$$
\omega_{\mathrm{K}}^{2}=\left(g^{\prime}+\sigma K^{2} / \rho\right) K \tanh (K d)
$$

Devido à presença do substrato, a constante de capilaridade é redefinida na forma

$$
\mathrm{K}_{\mathrm{c}}=\left(\rho g^{\prime} / \sigma\right)^{1 / 2}
$$

onde

$$
g^{\prime}=g+\frac{3 \eta}{\rho d^{4}}
$$

Substituindo as equações (5.33) e (5.34) na expressão da energia do estado fundamental, equação (4.18) e em termos de grande zas admensionais, obtemos finalmente a seguinte expressão

$$
E_{0}^{*}=\frac{\lambda^{1}}{2}-2 \alpha \int_{0}^{1} d x \frac{x^{2} \tanh (x d)}{\sqrt{x\left(1+x^{2}\right) \tanh (x d)}} \frac{\exp \left[-\frac{(1-a)^{2}}{\lambda^{\prime}} x^{2}\right]}{\sqrt{x\left(1+x^{2}\right) \tanh (x d)}+\frac{a^{2}}{\gamma}} x^{2}
$$

onde $E_{0}^{*}$ está expresso em unidades de $\hbar^{2} K_{c}^{2} / 2 m, \lambda$ em unidades de $\hbar \mathrm{K}_{\mathrm{c}}^{2} / 2 \mathrm{~m}$ e d em unidades de $\mathrm{K}_{\mathrm{c}}^{-1}$.

A constante de acoplamento é definida aqui como sendo

$$
\alpha=\frac{(e E)^{2}}{8 \pi \sigma \frac{\hbar^{2} K_{c}}{2 m}}
$$

onde: $E=\frac{e}{4 d^{2}}\left(\frac{\varepsilon_{s}^{-1}}{\varepsilon_{s}+1}\right)+E_{\perp} \quad$ e $\quad \gamma^{\prime}=\frac{2 m \sqrt{g^{\prime} K_{c}}}{\hbar K_{c}^{2}}$ 
$\varepsilon$ è a constante dielétrica do substrato, para neon-sólido $\varepsilon_{\mathrm{N}} \approx 1,24$ e para a safira $\varepsilon_{S} \simeq 19$.

No limite de filmes finos $(d<2000 \AA), g^{\prime}=\frac{3 \eta}{\rho d}$. Então a constante de acoplamento eq.(5.38) fica neste limite sendo dada por

$$
\begin{aligned}
& \alpha_{N}=19,7\left[0,13+\frac{E_{2}}{3} \times d^{2} \times 10^{-8}\right]^{2} \\
& K_{C N}=\frac{1,455 \times 10^{9}}{d^{2}} \\
& \gamma_{N}=7,13 \times 10^{-5} \times d
\end{aligned}
$$

para o substrato neon sólido, e

$$
\begin{aligned}
& \alpha_{S}=0,694\left[0,98+\frac{E_{\perp}}{3} \times 10^{-8} \times d^{2}\right]^{2} \\
& k_{C S}=\frac{7,746 \times 10^{9}}{d^{2}} \\
& \gamma_{S}=3,1 \times 10^{-5} \times d
\end{aligned}
$$

para o substrato safira.

Nas expressões (5.39) e (5.40) o campo elétrico está em unidades de $\mathrm{V} / \mathrm{cm}$ e a espessura do filme d em $\AA$.

A massa efetiva é obtida pela equação (4.19) na qual subs tituỉmos as equações $(5.33)$ e $(5.34)$ e tem a seguinte forma

$$
\frac{m^{*}}{m}=1+\frac{4 \alpha}{\gamma^{2}} \int_{0}^{1} d x \frac{x^{4} \tanh (x d)}{\sqrt{x\left(1+x^{2}\right) \tanh (x d)}} \frac{\exp \left[-\frac{(1-a)}{\lambda^{1}} x^{2}\right]}{\left[\sqrt{x\left(1+x^{2}\right) \tanh (x d)}+\frac{a^{2}}{\gamma} x^{2}\right]^{3}}
$$

No limite de longos comprimentos de onda e filmes finos, podemos aproximar a relação de dispersão eq.(5.34) e o potencial de interação eq. (5.33) por 


$$
\begin{aligned}
& \omega_{\vec{k}}=\sqrt{g^{\top} d} k \\
& v_{\vec{k}}=\left(\frac{\hbar k}{2 A_{\rho}} \sqrt{\frac{d}{g^{\prime}}}\right)^{1 / 2}\left(e E_{\perp}+\frac{\Omega}{d^{2}}\right)
\end{aligned}
$$

Nesta aproximação podemos obter analiticamente os casos limites de acoplamentos forte e fraco. No caso de acoplamento fraco temos que a constante de acoplamento é pequena $(\alpha<1)$ e $a=1$. ev dente da eq. $(5,37)$ que neste limite o minimo da energia, com rela ção ao parâmetro $\lambda^{\prime}$, se då para $\lambda^{\prime}=0$. Então a energia do estado fun damental e a massa efetiva serão respectivamente,

$$
\begin{aligned}
& E_{0}^{*} \simeq-2 \gamma \alpha \\
& \frac{m^{*}}{m} \simeq 1
\end{aligned}
$$

No caso de acoplamento forte correspondendo à constante de acoplamento grande $(\alpha>>4)$ e $a \rightarrow 0$, teremos:

$$
\begin{aligned}
& E_{0}^{*} \simeq-\alpha+\sqrt{\alpha}+\ldots \\
& \frac{m^{*}}{m} \simeq 1+\frac{2 \alpha}{\gamma}-\frac{\sqrt{\alpha}}{\gamma^{2}}+\ldots
\end{aligned}
$$

Em geral a equação (5.37), para um dado campo elētrico e uma dada espessura, deverá ser minimizada nos parâmetros variacio nais a e $\lambda^{\prime}$ através das equações

$$
\frac{\partial \mathrm{E}_{\mathrm{o}}^{*}}{\partial \mathrm{a}}=0 \quad \text { e } \quad \frac{\partial \mathrm{E}_{\mathrm{o}}^{*}}{\partial \lambda^{\prime}}=0
$$

Analogamente ao que acontece na mistura ${ }^{3} \mathrm{He}-{ }^{4} \mathrm{He}$, a energia do estado fundamental apresenta dois ramos distintos. A interseção dos dois ramos ocorre em uma constante de acoplamento a qual 
Chamamos de constante de acoplamento critica.

Para $\alpha=\alpha_{c}$ existe uma descontinuidade na derivada da energia caracterizando um comportamento do tipo transição de fase de primeira ordem. Quándo $\alpha<\alpha_{c^{\prime}}$ o polaron estará em um estado quase-livre. Esta conclusão pode ser obtida analisando-se a função de onda eletrô nica dada pela equação (4.11), pois como vimos, no acoplamento fra co $\lambda^{\prime}=0$. Para $\alpha>\alpha_{c}$ o polaron estará em um estado tipicamente localizado. Então, temos dois parâmetros, os quais permite-nos passar de um regime para outro. Estes parâmetros externos são: a espessura do filme e o campo elétrico o qual pressiona o elétron contra a superfície. A rápida mudança no estado do polaron é melhor observa da no comportamento da massa efetiva. Nas figuras 13-15 e 14-16 estão os resultados da energia e da massa em função do campo elétrico, para várias espessuras do filme. Observamos que para filmes finos de hê 1io, a contribuição do substrato é muito importante e domina total mente o campo elētrico externo. Das espessuras plotadas na figura 13 o filme de $15 \AA$ é o único que apresenta o valor de energia em um intervalo, acessivel fisicamente de modo que a transição referí da acima poderá ser detetada experimentalmente.

A transição de fase que estamos nos referindo aqui como uma localização é tomada no mesmo espírito que no trabalho de Toyo zawa ${ }^{46}$, isto é, em termos da rapidez e magnitude da mudança da mas sa efetiva do sistema.

Um resultado experimental recente obtido por Andrei ${ }^{33}$, tem confirmado esta previsão da localização do elétron num estado polarônico para filmes da ordem de $1000 \AA$ adsorvidos em substrato de safira num intervalo de temperatura de $0,4 \mathrm{~K}$ à $1,0 \mathrm{~K}$. Nesta experiência são medidas a mobilidade e massa efetiva dos elētrons so bre o filme de hélio. Para uma dada espessura crítica a mobilidade tem um salto de 4,5 ordens de grandeza e a massa efetiva aumenta a 
proximadamente quatro ordens de grandeza. Caracterizando, assim, uㅡ ma transição no estado do polaron superficial, como predita pela teoria de um elētron. Evidentemente, neste experimento existe a pre sença de outros elétrons, na verdade uma densidade de $6 \times 10^{7} \mathrm{~cm}^{-2}$ è utilizada e o efeito de muitos corpos deve ser levado em conta. Na figura 17 estão os resultados experimentais obtidos por Andrei ${ }^{33}$ para filmes de hēlio adsorvidos em safira. No capitulo seguinte estudaremos o problema de um dimple de muitos elétrons tanto na interface de misturas separadas de ${ }^{3}$ He${ }^{4}$ He como na superfície de hêlio. Obteremos as condições para a formação de tal dimple, a energia de formação, a massa efetiva, o raio e a densidade de carga no dimple. 
Figura 13 - Energia do estado fundamental em função do campo elētrico externo para um elétron na superfície de filmes de hélio adsorvidos em neon sólido. Plotamos os resultados para 3 espessuras de filmes 15,50 e $100 \AA$. As setas indicam o campo critico no qual ocorre a transição de um estado quase livre para um estado ligado. Apenas para filmes finos ( $\sim 15 \AA$ ) a energia de ligação é acessível ex perimentalmente. 


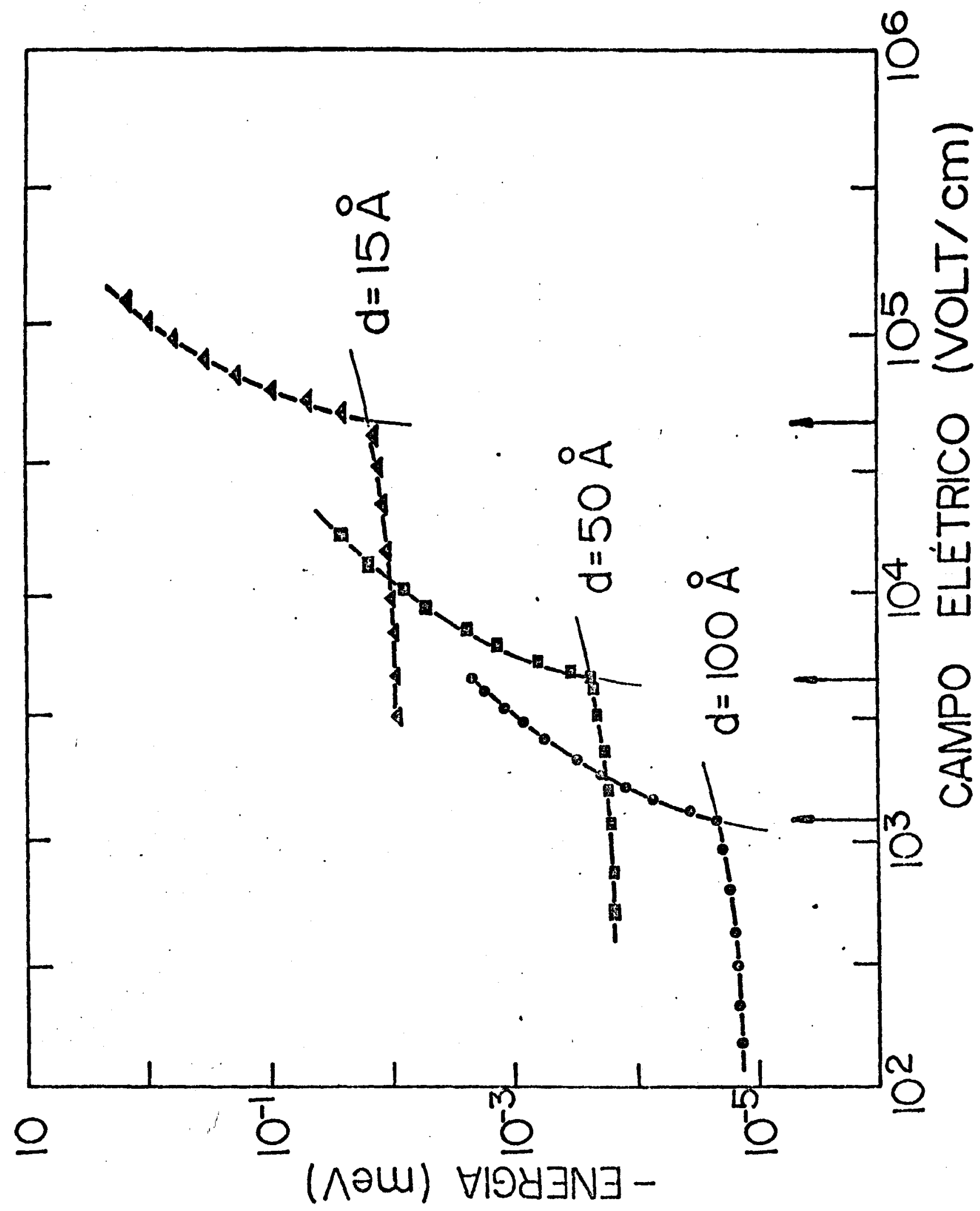


Figura 14 - Massa efetiva de um elétron na superfície de filmes de hélio líquido adsorvidos em neon sólido, em unidades da massa do elétron li vre, em função do campo elētrico externo • Plotamos os resultados para très espessuras 15,50 e $100 \AA$. As linhas tracejadas corres pondem aos campos críticos onde ocorre a transição do estado quase livre para o esta do localizado. 


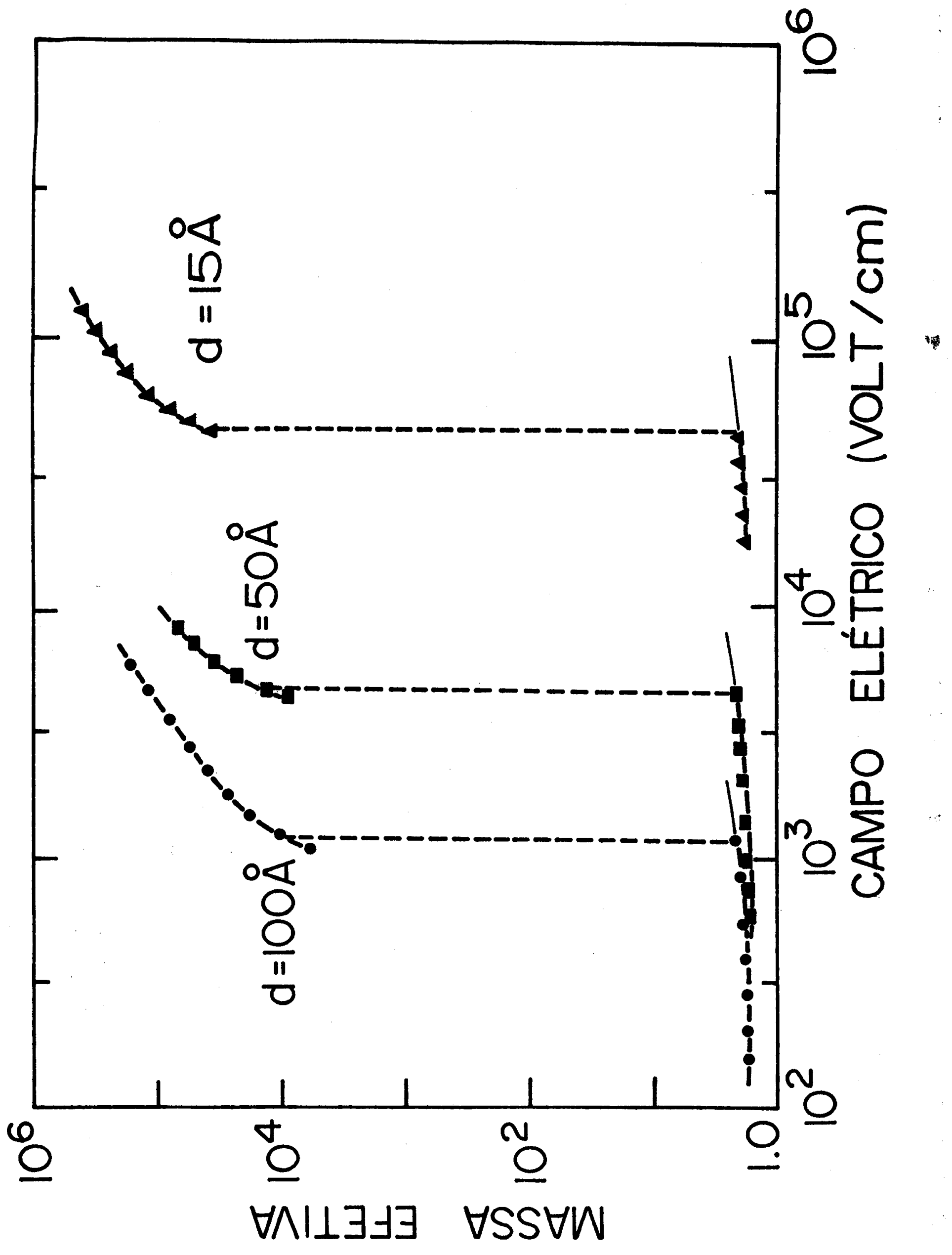


Figura 15 - Energia do estado fundamental em função do campo elétrico externo para um elétron na sü perfície de filmes de hēlio adsorvidos emsa fira. Plotamos os resultados para três es pessuras de filme 500, 1000 e $2000 \AA$. As se tas indicam o campo crítico no qual ocorre a transição de um estado quase livre para um estado ligado. 


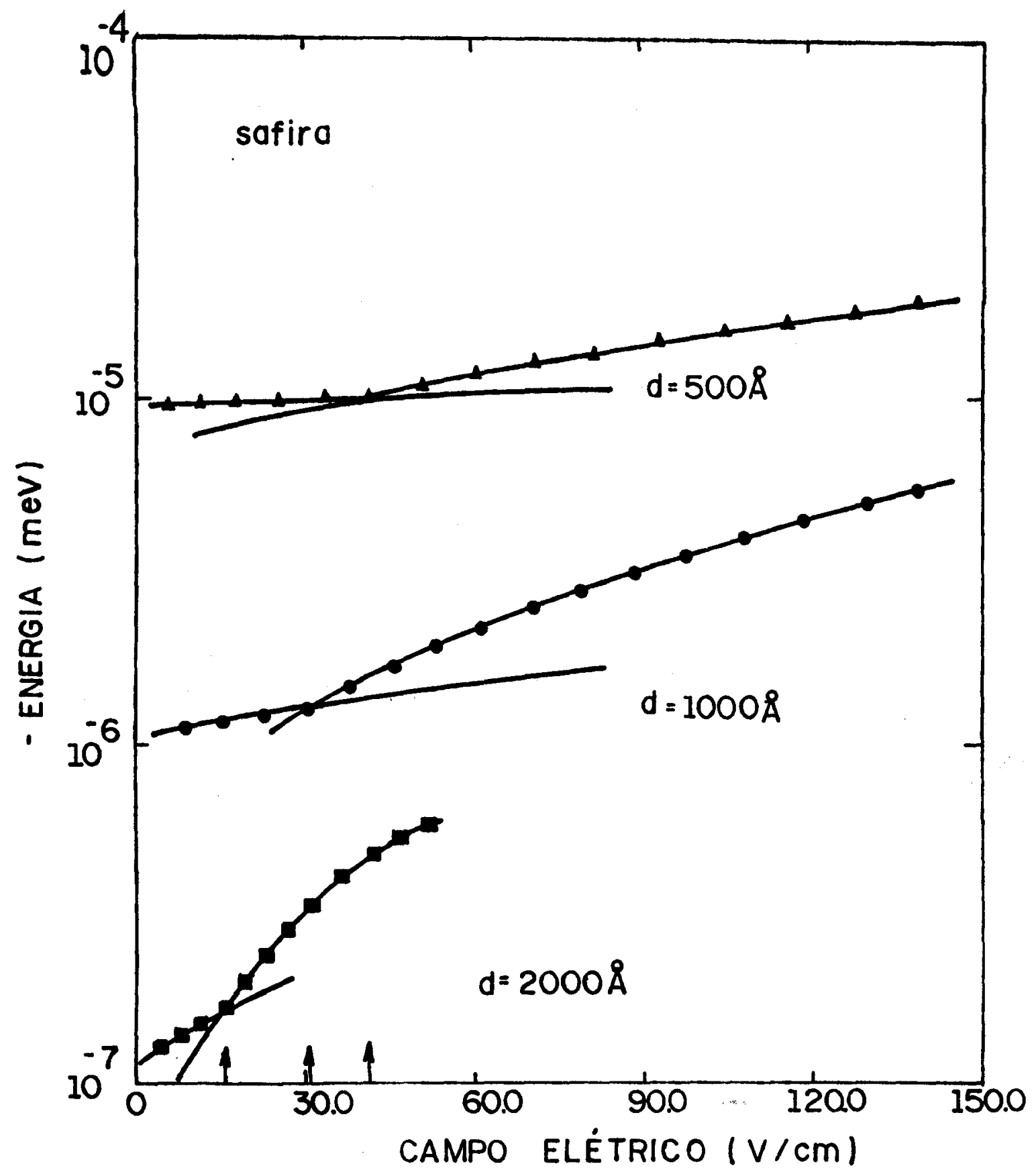


Figura 16 - Massa efetiva de um elétron na superfície de filmes de hélio adsorvidos em safira, em u nidades da massa do elétron livre em função do campo elétrico externo. Plotamos os re sultados para três espessuras de filme 500 , 1000 e $2000 \AA$. As linhas tracejadas corres pondem aos campos críticos onde ocorre a transição. 


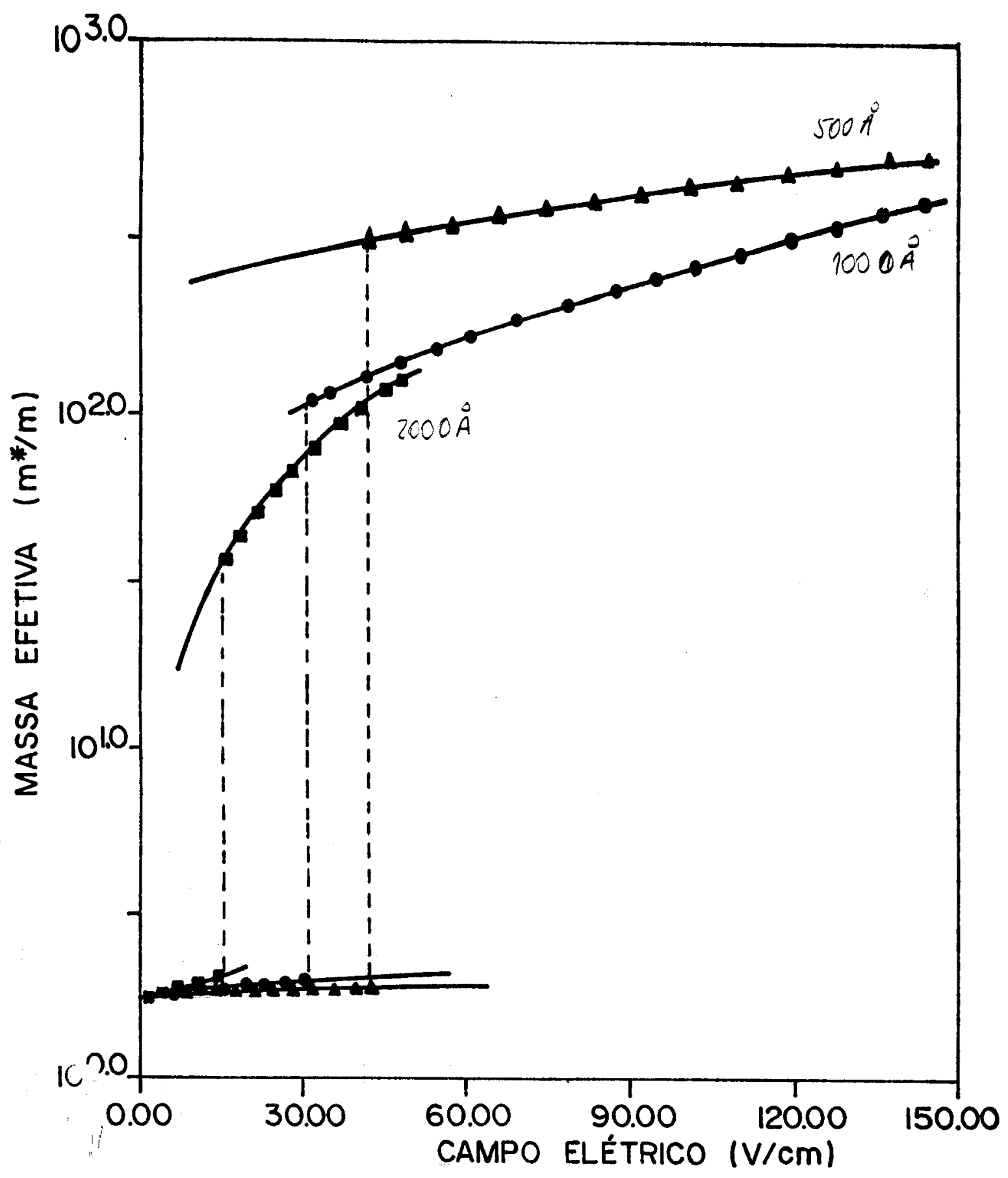


Figura 17 - Medida da mobilidade de elētrons na superfície de filmes de ${ }^{4}$ He líquido adsorvidos em safira obtida por Andrei ${ }^{33}$. Observamos clara mente a mudança abrupta na mobilidade para $\mathrm{T}=0,4 \mathrm{~K}$ em torno da espessura $1000 \AA$. Acima desta espessura os elétrons estavam quase $1 \underline{i}$ vres, abaixo de $1000 \AA$ os elētrons passam pạ ra um regime onde estão localizados. o campo elétrico E neste caso é de $\sim 80 \mathrm{~V} / \mathrm{cm}$. Os pon tos $(\bullet)$ são obtidos aumentando-se a espessura e os ( $($ ) diminuindo-se a espessura. A den sidade dos elétrons é de $6 \times 10^{7} \mathrm{~cm}^{-2}$. 


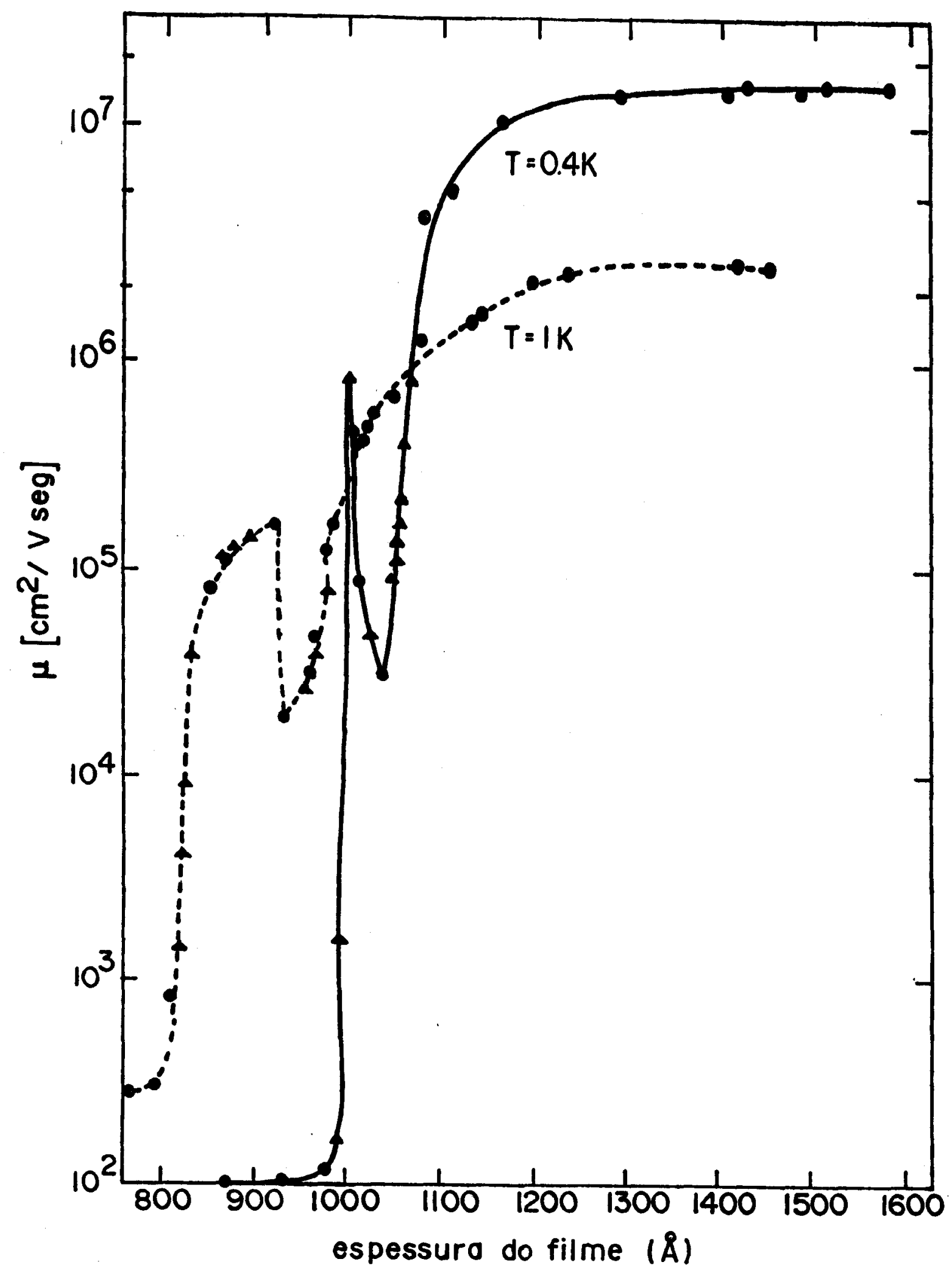


CAPITULO VI

DEPRESSÕES COM MUITOS ELETRONS NA SUPERFICIE DE HELIO IIQUIDO 
Quando um campo elêtrico intenso é aplicado ao sistema e lẻtron-superfície de hélio líquido aparecerã uma deformação na superfície devido à pressão do elétron. Esta deformação da superfĩ cie em torno do elétron forma uma depressão que tende a localizá 10 no plano.

Gor'kov e Chernicova ${ }^{43}$, depois Ikezi 44,50 ,previram teor $\underline{\underline{1}}$ camente a possibilidade da superfície carregada de um fluido adquí rir uma estrutura macroscópica periódica, quando um campo elétrico intenso $\left(\tilde{\sim} 10^{4} \mathrm{~V} / \mathrm{cm}\right)$ fôsse aplicado ao sistema. Através de considera ções de energia, a estrutura periódica favorecida teria uma sime tria hexagonal.

Esta previsão foi recentemente confirmada pelos experi mentos de Wanner e Leiderer ${ }^{13}$ e Giannetta e Ikezi ${ }^{14}$, que observa ram o fenômeno por meio de reflexão de luz. Nestes experimentos , constatou-se a simetria hexagonal e também observou-se que o parâmetro de rede é da ordem do inverso da constante de capilaridade $\left(\mathrm{K}_{\mathrm{C}}\right)$.

Como vimos no capítulo anterior, è esperado que o campoe létrico externo reduza a frequência dos riplons e em particular para o vetor de onda $K_{C^{\prime}}$ um campo elétrico crítico $E_{c}$ pode anular a frequência dos riplons e a superfície tornar-se instável, deforman do-se espontaneamente. O que é surpreendente é que nem todas as car gas deixam a superficie durante a instabilidade e as cargas que ne la permanecem não estão distribuídas homogeneamente mas sim em um novo estado coletivo com formato periódico de grupos carregados com aproximadamente $10^{6}$ elétrons cada um, dando origem ao chamado cris tal de "uimples".

A formação deste cristal foi observada pela primeira vez 
na interface de mistura ${ }^{3} \mathrm{He}-{ }^{4} \mathrm{He}$.

(A) Mistura ${ }^{3} \mathrm{He}-{ }^{4} \mathrm{He}$

Nesta secção investigaremos algumas propriedades de uma única depressão com muitos elētrons, localizada na interface da mis tura ${ }^{3} \mathrm{He}-{ }^{4} \mathrm{He}$. Determinaremos o campo critico, a partir do qual o correrã a formação da depressão, a massa efetiva e o raio médio da depressão em função do campo elētrico externo.

Wanner e Leiderer ${ }^{13}$ observaram experimentalmente a forma ção de uma única depressão, a qual continha um grande número de e létrons $\left(\mathrm{N} \sim 10^{6}\right.$ elétrons). Neste caso o campo critico, ou seja, o campo elētrico externo mínimo para o qual haverá a formação de tal depressão, foi de $1120 \mathrm{~V} / \mathrm{cm}$. Shikin e Leiderer 47 têm investigado as propriedades de uma única depressão com muitos elétrons e para is so eles admitem que os elétrons estão localizados em um buraco o qual tem a forma de um disco, como mostra a figura 18 .

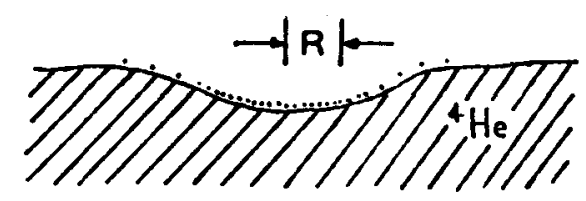

Figura 18

Consideraremos uma depressão constituĩda por $\mathrm{N} \sim 10^{6}$ elē trons, como a observada experimentalmente, então $Q=N e$ e $M=N m$ onde e e m são a carga elementar e a massa do elétron, respectivamente.

A constante de acoplamento definida na equação (5. 30 ) $\bar{e}$ aqui redefinida da seguinte forma

$$
\alpha^{*}=\frac{Q^{2} E_{\perp}^{2} \sqrt{\rho_{4-3}}}{8 \pi \sigma \frac{\hbar^{2} K_{c}^{2}}{2 M}}=N^{3} \alpha
$$


onde $k_{c}=\left(\rho_{4}-\rho_{3}\right) \mathrm{g} / \sigma=63 \mathrm{~cm}^{-1}$ e $\alpha$ é a constante de acoplamento no caso de um elêtron.

Como a constante de acoplamento $\alpha^{*}$ é proporcional ao cu bo do número de elētrons, o "polaron" estarā na região de acoplamento forte, mesmo para um campo elétrico externo muito ba1xo. Jã estudamos o regime de acoplamento forte e sabemos que neste limite - parâmetro variacional a tende a zero. Então, para obtermos a e nergia de formação de uma depressão com muitos elētrons precisaremos considerar, tambēm, a energia de interação coulombiana entre os elētrons que se encontram no interior da depressão. Esta energia é facilmente obtida como sendo

$$
v_{c}=\int \psi^{*}(\vec{r}) \quad \frac{Q^{2}}{2 r} \psi(\vec{r}) \quad d^{2} r
$$

onde a função de onda $\psi(\vec{r})$ é dada por

$$
|\psi\rangle=\left(\frac{M \lambda}{\pi h}\right)^{1 / 2} \exp \left(-\frac{M \lambda r^{2}}{2 \hbar}\right) \exp \left(-i \sqrt{\frac{M \lambda}{2 \hbar}} \vec{P}_{0} \cdot \vec{r}\right) S_{2}|0\rangle
$$

e $\mathrm{S}_{2} \bar{e}$ a transformação canônica definida pela equação (4.9). Efetuando a integração na equação (6.2) obtemos

$$
V_{c}=\frac{Q^{2}}{2} \sqrt{\frac{M \lambda \pi}{h}}
$$

ou, em unidades de $\hbar^{2} K_{c}^{2} / 2 M$

$$
v_{c}^{*}=\frac{M Q^{2}}{\hbar^{2} K_{c}} \sqrt{\frac{\pi \lambda^{2}}{2}}
$$

A expressão para a energia de formação da depressão com muitos elêtrons é então facilmente obtida da equação $(5.28)$, onde faremos as seguintes modificações: $\alpha \rightarrow \alpha^{*} ; a=0$ e adicionamos o termo 
devido à interação dos elētrons no interior da depressão, $V_{c}$ • Como estamos interessados na localização da depressão, os efeitos cinēticos poderão ser desprezados, o que significa eliminar o termo $\left(\lambda^{\prime} / 2\right)$ existente na expressão da energia, equação (5.28).

Então, em unidades de $\hbar^{2} \mathrm{~K}_{\mathrm{C}}^{2} / 2 \mathrm{M}$, a energia será

$$
E_{0}^{*}=v_{c}^{*}-\frac{2 \alpha^{*}}{\sqrt{\rho_{4-3}}} \int_{0}^{\infty} d x \frac{x}{1+x^{2}} e^{-x^{2} / \lambda}
$$

Podemos reescrever a energia $E_{0}^{*}$ em termos da função exponencial integral $\mathbf{E}_{i}(x)$ da seguinte forma

$$
E_{0}^{*}=V_{c}^{*}+\frac{\alpha^{*}}{\sqrt{\rho_{4-3}}} \exp \left(1 / \lambda^{\prime}\right) E_{i}\left(-1 / \lambda^{\prime}\right)
$$

A energia de formação da depressão, com muitos elētrons , será finalmente obtida minimizando-se a equação (6.6) com relação ao parâmetro variacional $\lambda^{\prime}$, isto é,

$$
\begin{aligned}
& \frac{\partial E_{O}^{*}}{\partial \lambda^{\prime}}=0 \\
& \text { O valor de } \lambda^{\prime} \text { que minimiza a equação }(6.8) \text { è } \\
& \left(\frac{1}{\lambda^{\prime}}\right)^{1 / 2}=\frac{\sqrt{2 \pi^{3}} \sigma K_{C}}{E_{\perp}^{2}} \simeq \frac{696542,3}{E_{\perp}^{2}}
\end{aligned}
$$

com $E_{\perp}$ em $V / c m$.

Substituindo-se este valor de $\lambda^{\prime}$ na expressão da energia, equação $(6.7)$ obtemos

$$
E_{0}^{*} \simeq-\frac{2 \alpha^{*}}{\sqrt{\rho_{4-3}}}\left[\ln \left(\frac{E_{\perp}^{2}}{\pi / 2 \sigma K_{c}}\right)-1\right]
$$




$$
E_{0} \simeq-8,6 E_{\perp}^{2}\left(\ell n E_{\perp}^{2}-14,1\right) e V
$$

Desta expressão, observamos que a formação de uma depres são com muitos elétrons na interface da mistura ${ }^{3} \mathrm{He}-{ }^{4} \mathrm{He}$ será energeticamente favorável $\left(E_{0}<0\right)$ se $\ln _{1}>7,05$. O campo crítico ou seja, o menor valor do campo elétríco externo que localiza a depressão na interface será $1153 \mathrm{~V} / \mathrm{cm}$. Este resultado estã em excelente acor do com os resultados experimentais de Wanner e Leiderer ${ }^{13}$ e Leiderer et.al ${ }^{51}$ que encontraram o valor do campo crítico para formação de uma depressão com muitos elétrons, para $T=0,567 \mathrm{~K}$, ser $1120 \mathrm{~V} / \mathrm{cm}$. A massa efetiva da depressão é, analogamente à energia, obtida da equação (5.31) através das seguintes modificações: $a=0, \alpha \rightarrow \alpha^{*}$ e $\gamma \rightarrow \gamma^{*}$, onde $\gamma^{*}=\mathbf{N} \gamma$ e $\gamma$ é definido na equação (5.29), como sendo

$$
\frac{M^{*}}{M}=1+\frac{4 \alpha^{*}}{3 / 2} \int_{0-3}^{\infty} \gamma^{* 2} d x \frac{x^{2}}{\left(1+x^{2}\right)^{2}} e^{-x^{2} / \lambda} \cdot
$$

onde $\lambda^{\prime}$ è dado pela equação (6.9).

Em unidades da massa atômica do hélio, a massa efetiva é reescrita na seguinte forma:

$$
\frac{M^{*}}{M^{4} \mathrm{He}} \simeq 1+\frac{\pi h^{2} K_{C}^{3}}{2 M^{2} g} \quad \alpha^{*}=5,22 \times 10^{11} \mathrm{E}_{\perp}^{2}
$$

com $E_{\perp}$ em $V / c m$. A dependência da massa efetiva com o quadrado do campo externo está de acordo com as previsões dos câlculos de Shikin e Leiderer ${ }^{48}$ que calcularam, através de considerações hidrodinâmi cas, a massa efetiva e a mobilidade.

Um fator geométrico importante que podemos tambëm obteré o raio médio da depressão, o qual é dado pela expressão

$$
<r>=\int \mathrm{d}^{2} r \psi^{*}(\overrightarrow{\mathrm{r}}) \mathrm{r} \psi(\overrightarrow{\mathrm{r}})
$$


onde $\psi(\vec{r})$ è a função de onda dada pela equação (6.3).

Calculando-se a integral, obtemos

$$
\langle r\rangle=\frac{1}{K_{c} \sqrt{\lambda^{1}}}=\frac{\sqrt{2 \pi^{3} \sigma}}{E_{\perp}^{2}}=\frac{11056,2}{E_{\perp}^{2}} \mathrm{~cm}
$$

Uma vez que o raio da depressão è inversamente proporcional ao qua drado do campo elétrico externo, aumentando-se o campo a depressão terá um raio menor mais por outro lado será mais profunda. Este sistema será estável se a profundidade da depressão não ultrapas sar o seu raio.

Os resultados para a energia de formação, o raio e a mas sa de uma depressão com muitos elētrons na interface da mistura ${ }^{3}$ He${ }^{4}$ He estão mostrados nas figuras 19,20 e 21 respectivamente. Nas mesmas figuras, são também apresentados os resultados de Shikin e Leiderer para efeito de comparação.

Na figura 22 mostramos os resultados de Wanner e Leiderer. Na figura $22 a$ observamos a deformação da interface da mistụ ra para uma temperatura de $0,567 \mathrm{~K}$ e um campo elétrico externo de $1120 \mathrm{~V} / \mathrm{cm}$, observada de um ângulo de $6^{\circ}$. A barra corresponde a 1 $\mathrm{mm}$. Na figura $22 \mathrm{~b}$ o campo elétrico externo foì aumentado para $\mathrm{E}_{\overline{\mathbf{L}}}$ $=1160 \mathrm{~V} / \mathrm{cm}$ e podemos observar a deformação espontânea da interface em vărias depressões menores dentro das quais existem aproximada mente $10^{6}$ elétrons. 
Figura 19 - Energia de formação de uma depressão com mu1 tos elétrons, $\left(N=10^{6}\right)$, na interface da mistu ra ${ }^{3} \mathrm{He}-{ }^{4} \mathrm{He}$ em função do campo elétrico ex terno. Nossos resultados são representados pelo símbolo (•). O símbolo (ム) representa os resultados teóricos obtidos por Shikin e Leiderer ' O campo crítico a partir do qual ocorrerá a formação da depressão obtido é de $1150 \mathrm{~V} / \mathrm{cm}$ e está em excelente concordân cia com os resultados experimentais de Wan ner e Leiderer. 


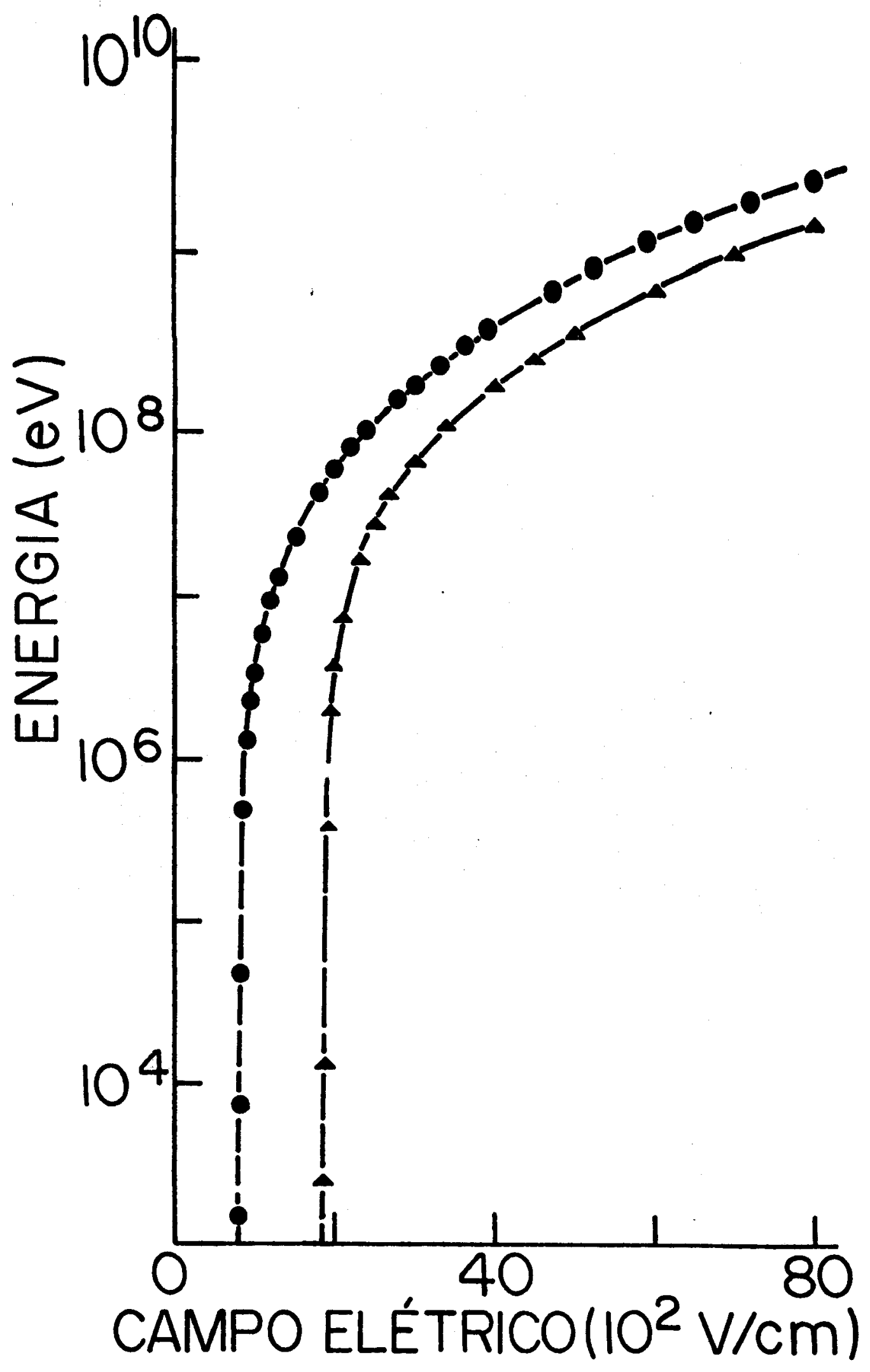


Figura 20 - Raio mëdio de uma depressão contendo muitos elétrons $\left(N=10^{6}\right)$ e localizada na interface da mistura ${ }^{3} \mathrm{He}-{ }^{4} \mathrm{He}$ em função do campo elé trico externo. Nossos resultados estão re presentados pelo símbolo (•) e os resultados teōricos de Shkin e Leiderer ' por (k). 


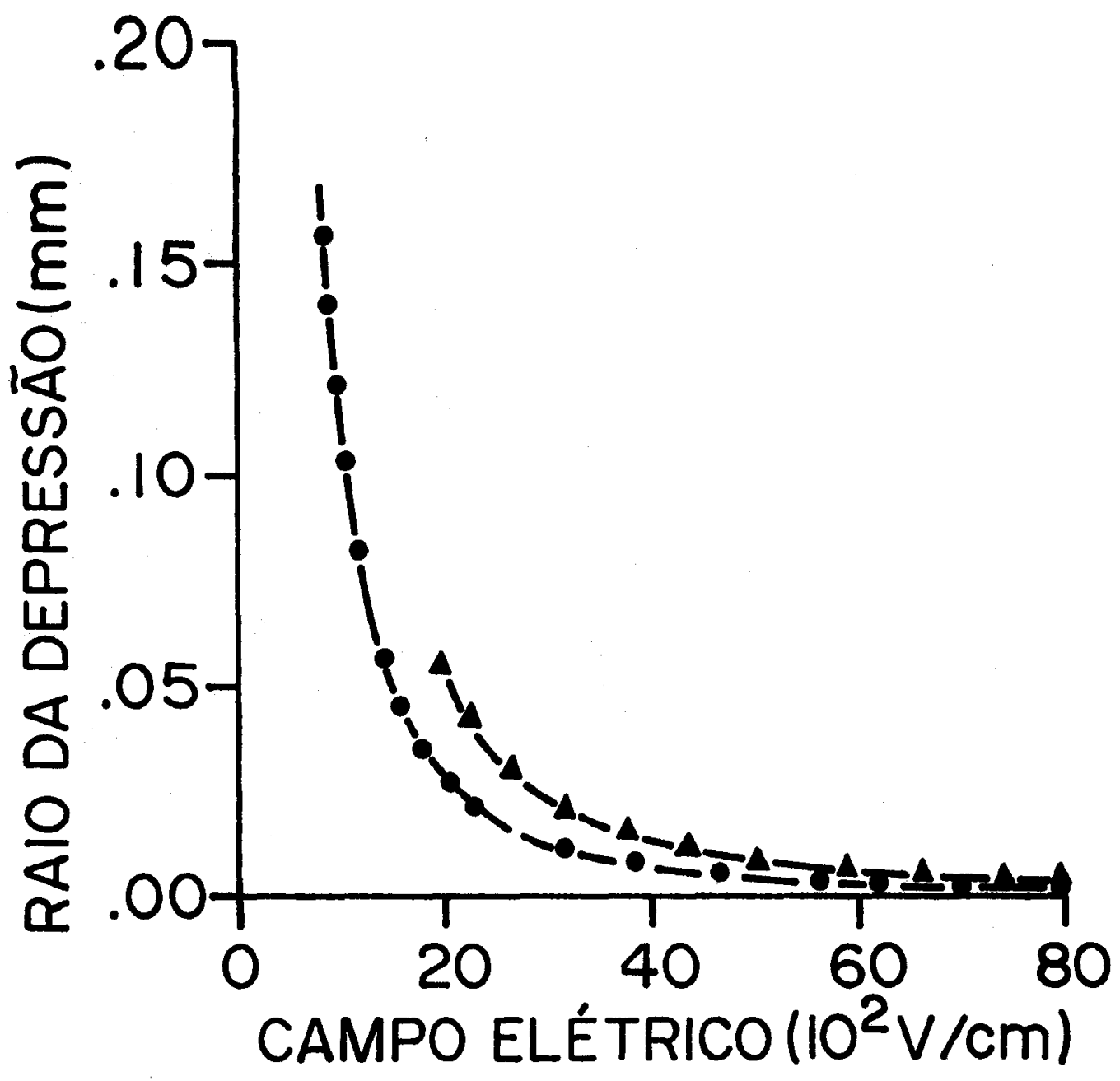


Figura 21 - Massa efetiva de uma depressão contendo mui tos elétrons $\left(\mathrm{N}=10^{6}\right)$ localizada na interface da mistura ${ }^{3} \mathrm{He}-{ }^{4} \mathrm{He}$ em unidades da massa a tômica do ${ }^{4}$ He em função do campo elētrico ex ternn. Nossos resultados estão representados pelo símbolo $(\bullet)$ e os resultados teóricos de Shikin e Leiderer ' por ( $\bullet$ ) 


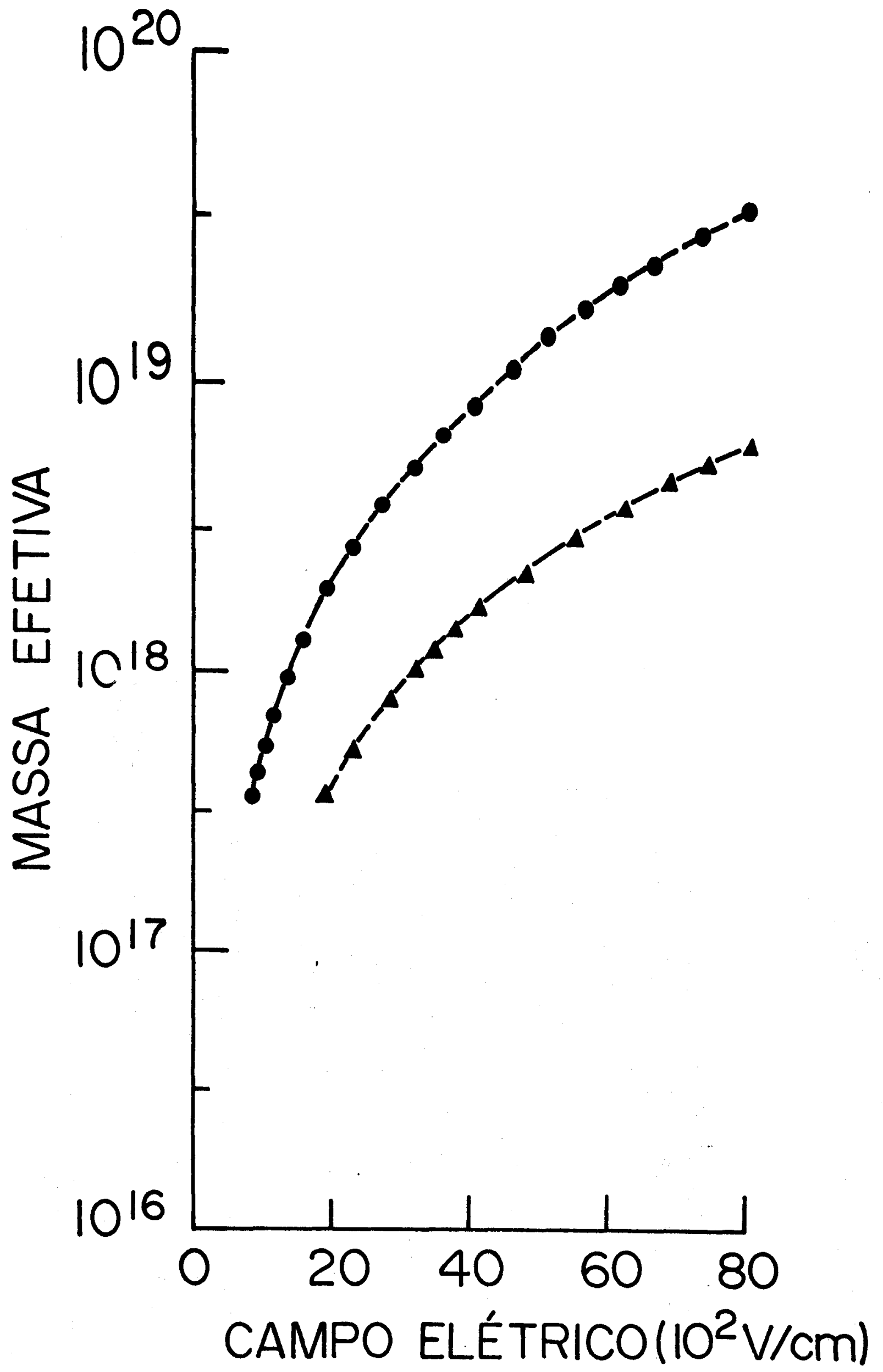


Fiqura 22- Deformação da interface da mistura ${ }^{3} \mathrm{He}-{ }^{4} \mathrm{He}$.

Resultados obtidos por Wanner e Leiderer ${ }^{13}$ para elētrons na interface da mistura ${ }^{3} \mathrm{He}-{ }^{4} \mathrm{He}$ para a temperatura $0,567 \mathrm{~K}$. A barra nas figuras $a$ e b representa $1 \mathrm{~mm}$.

$$
\begin{aligned}
& \text { Parte (a)- } 0 \text { campo elétrico externo (E ) é de } 1120 \mathrm{~V} / \mathrm{cm} \\
& \text { e a fotografia foi tirada formando um ângulo } \\
& \text { de } 6^{\circ} \text { com a superfície. Para este campo exis- } \\
& \text { te apenas uma depressão onde todos os elētrons } \\
& \text { estão nela contidos. }
\end{aligned}
$$

Parte (b) - o campo elétrico externo (E ) foi aumentado pa ra $1160 \mathrm{~V} / \mathrm{cm}$ e a superfície deforma-se num ar ranjo onde existe muitas depressões menores formando um cristal com simetria hexagonal. 
(a)

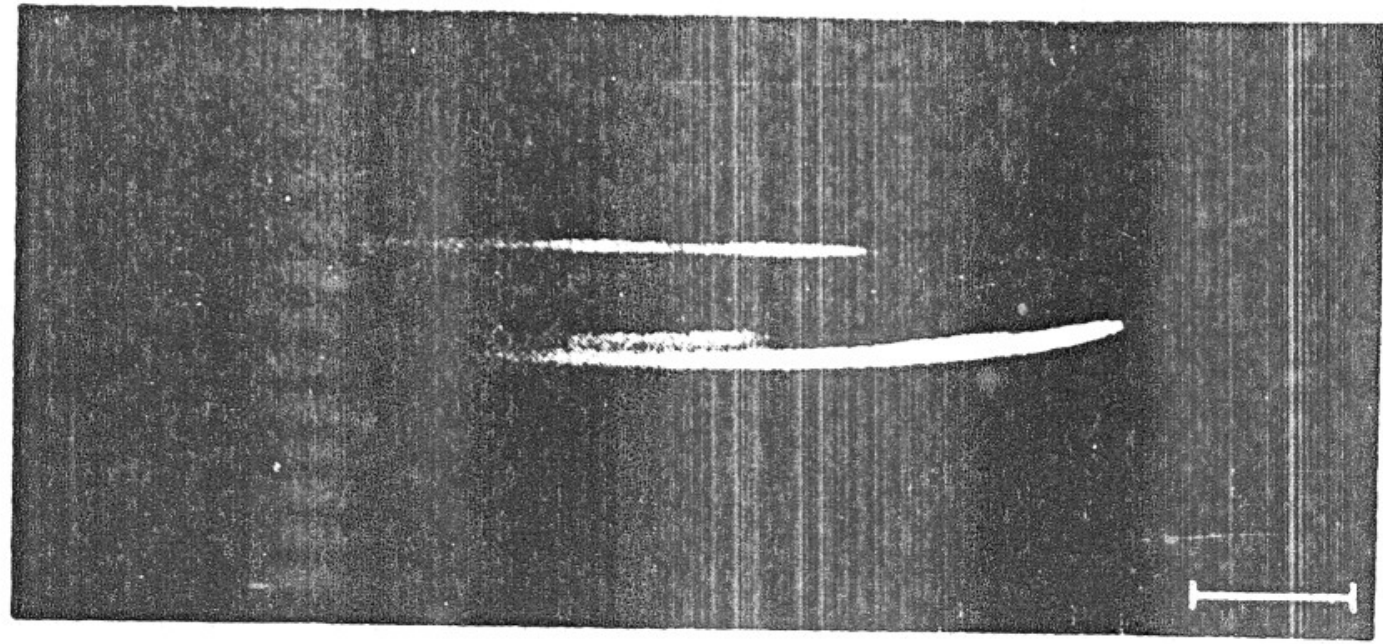

(b)

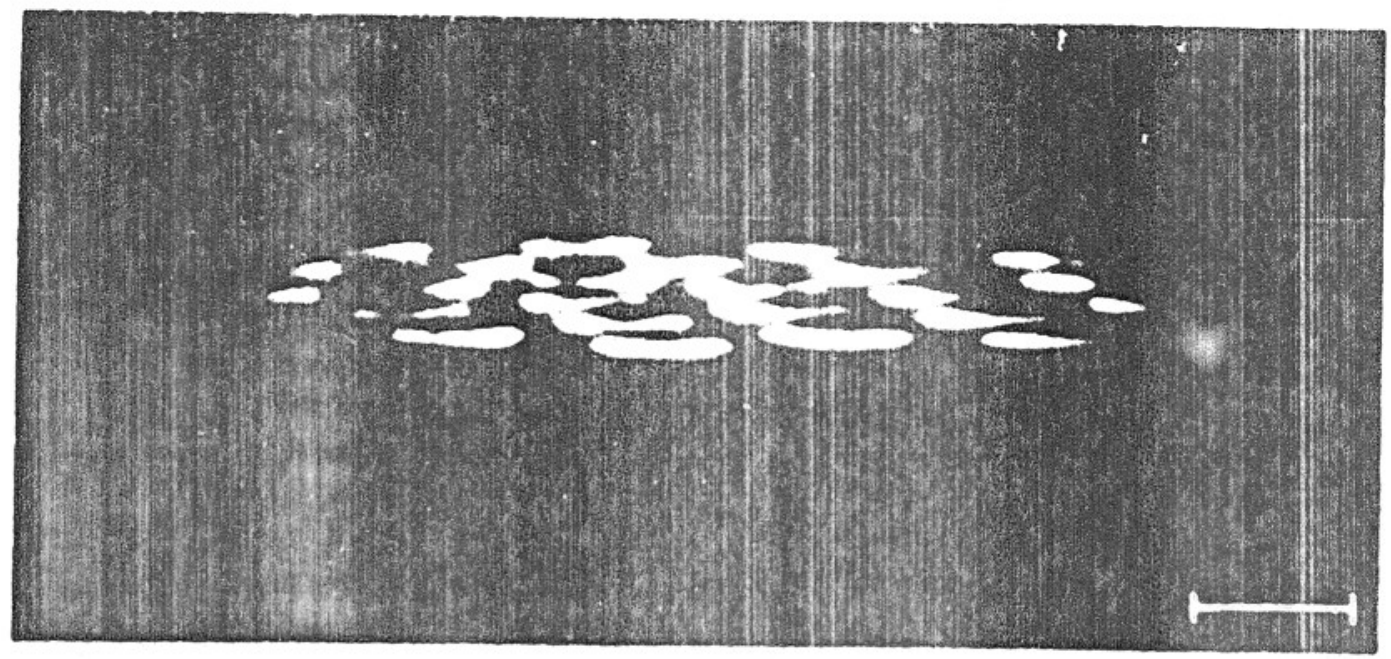


(B) ${ }^{4} \mathrm{He}$ líquido e filmes de ${ }^{4} \mathrm{He}$ liquido

Nesta secção, investigaremos algumas propriedades de uma única depressão contendo muitos elétrons, localizada na superfície de ${ }^{4}$ He líquido e em filmes de ${ }^{4}$ He liquido adsorvidos em safira e em neon sólido. Para estes sistemas obtemos a energia de localização, o raio, a densidade de carga e a massa efetiva da depressão em função da espessura do filme, do campo elétrico externo e do número $\mathrm{N}$ de elétrons contidos na depressão.

Leiderer et.al ${ }^{51}$, e Giannetta e Ikezi ${ }^{14}$ observaram experimentalmente, através de meios óticos, a formação de depressões com muitos elétrons na superfície de ${ }^{4}$ He líquido. Shikin e Leide $\operatorname{rer}^{48}$ tambēm têm estudado algumas propriedades da localização de depressões contendo muitos elētrons na superfície de ${ }^{4}$ He líquido. Eles consideram uma distribuição gaussiana para os elétrons em um disco de raio $R$ e minimizam a energia com relação à $R$.

Estudaremos uma depressão constituída por $\mathrm{N}$ elētrons . portanto a carga e a massa total serão respectivamente $Q=N$ e e $M=$ =Nm, onde e é a carga elementar e m a massa do elétron.

A constante de acoplamento $\alpha$ será redefinida na seguinte

forma

$$
: \alpha^{*}=\frac{Q^{2} E^{2}}{8 \pi \sigma \frac{h^{2} K_{C}^{2}}{2 M}}
$$

com

$$
\begin{gathered}
E=\frac{\mathrm{Q} \delta}{4 \mathrm{~d}^{2}}+\mathrm{E}_{\perp}, \\
\delta=\frac{\varepsilon-1}{\varepsilon+1}, \quad \mathrm{e} \\
\mathrm{K}_{\mathrm{C}}=\left[\frac{\rho \mathrm{g}}{\sigma}\left(1+\frac{3 \mathrm{nn}}{\rho g \mathrm{~d}}\right)^{1 / 2} .\right.
\end{gathered}
$$


$\rho$ ề a densidade e $\sigma$ ó coeficiente da tensão superficial do ${ }^{4}$ He líquido, $\eta$ é a constante de van der Waals, d è a espessura do fil me e g é a aceleração da gravidade. Para o neon sôlido $\delta=0,107$, pa ra a safira $\delta=0,9$.

No limite $d+\infty$, não haverá mais a contribuição do subs trato e a constante de acoplamento $\alpha^{*}$ dependerā somente do campo e lētrico externo $E_{\perp}$, ou seja, haverá a localização da depressão sọ mente atravês de um campo elétrico externo. Neste limite a constan te de capilaridade serā $k_{c}=\sqrt{\rho g / \sigma}$. Para o ${ }^{4}$ He $\rho=0,145 \mathrm{~g} / \mathrm{cm}^{3}$ e $\sigma=$ $=0,36 \mathrm{dyn} / \mathrm{cm}$ resultando, portanto, $\mathrm{K}_{\mathrm{c}}=19,87 \mathrm{~cm}^{-1}$.

Para filmes de hēlio, mesmo que o campo elētrico externo perpendicular à superfície seja nulo, haverá a contribuição do subs trato. Neste caso a constante de acoplamento $\alpha{ }^{*}$ será proporcional à quinta potência de $\mathrm{N}$ e por esta razão o polaron estará na região de acoplamento forte mesmo para filmes espessos. Utilizaremos aqui, o mesmo procedimento utilizado no caso da mistura ${ }^{3} \mathrm{He}-{ }^{4} \mathrm{He}$. Tomaremos $a=0$ na equação da energia do estado fundamental (5.37) e adicionaremos à energia o termo referente à interação coulombiana entre os elétrons dentro da depressão. Uma vez que estamos interessados na localização da depressão na superfície, desprezaremos o termo $\lambda^{1 / 2}$ da equação (5.37) referente à energia cinética. Assim sendo, a expressão para a energia de formação de uma depressão contendo muitos elêtrons em filmes de ${ }^{4} \mathrm{He}$ líquido, em unidades de $\hbar^{2} \mathrm{~K}_{\mathrm{C}}^{2} / 2 \mathrm{M}$, será

$$
E_{0}^{*}=v_{c}^{*}-2 \alpha^{*} \int_{0}^{\infty} d x \frac{x e^{-x^{2} / \lambda^{\prime}}}{1+x^{2}}
$$

onde $\mathrm{v}_{\mathrm{c}}^{*}$ é dado pela equação (6.5) e $\alpha^{*}$ pela equação (6.16). Efetu ando a integração ficamos com

$$
E_{0}^{*}=v_{C}^{*}+\alpha^{*} \exp \left(1 / \lambda^{\prime}\right) E_{i}\left(-1 / \lambda^{\prime}\right)
$$

onde $E_{i}(x)$ è a função exponencial integral. 
A energia de formação da depressão com muitos elétrons serâ finalmente obtida através da minimização da equação $(6.20) \mathrm{com}$ relação ao parâmetro variacional $\lambda^{\prime}$, isto é

$$
\frac{\partial E_{0}^{*}}{\partial \lambda^{\prime}}=0
$$

0 valor de $\lambda^{\prime}$ que minimiza a energia é dado por

$$
\left(\frac{1}{\lambda^{\prime}}\right)^{1 / 2}=\frac{\sqrt{2 \pi^{3}} K_{c} \sigma}{E^{2}}
$$

onde $K_{C}$ está definido em (6.18) e $E$ em (6.17). Substituindo este valor de $\lambda^{\prime}$ de volta na equação $(6.20)$ obteremos

$$
E_{0}^{*}=-2 \alpha^{*}\left[\ln \left(\frac{E^{2}}{\pi^{3 / 2} k_{c} \sigma}\right)-1\right]
$$

ou ainda

$$
E_{0}=-3,18 \times 10^{-14} \times(N E)^{2} \quad \ln \left(\frac{E^{2}}{5,45 K_{C}}\right) M e V
$$

Como podemos observar, a localização de uma depressão com muitos elētrons na superfície de filmes de ${ }^{4}$ He líquido seră energeticamente favorăvel se $E^{2}>5,45 \mathrm{~K}_{\mathrm{C}}$. No caso limite em que $\mathrm{d}+\infty$ o campo crítico, isto $\bar{e}$, o menor valor para o campo elétrico exter no no qual ocorrerá a localização da depressão seră então $E_{c} \approx 3121$ $\mathrm{V} / \mathrm{cm}$. Este resultado está em ótima concordância com os resultados. de Shikin e Leiderer ${ }^{48}$ e de Mel'nikov e Meshkov ${ }^{49}$ que calcularam o campo crítico para a formação da depressão atravēs de considera ções hidrodinâmicas.

A massa efetiva da depressão é obtida da equação (5.41) a través das seguintes modificações: $\alpha \rightarrow \alpha^{*}, a=0$ e $\gamma^{\prime}+\gamma^{*}$ onde $\gamma^{*}=\mathbf{N} \gamma^{\prime}$ e $\gamma$ é definido na equação (5.38). Então 


$$
\frac{M^{*}}{M}=1+\frac{4 \alpha^{*}}{\gamma^{*^{2}}} \int_{0}^{\infty} d x \frac{x^{2} e^{-x^{2} / \lambda^{\prime}}}{\left(1+x^{2}\right)^{2} \tanh (x d)}
$$

Um fator geométrico importante è o raio da depressão, o qual obtemos de forma análoga à mistura ${ }^{3} \mathrm{He}-{ }^{4}$ He. O raio é dado por

$$
\langle r\rangle=\frac{\sqrt{2 \pi^{3}} \sigma}{E^{2}} \mathrm{~cm}
$$

Um parâmetro relevante a ser calculado é a densidade de elétrons na depressão, pois como vimos no capítulo anterior, a den sidade é responsável pela forma estāvel da superfície. Existe uma densidade crítica acima da qual a superfície torna-se instável deformando-se espontaneamente. Calculamos a densidade da seguinte forma

$$
\overline{\mathrm{n}}=\frac{\mathrm{N}}{\langle\mathrm{A}\rangle}
$$

onde $\langle A\rangle$ é a área média da depressão, a qual é simplesmente calculada através da expressão

$$
\langle A\rangle=\int \psi^{*}(\vec{r}) \pi r^{2} \psi(\vec{r}) d^{2} r
$$

com $\psi(\vec{r})$ definida na equação (6.3).

A ărea média serã, então

$$
<A>=\frac{\pi^{3 / 2}}{K_{C}^{2} \lambda^{\prime}}
$$

Utilizando-se o valor de $\lambda^{\prime}$, equação $(6.22)$, a densidade será

$$
\overline{\mathrm{n}}=\frac{\mathrm{NK}_{\mathrm{C}} \mathrm{E}^{2}}{\sqrt{2} \pi^{3} \sigma}=0,063 \times \mathrm{N} \times \mathrm{K}_{\mathrm{c}} \times \mathrm{E}^{2} \text { elétrons } / \mathrm{cm}^{2}
$$

Na figura 23 estão os resultados obtidos por Leiderer et. 
$\mathrm{al}^{51}$ para ${ }^{4}$ He líquido.

o aparato experimental utilizado para estas observações

é constituído de um capacitor de placas paralelas horizontais com espaçamento de $1,5 \mathrm{~cm}$ e uma parede cilindrica de diâmetro $8 \mathrm{~cm}$. A placa inferior do capacitor è revestida de ouro e a superior é de vidro coberta com um condutor transparente, a qual permite a ob :servação da superfície de ${ }^{4}$ He. Na figura $23 a$ o campo externo é tal que somente duas depressões aparecem. Com o aumento do campo externo surgirão mais depressões, como ilustram as figuras $23 \mathrm{~b}$ e $23 c$.

Na figura 24 abaixo apresentamos um perfil da depressão na superfície de ${ }^{4} \mathrm{He}$ líquido para uma temperatura de $2,5 \mathrm{~K}$ e um campo externo de $2900 \mathrm{~V} / \mathrm{cm}^{51}$.

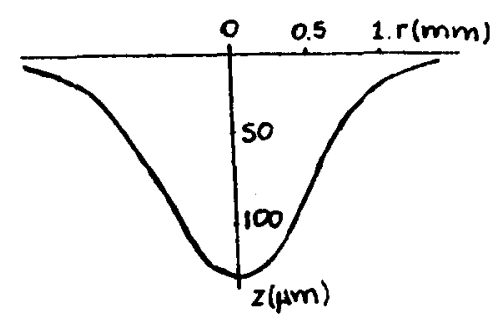

Figura 24

Já estudamos no capítulo $V$, a existência de uma densidade crítica acima da qual a superfície torna-se instável. No caso de filmes de hélio esta densidade crítica é dada por

$$
\mathrm{n}_{\mathrm{c}}=\left(\frac{\mathrm{K}_{\mathrm{c}} \sigma^{2}}{2 \pi^{2} \mathrm{e}^{2} \varepsilon_{\mathrm{s}}}\right)^{1 / 2}
$$

onde $K_{C}$ è dado pela equação (6.18) e $\varepsilon_{s}$ é a constante dielétrica do substrato. Para filmes suficientemente finos ( $(\tilde{\sim} 100 \AA)$ esta densidade é da ordem de $10^{11}$ elétrons $/ \mathrm{cm}^{2}$. Assim sendo, uma depressão com muitos elétrons será estável se a densidade média for menor que a densidade crítica, ou seja, 
Por outro lado, para um dado campo elëtrico externo e um dado número $\mathbf{N}$ de elétrons existirá uma espessura crítica para o filme de hélio líquido, na qual a energia passará a ser positiva e a de pressão não será mais formada. A espessura do filme e a densidade de carga na depressão limitarão a região na qual a depressão será estável. Nas figuras $25,26,27$ e 28 estão os resultados para a den sidade média de carga, a energia de formação, o raio e a massa efetiva de uma depressão com muitos elētrons, em função da espessü ra do filme, do número de elétrons e do campo elétrico externo pa ra filmes de ${ }^{4}$ He líquido adsorvidos em neon sólido e em safira.

Nas figuras 29 e 30 estão a densidade de carga e a ener gia de formação de uma depressão na superfície de ${ }^{4}$ He líquido no limite em que a espessura é infinita, em função do campo elétrico externo e do número de elétrons. Neste caso, observamos que uma de pressão contendo $\mathrm{N} \sim 10^{6}$ elētrons é, energeticamente, a mais estāvel para campos próximos ao campo crítico de formação da depressão • Se o campo elētrico externo é aumentado até o valor onde a densida de média $\bar{n}$ atinge o valor crítico $\mathrm{n}_{C^{\prime}}$, esta depressão não será mais estäyel, mas uma depressão com um número menor de elétrons será es tável. Novamente aumentando-se o campo elétrico externo até um vâ lor onde a densidade média $\bar{n}$ da nova depressão atinge o valor crítico $n_{c}$ então esta depressão não será mais estável e existirá ou tra com menos elētrons que será estável e assim sucessivamente.

O resultado de que a depressão com $N \sim 10^{6}$ elētnons, para campos elétricos externos próximos ao campo crítico de formação, é a mais estável está ém ótima concordância com os resultados expe rimentais ${ }^{13,14}$.

Os resultados obtidos para filmes de hélio em neon sōlido e em safira tem mostrado que a formação de depressões nestes siste mas deverão ocorrer para filmes muito espessos, da ordem de $10^{6} \AA$. Como na experiência de Andrei $^{33}$ são utilizados filmes finos da or- 
dem de $1000 \AA$, não deverã existir depressões com muitos elétrons neste sistema, justificando que as medidas da mobilidade são de de pressões de poucos elētrons ou talvez atē um elétron.

Nas figuras 3la e $31 \mathrm{~b}$ mostramos uma sequência de fotografias obtidas por Giannetta e Ikezi ${ }^{14}$ onde ilustramos a formação do cristal de depressões na superfície de ${ }^{4} \mathrm{He}$ líquido. Na figura 31 a o campo externo está sendo aumentado e observamos a formação do cristal. Na figura $31 \mathrm{~b}$ o campo externo está diminuindo e è observa do um efeito do tipo histerése, pois para campos abaixo do campo crítico ainda existe um vestígio do cristal.

Finalmente na figura 32 apresentamos os resultados da espessura critica, ou seja a espessura onde a energia cai abruptamente a'zero, em funçäo do nūmero de elétrons, para um campo elétrico externo nulo para filmes de hẻlio adsorvidos em neon sólido e em safira. Como a safira apresenta uma constante dielétrica maior que o neon sólido a espessura crítica para safira será maior. 
Figura 23 - Formação de depressões com muitos elētrons na superficie de ${ }^{4}$ He líquido.

Observação de Leiderer et.al ${ }^{51}$ da formação de depressões com muitos elétrons na superfície de ${ }^{4}$ He líquido para uma temperatura de $2,5 \mathrm{~K}$ e um campo elëtrico externo maior que o campo crítico no qual a superfície torna-se instável.

Parte (a) Apenas duas depressões é detectada

Parte (b) Aumentando-se o campo elétrico externo novas

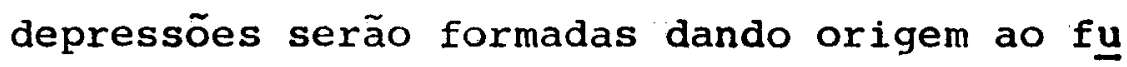
turo cristal a ser formado

Parte (c) Aumentando-se ainda mais o campo elētrico externo um número maior de depressões serã formada e já podemos verificar a estrutura hexagonal. 

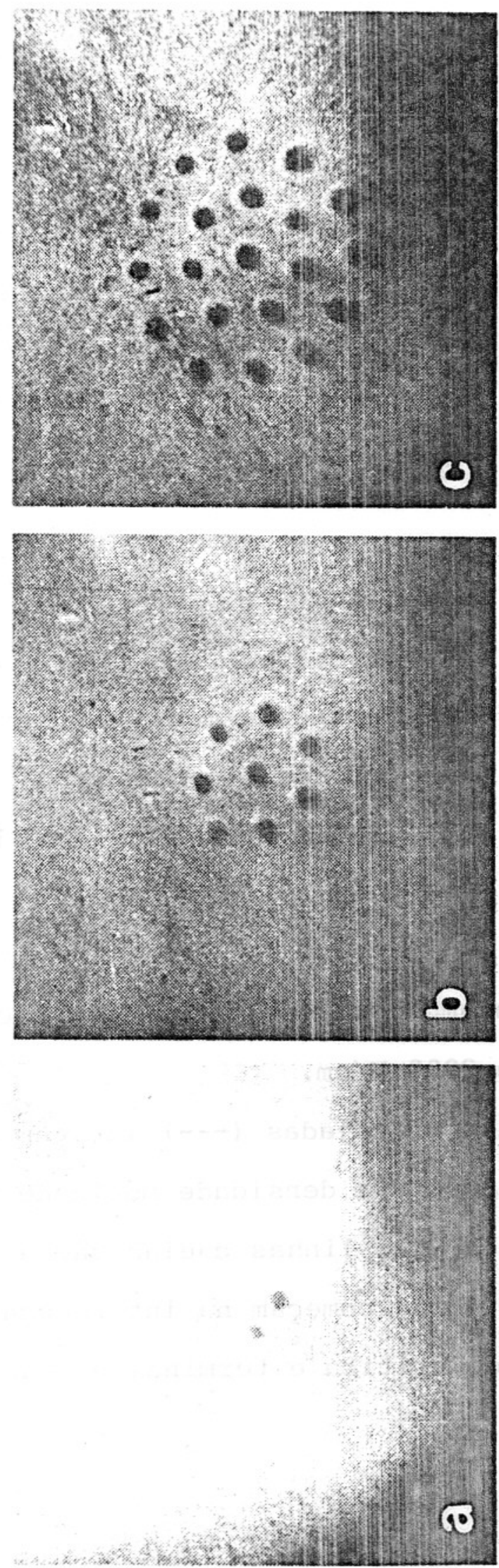
Figura 25a- Densidade mēdia de carga no interior de uma depressão contendo $10^{6}$ elétrons na superfi cie de filmes de ${ }^{4}$ He líquido adsorvidos em neon sólido.

Apresentamos os resultados para o campo elētrico externo nulo, 500,1000 e $2000 \mathrm{~V} / \mathrm{cm}$.

As linhas tracejadas (--) indicam as regiões onde a depressão é instável pois a densidade média de carga é maior que a densidade crítica $n_{c}$. As linhas cheias são as regiões onde a de pressão é estável. Elas começam na intersecção entre a densidade média e a densidade crítica e terminam na espessura em que a energia torna-se nulà. 


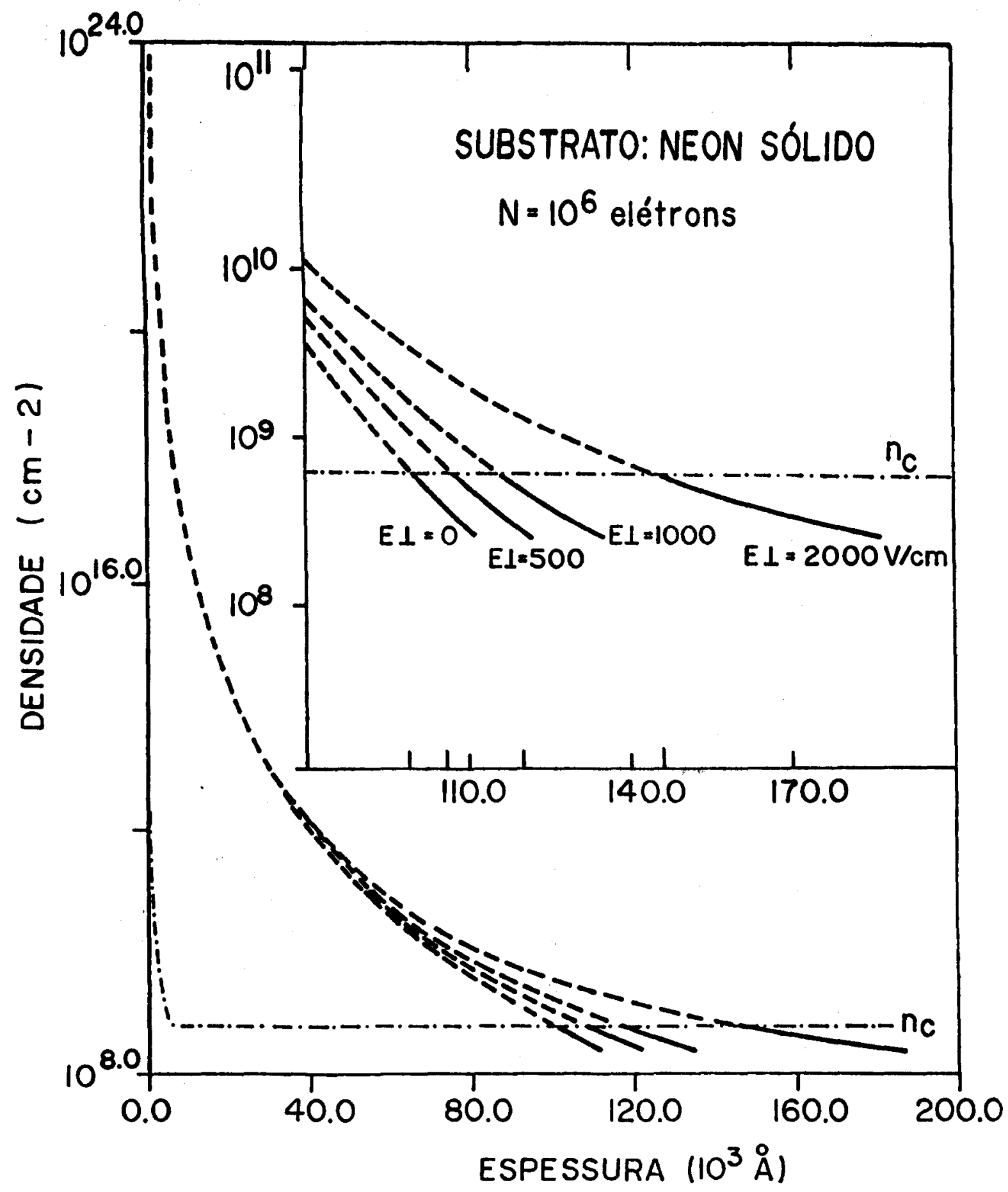


Figura $25 b$ - Densidade média de carga no interior de uma depressão contendo $10^{6}$ elétrons na superficie de filmes de ${ }^{4}$ He liquido adsorvidos em safira.

Apresentamos os resultados para o campo elētrico externo nulo, 500,1000 e $2000 \mathrm{~V} / \mathrm{cm}$.

As linhas tracejadas (--) indicam as regiōes onde a depressão é instável pois a densidade média de carga é maior que a densidade crítica $\mathrm{n}_{C}$. As linhas cheias são as regiões onde a de pressão é estāvel. Elas começam na intersecção entre a densidade média e a densidade crítica e terminam na espessura em que a enerqia torna-se nula. 


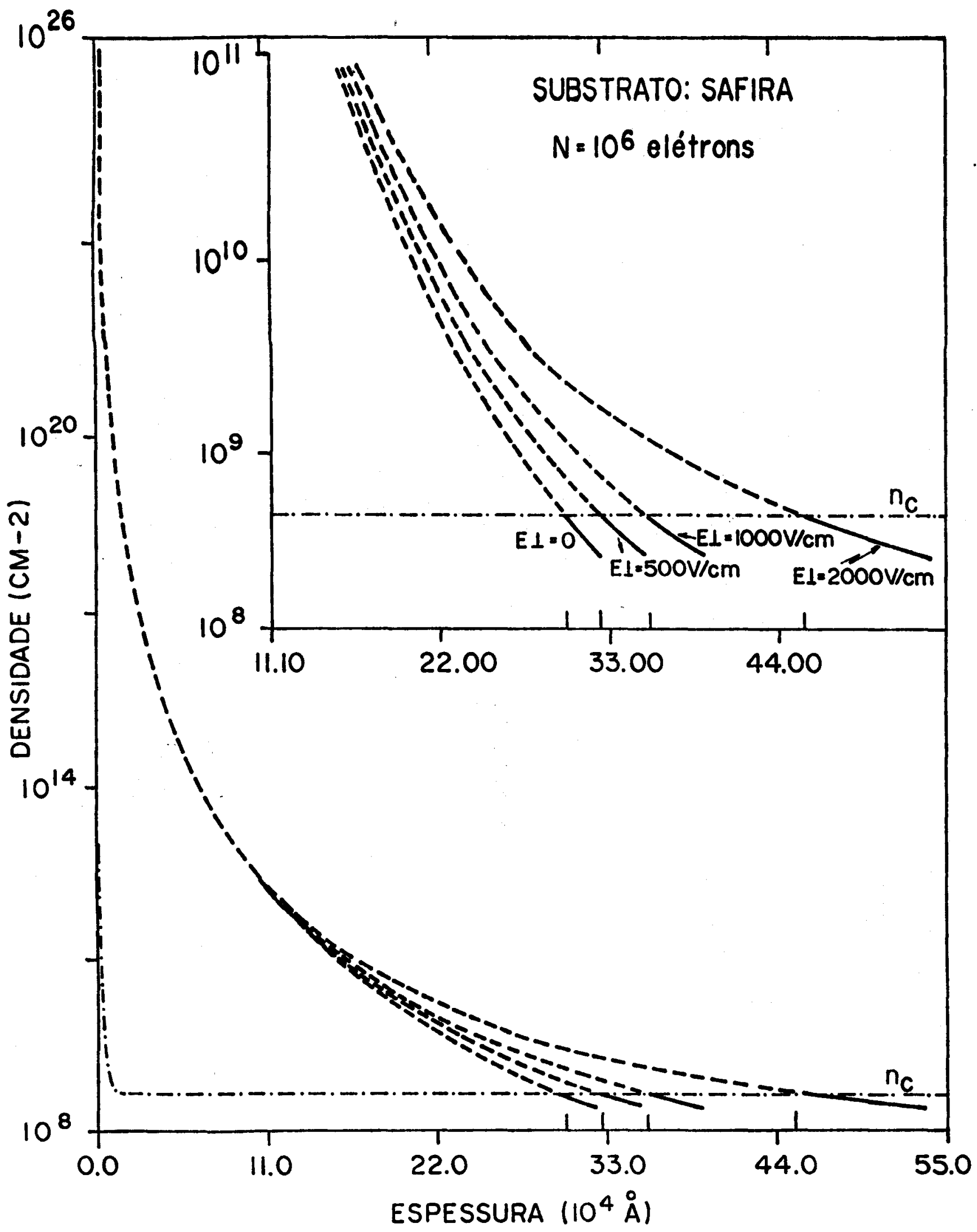


Figura 26a- Energia de formação de uma depressão contendo $10^{6}$ elëtrons na superfície de filmes de ${ }^{4}$ He liquido adsorvidos em neon sōlido.

Apresentamos os resultados para o campo elétrico externo nulo, 500,1000 e $2000 \mathrm{~V} / \mathrm{cm}$.

As linhas tracejadas (--) indicam as regiões onde a depressão é instável pois a densidade de carga correspondente à esta espessura é maior que a densidade crítica $\mathrm{n}_{\mathrm{c}}$. As linhas cheias são as regiões onde a depressão é estāvel. A espessura crítica é aquela na qual a energia cai abruptamente a zero.

Portanto, para haver a formação de depressões com muitos elētrons em filmes de hēlio líquido os mesmos devem ser muito es pessos. 


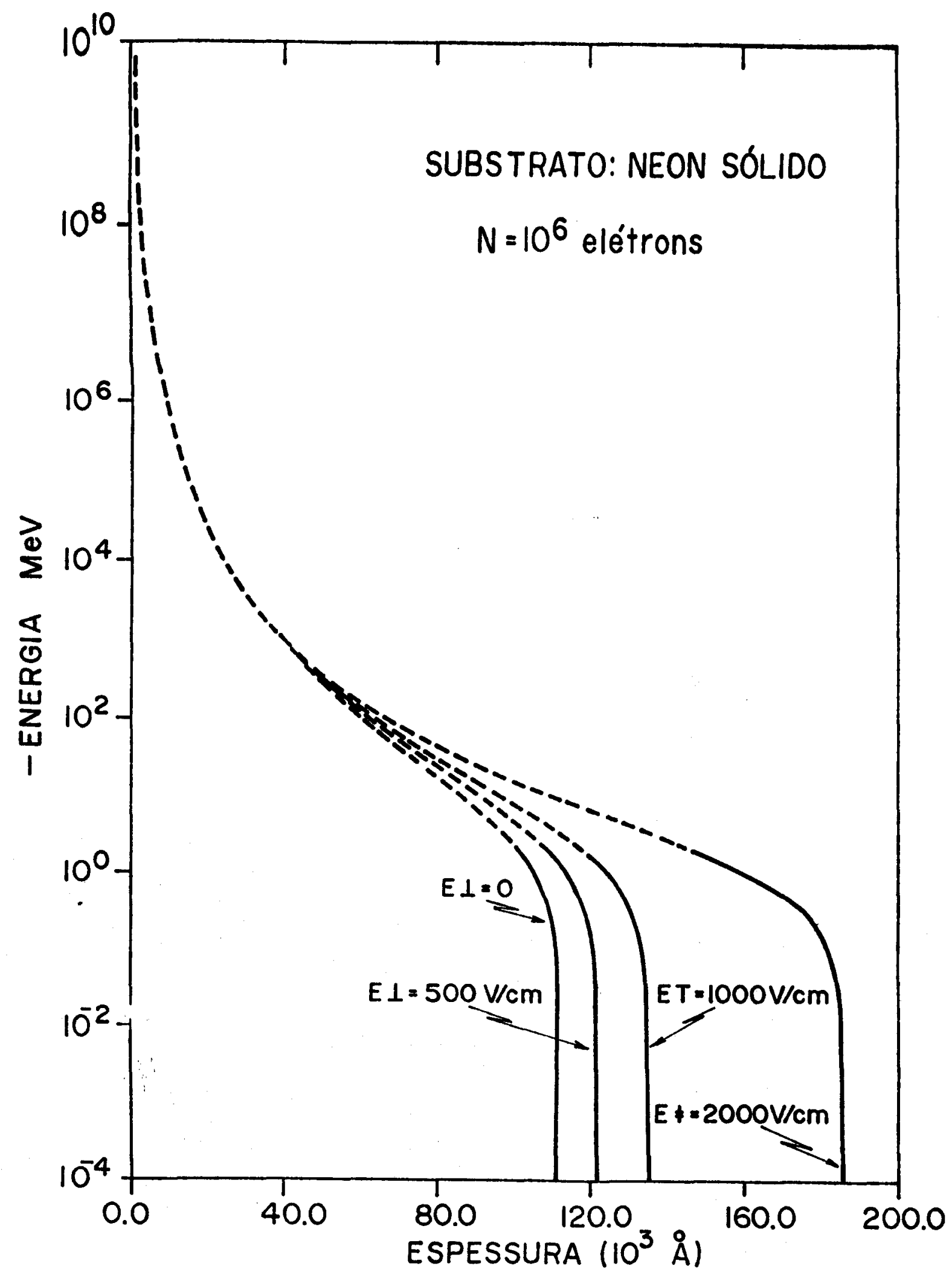


Figura 26b- Energia de formação de uma depressão contendo $10^{6}$ elētrons na superfície de filmes de ${ }^{4}$ He líquido adsorvidos em safira.

Apresentamos os resultados para o campo elétrico externo nulo, 500,1000 e $2000 \mathrm{~V} / \mathrm{cm}$.

As linhas tracejadas (---) indicam as regiões onde a depressão é instável pois a densidade de carga correspondente à esta espessura é maior que a densidade critica $n_{c}$. As linhas cheias são as regiões onde a depressão é estável. A espessura crítica é aquela na qual a energia cai abruptamente a zero.

Portanto, para haver a formação de depressões com muitos e lētrons em filmes de hêlio líquido os mesmos devem ser muito espes sos. 


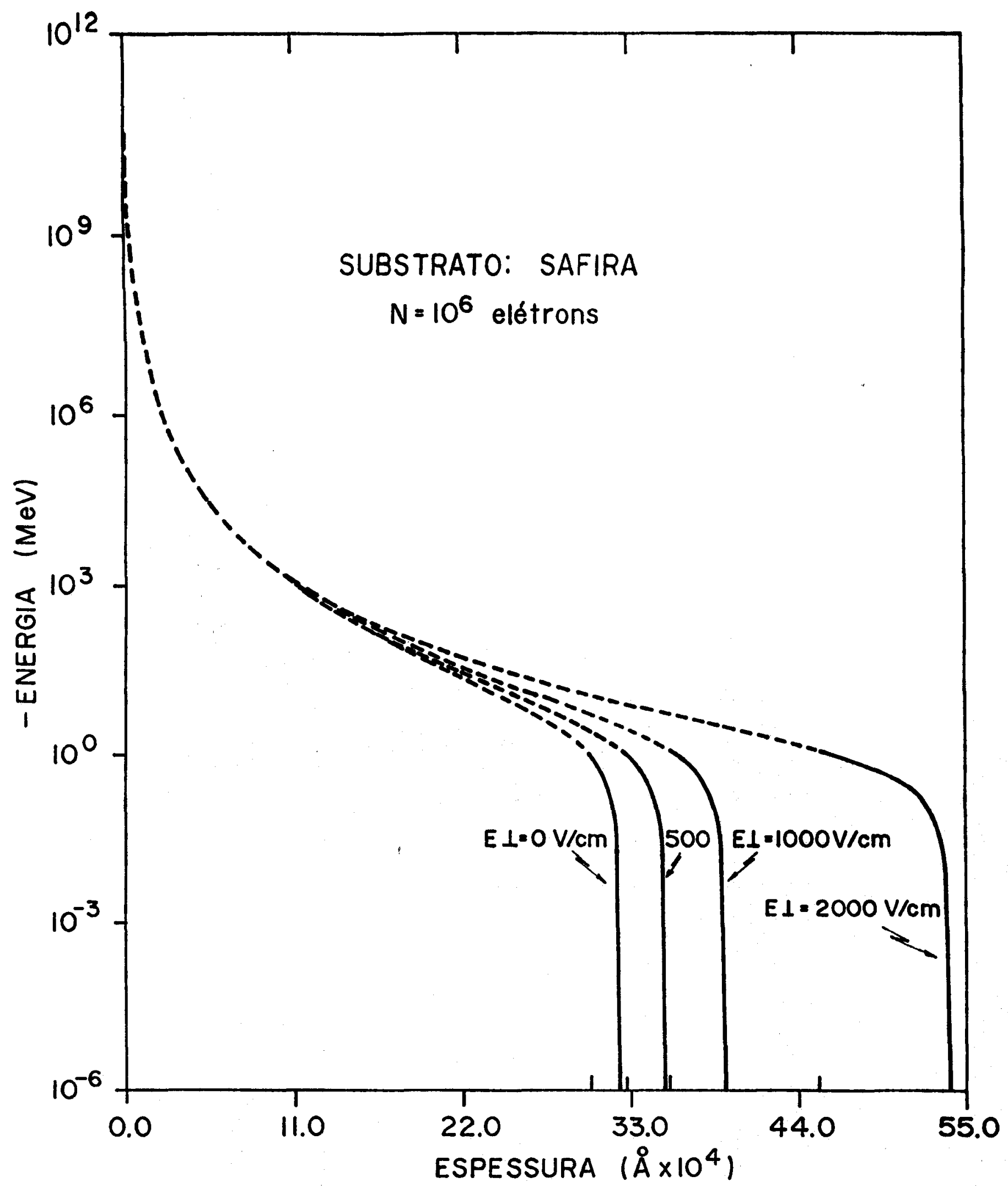


$\begin{aligned} \text { Figura } 27 a- & \text { Raio médio de uma depressão contendo } 10^{6} \text { ele ê } \\ & \text { trons na superfície de filmes de }{ }^{4} \text { He adsorvi } \\ & \text { dos em neon sólido. }\end{aligned}$

Apresentamos os resultados para o campo elētrico externo nulo, 500,1000 e $2000 \mathrm{~V} / \mathrm{cm}$.

As linhas tracejadas (--) indicam regiões onde a depres são é instãvel pois a densidade média de carga é maior que a densi dade crítica $\mathrm{n}_{\mathrm{c}}$. As linhas cheias são as regiões onde a depressão é estāvel. Elas começam na espessura em que a densidade mēdia ultrapassa o valor de $n_{c}$ e terminam quando a energia tende a zero. 


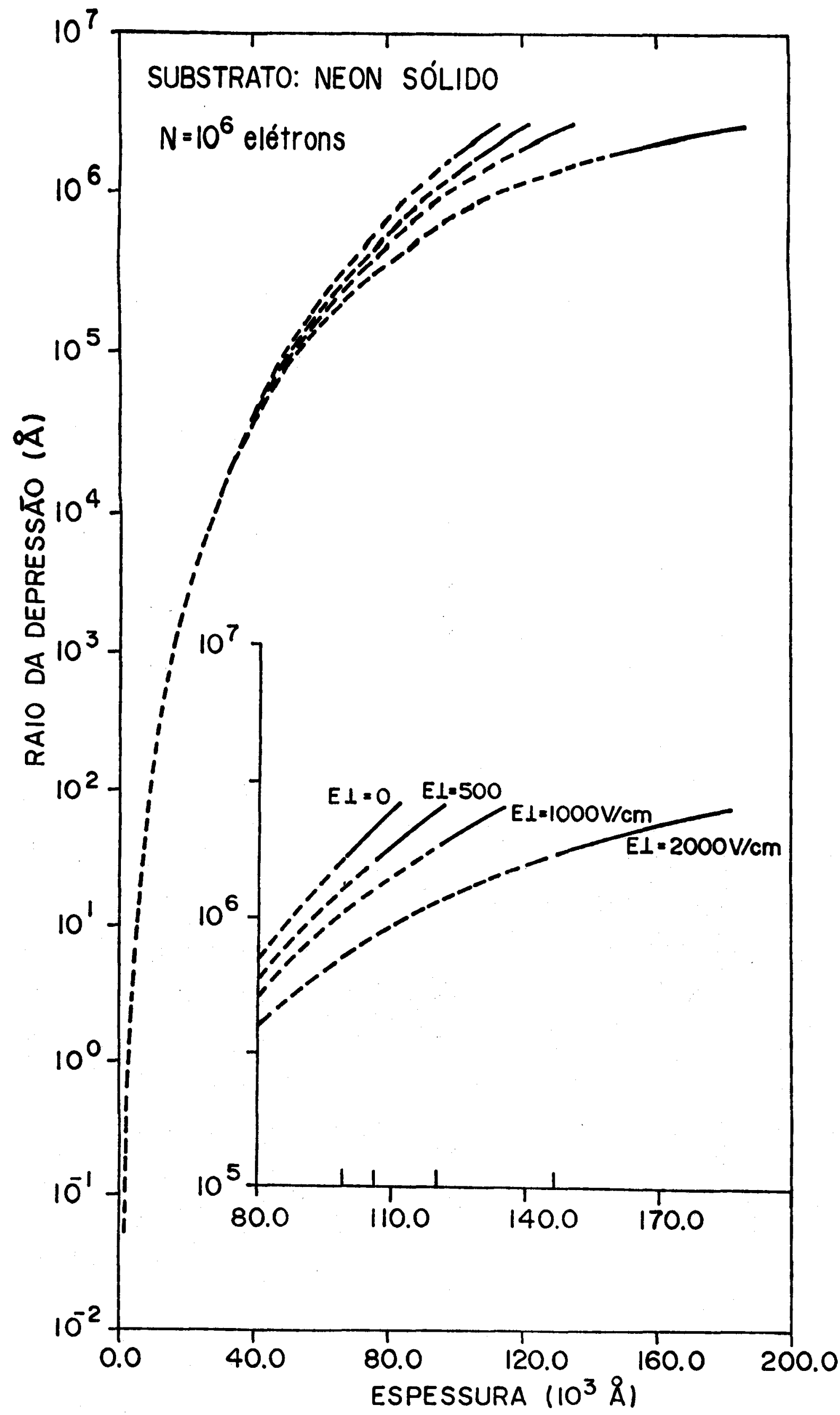


Figura $27 \mathrm{~b}$ - Raio médio de uma depressão contendo $10^{6}$ elé trons na superfície de filmes de ${ }^{4}$ He adsorví dos em safira.

Apresentamos os resultados para o campo elétrico externo nulo, 500,1000 e $2000 \mathrm{~V} / \mathrm{cm}$.

As linhas tracejadas (--) indicam regiões onde a depres são é instável pois a densidade média de carga é maior que a densí dade crîtica $n_{c}$. As linhas cheias são as regiões onde a depressão é estável. Llas começam na espessura em que a densidade média ul trapassa o valor de $n_{c}$ e terminam quando a energia tende a zero. 


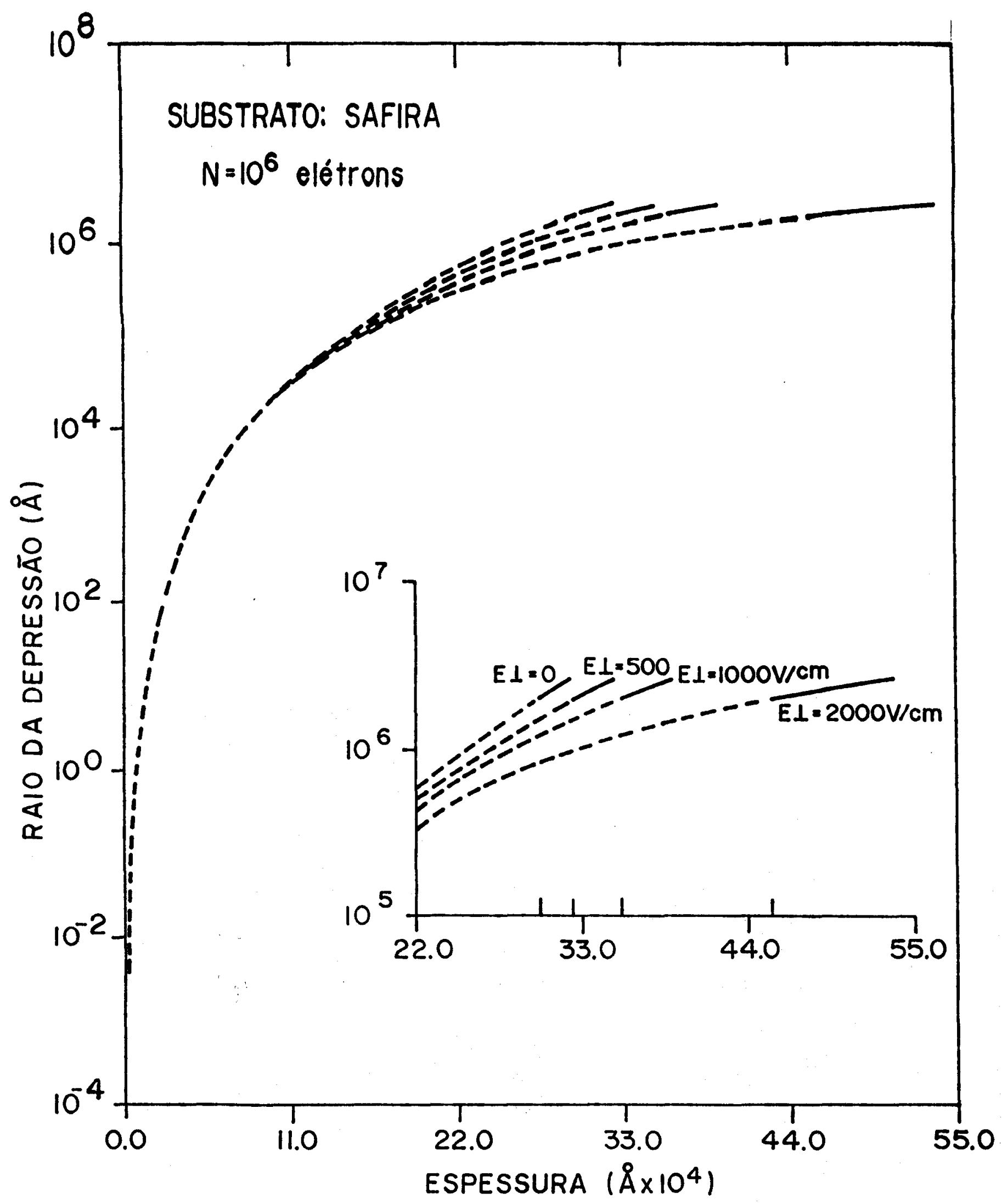


Figura 28a- Massa efetiva de uma depressão contendo $10^{6}$ elétrons na superfície de filmes de ${ }^{4} \mathrm{He} 1 \mathrm{i}$ quido adsorvidos em neon sólido.

Apresentamos os resultados para o campo elétrico externo nulo, 500,1000 e $2000 \mathrm{~V} / \mathrm{cm}$.

As linhas tracejadas (--) indicam regiões onde a depres são é instável pois a densidade média de carga é maior que a densi dade crítica $n_{c}$. As linhas cheias são as regiões onde a depressão é estāvel. Elas começam na espessura em que a densidade média ul trapassa o valor de $\mathrm{n}_{c}$ e terminam quando a energia tende a zero. A massa efetiva $M^{*}$ está em unidades de $M$, onde $M=N m$ com $m$ sendo a massa de um elētron. 


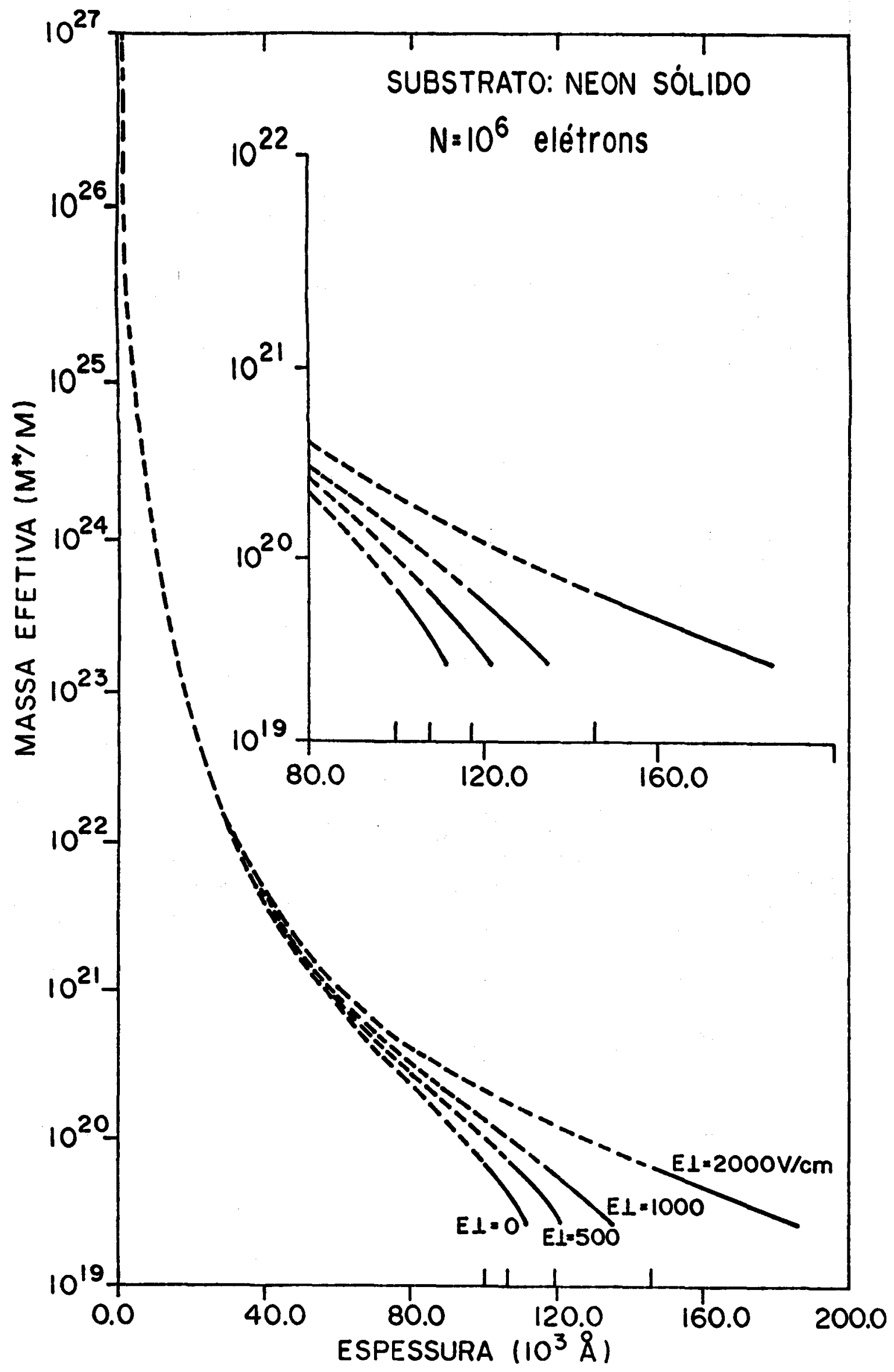


Figura 28b-Massa efetiva de uma depressão contendo $10^{6}$ elētrons na superfície de filmes de ${ }^{4} \mathrm{He}$ li quido adsorvidos em safira.

Apresentamos os resultados para o campo elétrico externo nulo, 500,1000 e $2000 \mathrm{~V} / \mathrm{cm}$.

As linhas tracejadas (--) indicam regiões onde a depres são é instável pois a densidade média de carga é maior que a densi dade crîtica $n_{c}$. As linhas cheias são as regiões onde a depressão é estável. Elas começam na espessura em que a densidade média ul trapassa o valor de $n_{c}$ e terminam quando a energia tende a zero. A massa efetiva $M^{*}$ está em unidades de $M$, onde $M=N m$ com $m$ sendo a massa de um elētron. 


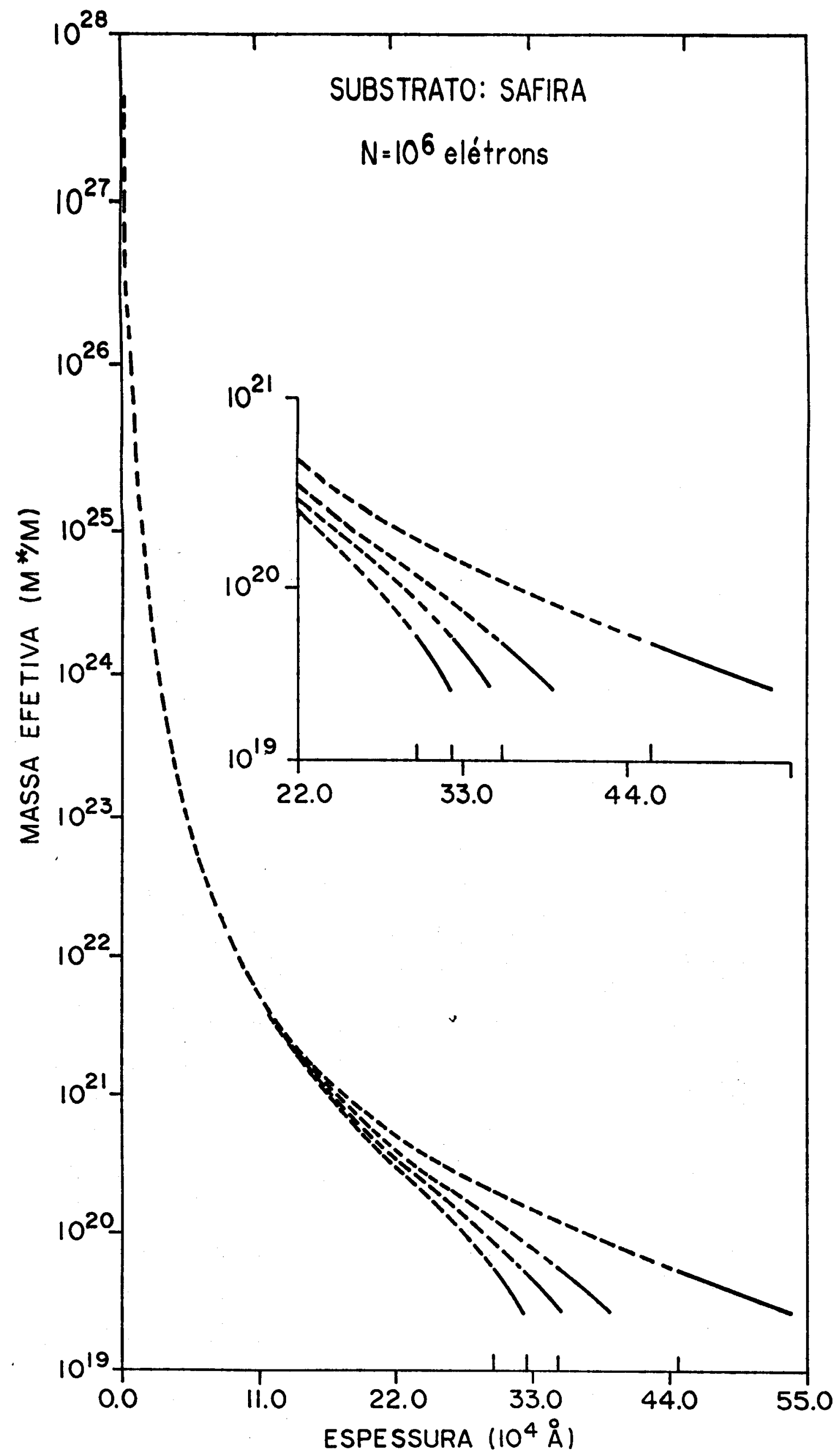


Figura 29 - Densidade de carga em uma depressão com muitos elétrons na superfície de ${ }^{4}$ He líquido no limite de espessura infinita $(d \rightarrow \infty)$. O campo crítico, ou seja, o menor valor do campo e lētrico para que ocorra a formação da depres são è de $3121 \mathrm{~V} / \mathrm{cm}$. A linha (--)•) representa a densidade critica, acima da qual a superfí cie torna-se instävel. Depressões com $\mathrm{N} \sim 10^{7}$ elētrons são instāveis pois a densidade de carga é sempre superior à densidade crítica. A depressão mais estável para campos próxi mos ao campo crítico contëm $\mathrm{N} \sim 5 \times 10^{6}$ elétrons. As linhas cheias são regiões onde a depres são é estável e as linhas tracejadas (--) regiões onde a depressão é instável. 


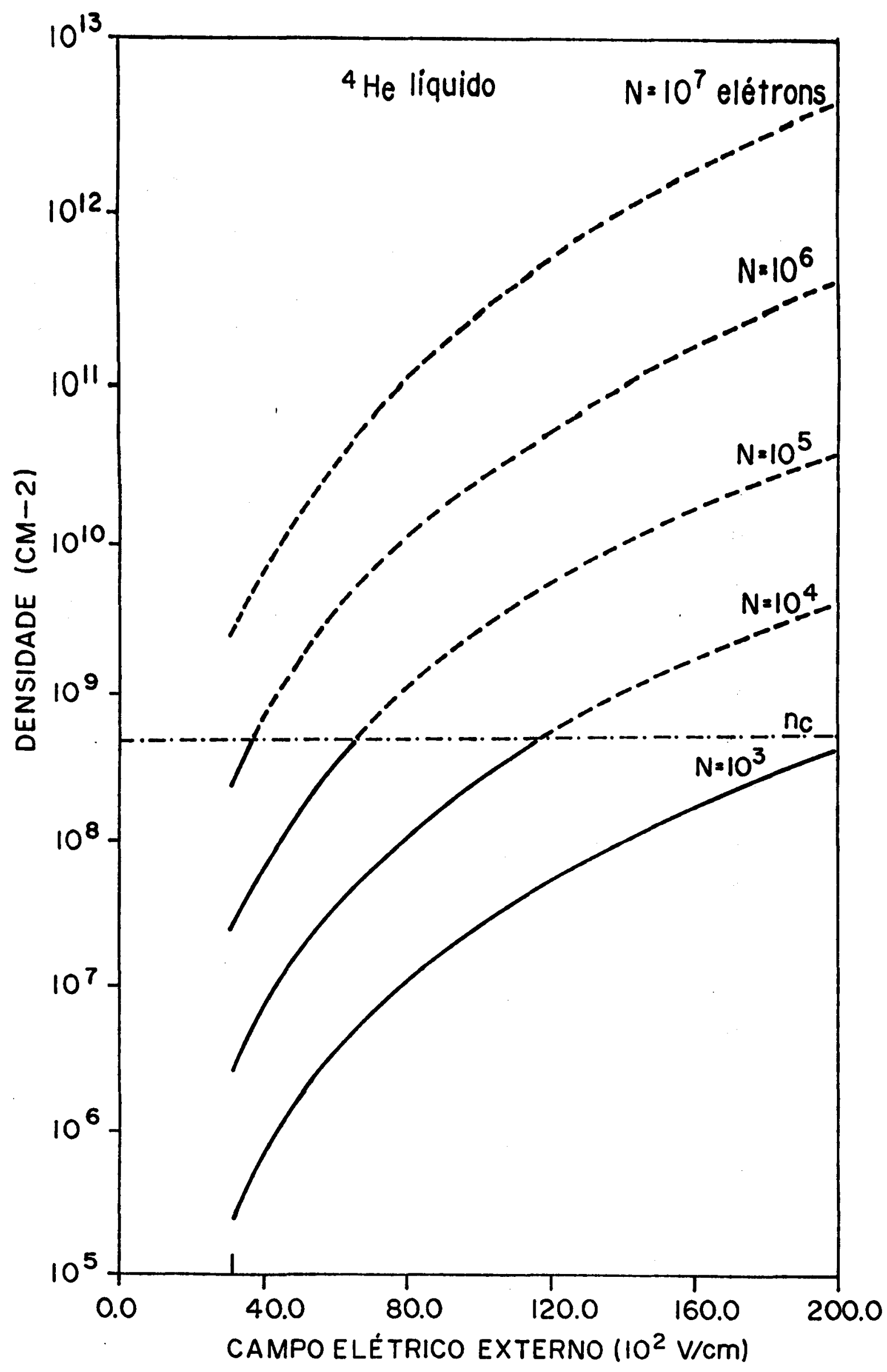


Figura 30 - Energia de formação de uma depressão com muitos elétrons na superfície de ${ }^{4}$ He líquido no limite de espessura infinita $(d \rightarrow \infty)$. As linhas cheias são as regiões onde a de pressão é estãvel e as linhas tracejadas (--) são regiões onde a depressão é instável. Para um dado número $\mathrm{N}$ de elétrons, o campo elétrico onde a região de instabilidade ini cia, è obtido no gráfico da densidade de carga quando esta ultrapassa o valor da den sidade crítica. 


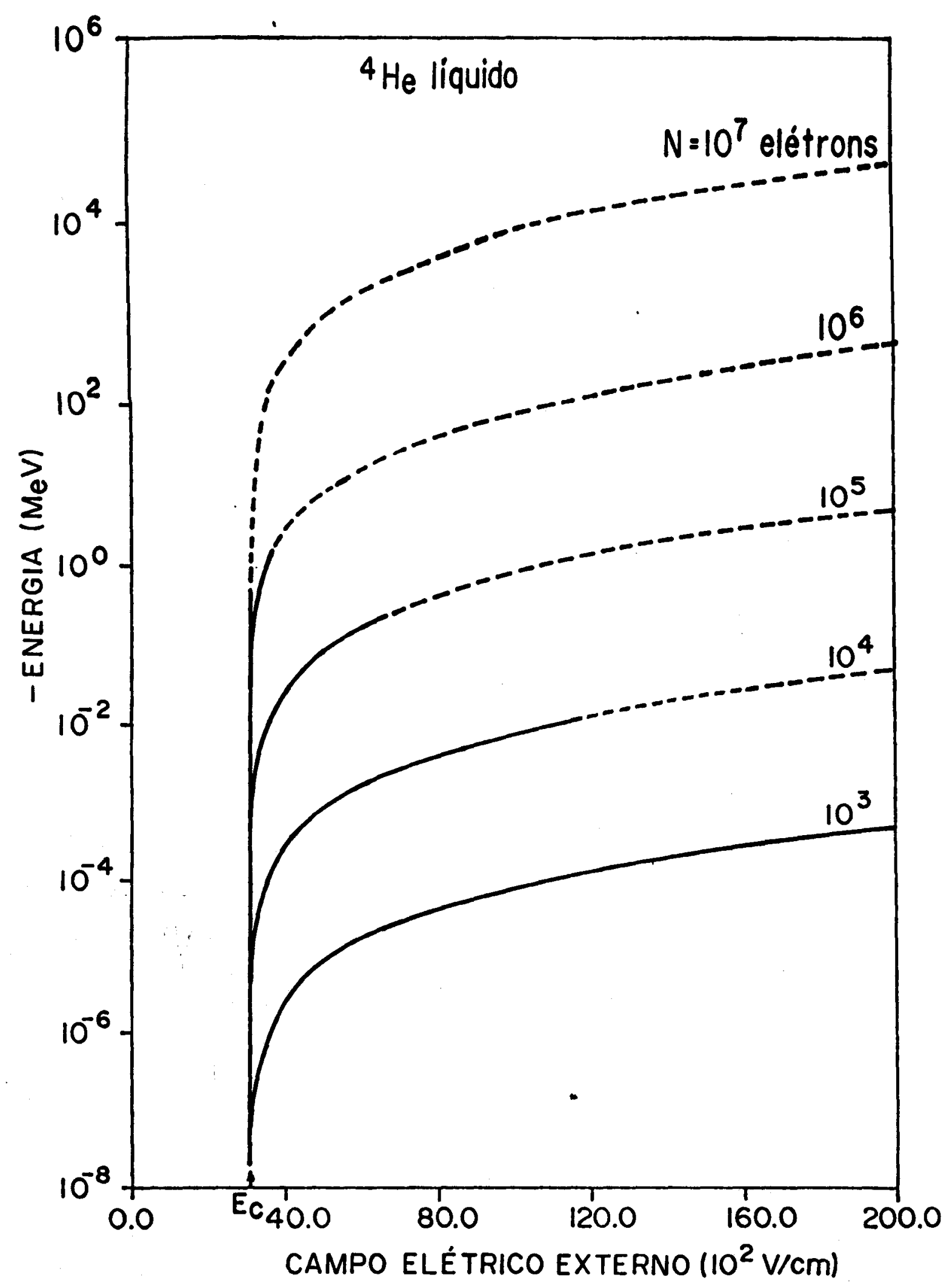




\section{Figura 31 - Formação de estruturas macroscópicas na sü perfície de ${ }^{4}$ He líquido.}

Mostramos uma sequência de fotografias obtidas por Giannetta e Ikezi ${ }^{14}$ nas quais observamos a formação do cristal de de pressões na superfície de ${ }^{4}$ He líquido.

Parte (a) Aumentando-se o campo elétrico externo podemos obser var a formação do cristal de depressões com simetria hexagonal. Inicialmente para um campo elëtrico inferior ao campo crítico no qual ocorre a instabilidade eletrohidrodinâmica, não existe nenhuma estrutura macroscópica observável. Já para $E=E_{2}$ surge algumas depressões nas quais existem muitos elétrons. Aumentando-se mais 0 campo elétrico o cristal torna-se nítido.

Parte (b) Diminuindo-se o campo elétrico externo observa-se que o cristal começa a perder sua forma, mas agora para um campo elétrico menor que o campo crítico ainda existe vestígios do cristal de depressões o que implica na e xistência de histerese. 


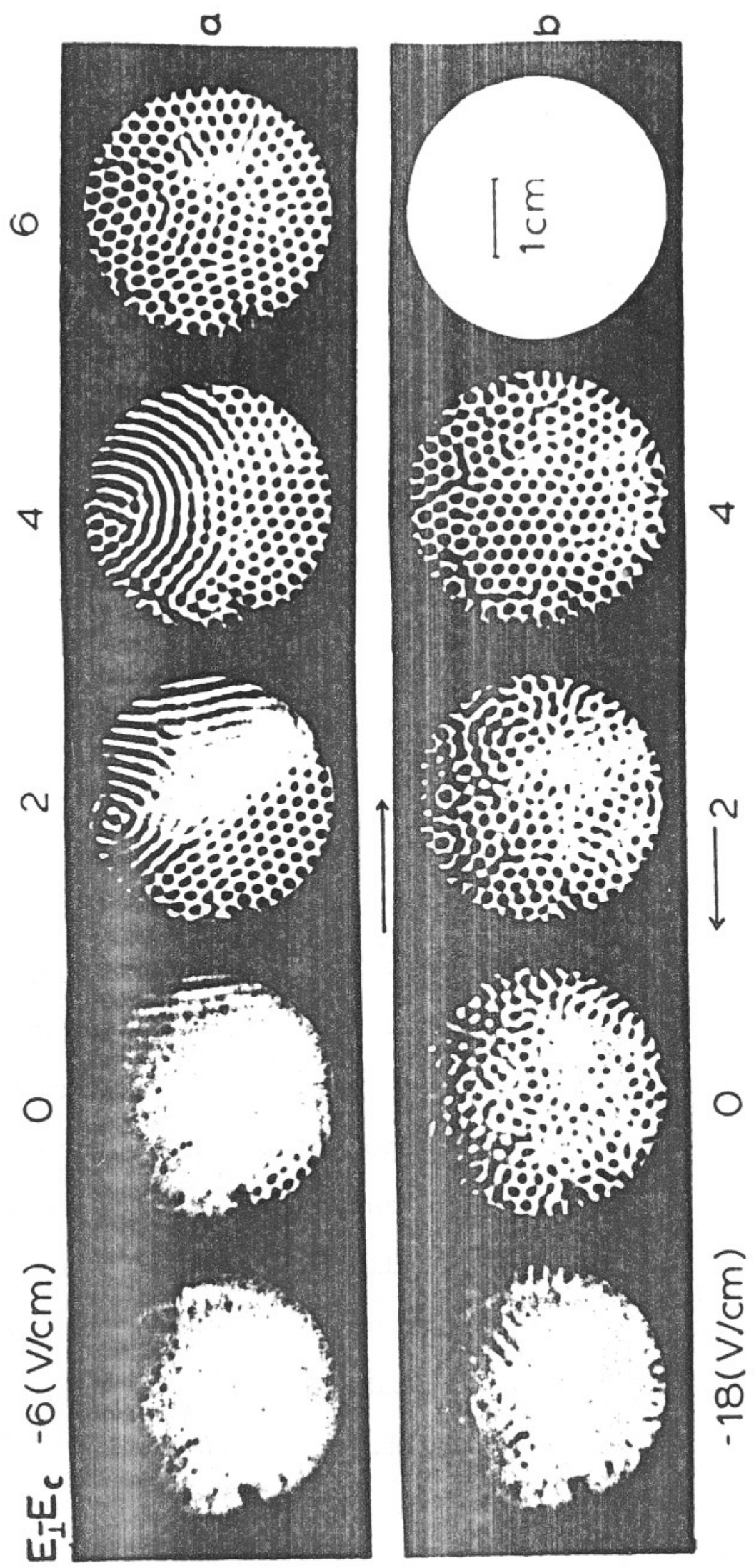


Figura 32 - Neste gráfico apresentamos a espessura crítica na qual a energia de formação da de pressão cai abruptamente a zero em função do número $\mathrm{N}$ de elétrons na depressão. Os pontos (4) referem-se ao substrato safira e os pontos (•) ao substrato neon sólido. Estes resultados são para o campo elétrico ex terno nulo. o substrato safira apresenta uma espessura critica maior pois sua constan te dielétrica é 19 e a contribuição para o potencial imagem é bem maior que a do neon sólido que tem uma constante dielétrica 1,24 . 


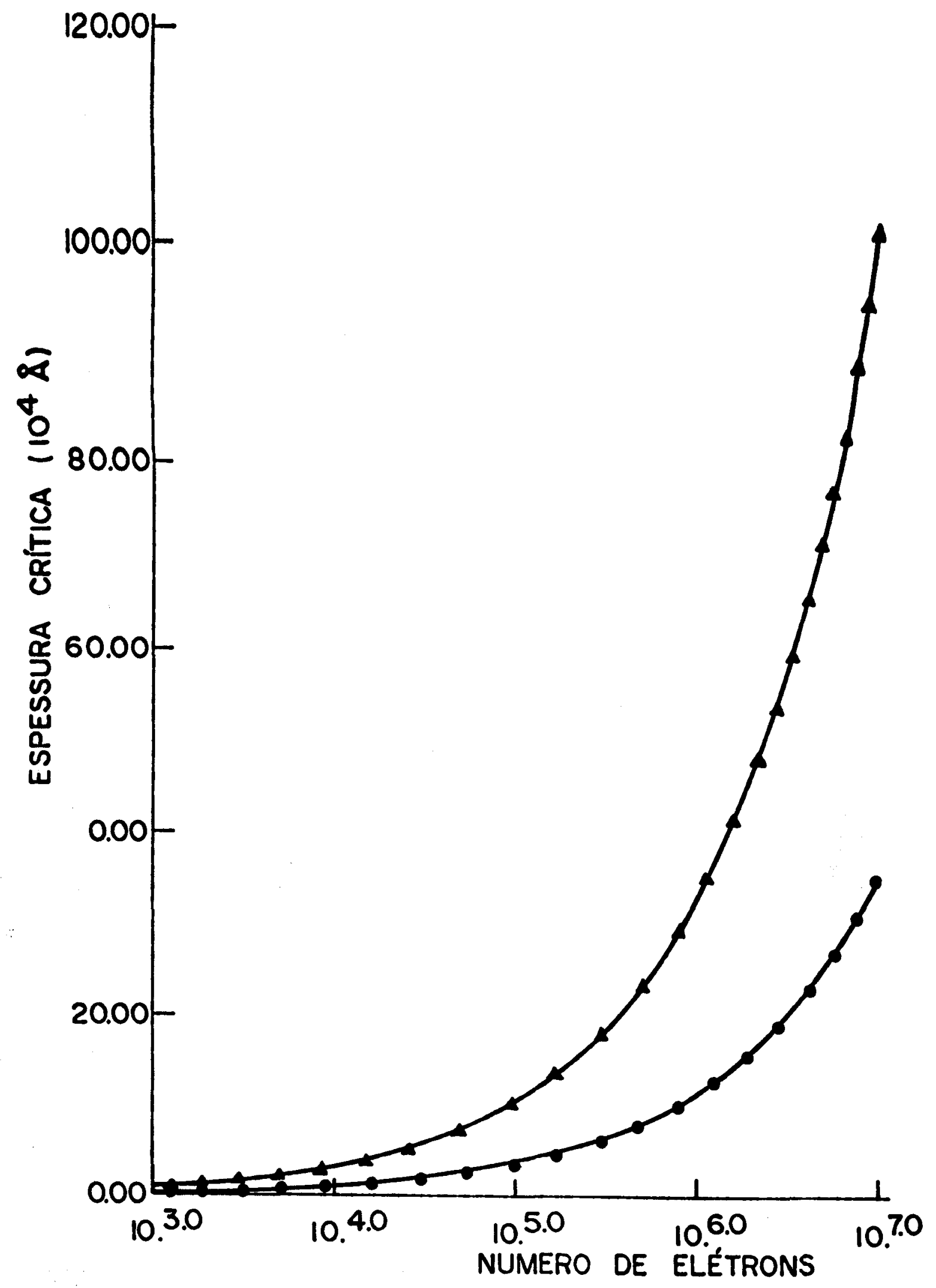


CAPITULO VII

CONCLUSÕES 
Neste trabalho utilizamos um método, baseado no formalis mo de transformações canônicas, para investigar as propriedades do estado fundamental de elétrons ligados à superficie de ${ }^{4} \mathrm{He}$ líguido, em filmes de hẻlio adsorvidos em neon sölido e em safira e também para elētrons localizados na interface da mistura ${ }^{3} \mathrm{He}-{ }^{4} \mathrm{He}$. Utili zando este método calculamos a energia do estado fundamental e a massa efetiva de um elētron interagindo com os modos superficiais (riplons) de filmes de hëlio líquido adsorvidos em neon sölido e em safira e também na interface da mistura ${ }^{3}$ He- ${ }^{4} \mathrm{He}$, para isso utilizamos o potencial de interação elétron-riplon obtido por Shikin e Monarka. Observamos um comportamento tipo transiça de fase de primei ra ordem onde o elétron passa de um estado quase livre para um esta do localizado, quando o campo elētrico externo excede um valor crítico. Este resultado foi recentemente verificado experimentalmente através de medidas da mobilidade de elétrons localizados na superfí cie de filmes de hêlio líquido adsorvidos em safira.

Como uma segunda aplicação do método, estendemos o forma lismo para uma depressão contendo muitos elētrons localizados na superfície de ${ }^{4}$ He líquido, filmes de hélio adsorvidos em neon sólido e em safira e na interface da mistura ${ }^{3} \mathrm{He}-{ }^{4} \mathrm{He}$. Para elétrons localizados na superfície de ${ }^{4}$ He líquido encontramos a densidade média de carga, a energia de formação e o raio médio da depressão em fun ção do campo elétrico externo e do número de elétrons na depressão. o campo crítico , ou seja, o menor valor do campo elétrico externo necessário para formar a depressão è independente do número de elétrons nela contida e tem o valor de $3121 \mathrm{~V} / \mathrm{cm}$. No caso de misturas ${ }^{3} \mathrm{He}-{ }^{4} \mathrm{He}$ obtivemos a energia de formação de uma depressão contendo $10^{6}$ elétrons, a massa efetiva e o seu raio mëdio. o campo critico, neste caso, è de $1153 \mathrm{~V} / \mathrm{cm}$ e tambēm independe do número de elétrons. Estes resultados, tanto para ${ }^{4} \mathrm{He}$ Iíquido quanto para mistura ${ }^{3} \mathrm{He}-$ ${ }^{4}$ He estão em excelente acordo com os resultados experimentais atê 
agora existentes.

Para elétrons localizados na superfície de fjumes de hélio adsorvidos em neon sólj.do e em safira obtivemos a energia de formação, a massa efetiva, o raio médio e a densidade média de car ga em uma depressão contendo $\mathrm{N}$ elétrons em função do campo elétrico externo, da espessura do filme e do número de elétrons. Como re sultado obtivemos o intervalo de espessura do filme no qual uma de pressão com $\mathrm{N}$ elētrons é estável. A região de espessura onde a depressão é estâvel é da ordem de $10^{6} \AA$, isto porque para espessuras menores o potencial imagem domina completamente o campo elëtrico externo e a densidade média de carga na depressão, torna-se maior que a densidade crítica e consequentemente a depressão fica instāvel.

Os resultados obtidos para uma depressão localizada na sụ perfície de filmes de hēlio mostram que nas condições experimentais da medida da mobilidade de elétrons em filmes de hélio adsorvidos em safira obtidos por Andrei ${ }^{33}$ não deverão existir depressões com muitos elétrons pois os filmes utilizados são da ordem de $10^{3} \AA$ de espessura. Nesta experiência a densidade de elétron na superfície de hêlio è de $6 \times 10^{7}$ elétrons/ $\mathrm{cm}^{2}$. Evidentemente é muito importante levar-se em conta a interação coulombiana entre os elétrons. Devido a esta interação a energia do sistema de elétrons torna-se mais negativa de modos a permitir a observação experimental. Uma vez que a contribuição à massa efetiva do elētron devido à energia de correlação é desprezível, os efeitos de transporte dos elētrons são de terminados pelo acoplamento elétron-riplon e a presença de muitos lētrons é importante para que a energia do sistema esteja acima do intervalo de temperatura $0,4-1,0 \mathrm{~K}$.

Finalmente, sugerimos alguns problemas nesta ārea: cãlculo da energia do estado fundariental ce ur. gās de polarons interagentes; 
utilizar filmes finos onde a densjdade de elētrons è da ordem de $10^{11}$ elétrons $/ \mathrm{cm}^{2}$ e portanto o găs de elētrons passa a ser quântico:

introduzir o efeito da temperatura no espectro de ener gia, na massa efetiva, na mobilidade, etc. 
APENDICE

QUANTIZAÇÃO DAS ONDAS DE CAPILARIDADE-GRAVIDADE 
Riplons são as ondas de capilaridade-gravidade, quantiza das, na superfície de um líquido.

Consideraremos aqui um fluido ideal incompressivel semiinfinito limitado pelo plano $z=0$. A técnica hidrodinâmica empregada é devida à Pitaevskii .

Para um fluido ideal, a velocidade é o gradiente do poten clal $\Phi$. A condição de incompressibilidade implica que o potencial Ф satisfaz a equação de Laplace. A energia cinética é dada por

$$
\begin{aligned}
\mathbf{T} & =\frac{1}{2} \rho \int(\nabla \Phi)^{2} \mathrm{~d} \tau \\
& =-\frac{1}{2} \int \Phi \nabla^{2} \Phi \mathrm{d} \tau+\frac{1}{2} \rho \int \vec{d} \vec{s} \cdot \Phi \nabla \Phi \\
& =\frac{1}{2} \rho \int \mathrm{d} \overrightarrow{\mathrm{s}} \cdot \Phi \nabla \Phi
\end{aligned}
$$

onde utilizamos o teorema da divergència.

Usaremos a função de Green $G\left(\vec{r}, \vec{r}^{\prime}\right)$ solução da equação

$$
\begin{aligned}
& \nabla^{2} G\left(\vec{r}, \vec{r}^{\prime}\right)=-4 \pi \delta\left(\vec{r}-\vec{r}^{\prime}\right) \\
& G\left(\vec{r}, \vec{r}^{\prime}\right)=\frac{1}{\left|\vec{r}-\vec{r}^{\prime}\right|}
\end{aligned}
$$

No caso em que $\vec{r}$ estã no plano, a função delta da equação (A.2) con tribuirá com um meio do valor total da expressão, ou seja

$$
\Phi(\vec{r})=-\frac{1}{2 \pi} \int d^{3} \vec{r}^{\prime} \Phi\left(\vec{r}^{\prime}\right) \nabla^{2} \cdot G\left(\vec{r}, \vec{r}^{\prime}\right)
$$

Adicionando o termo nulo e usando o teorema de Green te- 


$$
\begin{aligned}
\Phi(\vec{r}) & =-\frac{1}{2 \pi} \int d^{3} \vec{r}^{\prime}\left[\Phi\left(\vec{r}^{\prime}\right) \nabla^{2} \cdot G\left(\vec{r}, \vec{r}^{\prime}\right)-G\left(\vec{r}, \vec{r}^{\prime}\right) \nabla^{\prime}{ }^{2} \Phi\left(\vec{r}^{\prime}\right)\right] \\
& =\frac{1}{2 \pi} \int \vec{S}^{\prime} \cdot G\left(\vec{r}, \vec{r}^{\prime}\right) \nabla^{\prime} \Phi\left(\vec{r}, \vec{r}^{\prime}\right) \\
& =\frac{1}{2 \pi} \int d s^{\prime} \cdot\left[\frac{u\left(\vec{r}^{\prime}\right)}{\left|\vec{r}-\vec{r}^{\prime}\right|}\right]
\end{aligned}
$$

0 ponto significa diferenciação em relação ao tempo, para obtermos $(A, 4)$ temos usado

$$
\begin{aligned}
& {\left[\nabla^{\prime} G\left(\vec{r}, \vec{r}^{\prime}\right), \vec{n}^{\prime}\right] \vec{r}, \vec{r}^{\prime} \text { sobre } \vec{s}^{\prime}=0} \\
& \dot{u}\left(\vec{r}^{\prime}\right)=\left[\nabla^{\prime} \Phi\left(\vec{r}^{\prime}\right), \vec{n}^{\prime}\right] \vec{r}^{\prime} \text { sobre } \vec{s}^{\prime}
\end{aligned}
$$

$\hat{n}$ é a normal unitāria e $\mathrm{u}(\vec{r})$ o deslocamento da superfície. Conside ramos aqui somente movimentos oscilatórios associados com o lado superior da superfície.

Usando (A.4) em (A.1), a energia cinética será

$$
T=\frac{\rho}{4 \pi} \iint \operatorname{dSdS}^{\prime} \frac{\dot{u}(\vec{r}) \dot{u}\left(\vec{r}^{\prime}\right)}{\left|\vec{r}-\vec{r}^{\prime}\right|}
$$

A energia potencial $V$ devida à deformação da superfície tem contribuições das forças gravitacional e da tensão superficial.

$$
\begin{aligned}
& \mathrm{v}=\int \mathrm{ds} \int_{-\infty}^{\mathrm{u}(\overrightarrow{\mathrm{r}})} \mathrm{dz} \rho \mathrm{gz}+\sigma \int \mathrm{ds}\left(1+(\nabla \mathrm{u})^{2}\right)^{1 / 2} \\
& \mathrm{v} \approx \mathrm{v}_{\mathrm{g}}+\int \mathrm{ds}\left[\rho g \mathrm{u}^{2} / 2+\sigma / 2(\nabla \mathrm{u})^{2}\right]
\end{aligned}
$$

onde $\mathrm{v}_{\mathrm{g}}$ é o valor de equilíbrio, $\sigma$ é o coeficiente da tensão superficial, g é a aceleração da gravidade, em (A.6) temos usado $|\nabla u|<<1$. o próximo passo é expandir o deslocamento e sua derivada 
temporal em coordenadas dos modos normais dos riplons.

$$
\begin{aligned}
& u(\vec{r})=A^{-1 / 2} \sum_{\vec{K}} Q_{\vec{K}} e^{i \vec{K} \cdot \vec{r}} \\
& \dot{u}(\vec{r})=A^{-1 / 2} \sum_{\vec{K}} \dot{Q}_{K} e^{i \vec{K} \cdot \vec{r}}
\end{aligned}
$$

A Lagrangeana do sistema è dada por

$$
\begin{aligned}
& L=\sum_{\vec{K}}\left(T_{\vec{K}}-V_{\vec{K}}\right) \\
& \sum_{\vec{K}} T_{\vec{K}}=\frac{d}{4 \pi A} \sum_{\vec{K} \vec{K}} \cdot \dot{Q}_{\vec{K}} \dot{Q}_{\vec{K}} \cdot \iint d S d S \cdot \frac{e^{i\left(\vec{K} \cdot \vec{r}+\vec{K}^{\prime} \cdot \vec{r}^{\prime}\right)}}{\left|\vec{r}-\vec{r}^{\prime}\right|}
\end{aligned}
$$

Atravēs da representação integral da função de Bessel obtemos

$$
\begin{aligned}
\mathrm{T}_{\overrightarrow{\mathrm{K}}} & =\frac{\rho}{4 \pi \mathrm{A}} \quad \dot{\mathrm{Q}}_{\overrightarrow{\mathrm{K}}} \sum_{\overrightarrow{\mathrm{K}}} \cdot \dot{\mathrm{Q}}_{\overrightarrow{\mathrm{K}}} \cdot \frac{2 \pi}{\mathrm{K}} \int \mathrm{dS} \mathrm{e}^{i(\overrightarrow{\mathrm{K}}+\overrightarrow{\mathrm{K}}) \cdot \overrightarrow{\mathrm{r}}} \\
& =\frac{\rho}{2 \mathrm{~K}} \quad \dot{\mathrm{Q}}_{\mathrm{K}} \dot{Q}_{-\vec{K}}
\end{aligned}
$$

Analogamente calculamos $V_{\overrightarrow{\mathrm{K}}}$ e obtemos

$$
\begin{aligned}
& \mathrm{L}_{\overrightarrow{\mathrm{K}}}=\frac{\rho}{2 \mathrm{~K}} \dot{\mathrm{Q}}_{\overrightarrow{\mathrm{K}}} \dot{Q}_{-\overrightarrow{\mathrm{K}}}-\frac{1}{2}\left(\rho \mathrm{g}+\sigma \mathrm{K}^{2}\right) Q_{\overrightarrow{\mathrm{K}}} Q_{-\overrightarrow{\mathrm{K}}} \\
& \text { O momentum canônico e a Hamiltoniana são obtidos da mane } \underline{i}
\end{aligned}
$$
ra usual

$$
\begin{aligned}
& \pi_{\vec{K}}=\frac{\rho}{K} \dot{Q}_{-\vec{K}} \\
& H=\sum_{\vec{K}}\left\{\vec{K}^{\pi}-\overrightarrow{\mathrm{K}}(K / 2 \rho)+Q_{\vec{K}^{Q}-\vec{K}}\left[\frac{1}{2}\left(\rho g+\sigma K^{2}\right)\right]\right\}
\end{aligned}
$$


Quantizamos H impondo a relação de comutação entre os $\underline{0}$ peradores $Q$ e $\pi$

$$
\left[Q_{\vec{K}^{\prime}}, \pi \vec{K}^{\prime}\right]=i \hbar \delta \vec{K}^{\prime}
$$

e então transformamos numa forma diagonal em termos de operadores de criaçau e destruição de riplons $a_{\vec{K}}^{+}$e $a_{\vec{K}}$

$$
\begin{aligned}
& \pi_{\vec{K}}=i\left(\hbar \rho \omega_{\vec{K}} / 2 K\right)^{1 / 2}\left(a_{\vec{K}}^{+}-a_{-\vec{K}}\right) \\
& r_{\vec{K}}=\left(\hbar K / 2 \rho \omega_{\vec{K}}\right)^{1 / 2}\left(a_{-\vec{K}^{+}+a_{\vec{K}}}^{+}\right) \\
& H=\sum_{\vec{K}} \hbar \omega_{\vec{K}}\left(a_{\vec{K}}^{+} a_{\vec{K}}^{+1 / 2}\right) \\
& \omega_{K}^{2}=g K+\frac{\sigma}{\rho} K^{3} \\
& o \text { operador deslocamento terä a seguinte forma } \\
& u(\vec{r})=\sum_{\vec{K}}\left(\hbar K / 2 \text { A } \rho \omega_{\vec{K}}\right)^{1 / 2}\left(a_{-\vec{K}}^{+}+a_{\vec{K}}\right)
\end{aligned}
$$


REFERENCIAS 
(1) N.R.Kestner, J.Jortner, M.H.Cohen e S.A.Rice. Phys.Rev.A56, 140 (1965).

(2) W.T.Sommer. Tese de doutorado- Stanford University- 1964 (não publicado).

(3) M.W.Cole e M.H.Cohen. Phys.Rev.Lett.23, 1238 (1969). M.W. Cole. Phys.Rev.B2, 4239 (1970).

(4) V.B.Shikin. Sov.Phys.JETP 31, 936 (1970); Sov.Phys.JETP 33, 387 (1971). Sov.Phys.JETP 34, 1095(1972).

(5) M.W.Cole. Phys.Rev.A1, 1838 (1970).

(6) O.Hipólito, G.A.Farias,J.R.D.de Felício. Solid States Commun. 28, 365 (1978).

(7) W.T.Sommer. Phys.Rev.Lett, 12, 271 (1964).

(8) W.T.Sommer e D.J.Tanner. Phys.Rev.Lett.,27, 1345 (1971).

(9) R.Williams, R.S.Crandall e A.H.Willis. Phys.Rev.Lett.,26,7 (1971).

(10) R.M.Ostermeier e K.W.Sxhwarz. Phys.Rev.Lett.,29, 25 (1972).

(11) C.C.Grimes e P.Leiderer. Phys.Rev.Lett.,32, 280 (1974).

(12) R.S.Crandall e R.Williams. Phys.REv.A 5,2183 (1972).

(13) M.Wanner e P.Leiderer. Phys.Rev.Lett.,42, 315 (1979).

(14) R.W.Giannetta e H.Ikezi. Phys.Rev.Lett., 47, 849 (1981).

(15) V.V.Shikin e Yu.P.Monarkha. J.Low.Temp. Phys.,16,193 (1974).

(16) A.M.Gabovich, L.G.Il'chenko e E.A.Pashitskil. Sov.Phys.JETP 54, 1089 (1981).

(17) H.Ikezi e P.M.Platzman. Phys.Rev.B 23,1145 (1981).

(18) M.W.Cole. Phys.Rev.B2, 4239 (1970).

(19) R.S.Crandall. Phys.Rev.Aㅌ, 790 (197).

(20) M.Saitoh. J.Phys.Soc.Japan 42, 201 (1977).

(21) C.C.Grimes e G.Adams. Phys.Rev.Lett., 36, 145 (1976).

(22) A.S.Rybalko, Yu.Z.Kovdrya e B.N.Esel'son. JETP Letters $\underline{22}$, $280(1976)$. 
(23) T.R.Brown e C.C.Grimes. Phys.Rev.Lett.,29, 1233 (1972).

(24) P.M.Platzman e G.Beni. Phys.Rev.Lett.,36, 626 (1976).

(25) G.D.Gaspari e F.Bridges. J.Low Temp.Phys.,21. 535 (1975).

(26) Yu.P.Monarka. Soviet J.Low Temp.Phys.,3, 282 (1977).

(27) W.J.Huybrechts. J.Phys.C 9 , L211 (1976); 10, 3761 (1977).

(28) T.D.Lee, F.Low e D.Pines. Phys.Rev.,90, 297 (1953).

(29) O.Hipólito. Solid State Commun.,32, 515 (1979); J.Phys,C,12, 4667 (1979).

(30) S.Tomonaga. Prog.Theor.Phys.,2, 6 (1947).

(31) C.C.Grimes, T.R.Brown, M.L.Burns e C.L.Zipfel. Phys.Rev.B, 13, $140(1976)$.

(32) K.Kajita. J.Phys.Soc.Japan 12, 3747 (1982); J.Phys.C (a ser publicado).

(33) E.Y.Andrei. V Intern.Conf.on Elect.Properties of 2D System. Oxford (England), 5-9 september (1983).

(34) G.A.Farias. Tese de doutorado- IFQSC/USP (1980) (não publicada).

(35) O.Hipölito, G.A.Farias e N.Studart. Surf.Science 113, 394 (1982).

(36)-R. Feynman. Phys.Rev.97, 660 (1955).

(37) S.J.ackson e P.M.Platzman. Phys.Reb.B 24, 490 (1981) e Phys. Rev.B 25, 4886 (1982).

(38) M.Saitoh. V Intern.Conference on Elect.Properties of 2D System. Oxford (England), 5-9 september (1983).

(39) L.D.Landau e E.M.Lifshitz. Fluid Mechanics (Pergamon, Oxford 1959) pp.237.

(40) P.Leiderer, H.Poisel e M.Wanner. J.Low Temp.Phys., 28, 167 (1977).

(41) P.Leiderer, M.Wanner e W.Schoepe. Journal de Physique C6,8 (1978) 1328.

(42) L.D.Landau e E.M.Lifshitz. Electrodynamics of Continuos Média (Pergamon-Oxford-1960) p.35 (probl.5).

(43) L.P.Gor'kov e D.M.Chernikova. JETP Lett.,18, 68 (1973).

(44) K.Mima, H.Ikezi e A.Sasegawa. Phys.Rev.B 14, 3953 (1976). 
(45) Veja por exemplo: S.D.Conte. Elementary Numerical Analysisan algorithimic Aproach (McGraw Hill, Inc.,1865).

(46) V.Toyozawa. Prog.Theor.Phys.,26, 29 (1961).

(47) V.B.Shikin e P.Leiderer. JETP Lett.,32 (1980) 416.

(48) V.B.Shikin e P.Leiderer. Soviet Phys.JETP 54(1), (1981) 92.

(49) V.L.Mel'nikov e S.V.Meshkov. Soviet Phys.JETP 54(3), (1982) 505.

(50) H.Ikezi. Phys.Rev.Lett.,42 (1979) 1688.

(51) P.Leiderer, W.Ebner e V.B.Shikin. Surf.Science 113 (1982)405. 